\title{
(ब)
}

AUTARQUIA ASSOCIADA À UNIVERSIDADE DE SÃO PAULO

\section{AVALIAÇÃO DO TRATAMENTO DE EFLUENTE LÍQUIDO GERADO EM USINA TERMELÉTRICA USANDO ZEÓLITA DE CINZAS DE CARVÃO}

\author{
CAIO DA SILVA MIRANDA
}

Dissertação apresentada como parte dos requisitos para obtenção do Grau de Mestre em Ciências na Área de Tecnologia Nuclear - Materiais

Orientadora:

Profa. Dra.Denise Alves Fungaro 
INSTITUTO DE PESQUISAS ENERGÉTICAS E NUCLEARES

Autarquia associada à Universidade de São Paulo

AVALIAÇÃO DO TRATAMENTO DE EFLUENTE LÍQUIDO GERADO EM USINA TERMELÉTRICA USANDO ZEÓLITA DE CINZAS DE CARVÃO

CAIO DA SILVA MIRANDA

Dissertação apresentada como parte dos requisitos para obtenção do Grau de Mestre em Ciências na Área de Tecnologia Nuclear - Materiais

Orientadora:

Profa. Dra.Denise Alves Fungaro

Versão Corrigida

São Paulo

2018 
Fonte de Financiamento: CAPES

Autorizo a reprodução e divulgação total ou parcial deste trabalho, para fins de estudo e pesquisa, desde que citada a fonte

Como citar:

DA SILVA MIRANDA, C. Avaliação do tratamento de efluente líquido gerado em u ina termelétrica usando zeólita de cinzas de carvão. 2018. 83 p. Dissertação (Mestrado em Tecnologia Nuclear), Instituto de Pesquisas Energéticas e Nucleares, IPEN-CNEN/SP, São Paulo. Disponível em: <www.teses.usp.br> (data de consulta no formato: $\mathrm{dd} / \mathrm{mm} / \mathrm{aaaa}$ )

Ficha catalográfica elaborada pelo Sistema de geração automática da Biblioteca IPEN/USP, com os dados fornecidos pelo(a) autor(a)

da Silva Miranda, Caio

Avaliação do tratamento de efluente líquido gerado em usina termelétrica usando zeólita de cinzas de carvão / Caio da

Silva Miranda; orientadora Denise Alves Fungaro. -- São

Paulo, 2018.

$83 \mathrm{p}$.

Dissertação (Mestrado) - Programa de Pós-Graduação em Tecnologia Nuclear (Materiais) -- Instituto de Pesquisas Energéticas e Nucleares, São Paulo, 2018.

1. Tratamento de efluente industrial. 2. zeólita. 3. lixiviado de cinzas de carvão. I. Alves Fungaro, Denise, orient. II. Título. 
Aos meus pais Cristina e Marcio, meus alicerces, por toda a dedicação, incentivo, educação e amor que recebi,

A minha irmã Gabrielle, que sempre me apoiou nos momentos de fraquezas e vitórias. 


\section{AGRADECIMENTOS}

Aos meus pais, Cristina e Marcio Miranda, que são tudo pra mim, por todo amor, apoio, palavra de carinho e, principalmente, por acreditarem em mim.

A minha querida e amada irmã, Gabrielle Miranda, por ser minha melhor amiga, por me incentivar e fazer eu me sentir especial.

À Dra. Denise Alves Fungaro que me deu a oportunidade de realizar este trabalho sob sua orientação com muita dedicação, compreensão e carinho.

À Dra. Juliana Izidoro que me co-orientou durante todo o trabalho, me ajudando em todas as fases.

À Dra. Sabine Guilhen que contribuiu muito com o trabalho, sendo sempre solicita para realização das analises.

Ao Instituto de Pesquisas Energéticas e Nucleares e ao Centro de Química e Meio Ambiente.

A CAPES pelo incentivo financeiro por meio da bolsa de estudos.

À Usina termelétrica de Figueira por ter nos fornecido as amostras de cinzas de carvão.

Ao Dr. Paulo Sergio Cardoso da Silva, por ser sempre solícito e pela contribuição neste trabalho.

Ao meu grande amigo, Alexandre Indriunas, por toda amizade, contribuição ao trabalho e por toda paciência e ajuda nos piores momentos.

Aos meus grandes amigos do grupo de pesquisa e da vida Felipe Campello e Lucas Grosche, que sempre estiveram presentes em todos os momentos.

As amigas do mestrado, Tatiane Bernardino de Seixas Carvalho da Silva, Joyce Marques, Camila Tanzillo e Thamiris Stellato, por estarem presentes durante todo o curso, pela companhia e por serem minhas amigas em todos os momentos.

Aos meus amigos do grupo de pesquisa, alunos orientados pela Dra. Denise Fungaro.

Aos funcionários e alunos do CQMA, muito obrigada por toda ajuda técnica e pela convivência.

Foram tantas as pessoas que cruzaram meu caminho e que me ajudaram nessa trajetória, que eu só tenho a agradecer por todo apoio e carinho.

E a Deus. 
"Failure defeats losers,

failure inspire Winners"

Robert T. Kiyosaki 


\section{RESUMO}

MIRANDA, C. S. da. Avaliação do tratamento de efluente líquido gerado em usina termelétrica usando zeólita de cinzas de carvão. 2018. Dissertação (Mestrado) Instituto de Pesquisas Energéticas e Nucleares -IPEN-CNEN/SP, São Paulo

As indústrias lançam diversos poluentes no meio ambiente. Dentre os poluentes destacam-se os elementos tóxicos presentes em efluentes líquidos por acarretarem alto risco potencial à saúde humana e ao meio ambiente. Os efluentes podem ser tratados por materiais adsorventes, os quais podem ser provindos de resíduos industriais. Uma forma de contribuir significativamente na sustentabilidade de uma indústria é a transformação de um de seus resíduos em sub-produto de valor agregado para aplicação no tratamento de seus efluentes líquidos como adsorvente de baixo custo. $\mathrm{O}$ objetivo deste trabalho foi sintetizar, e caracterizar zeólitas de cinzas de carvão e avaliar sua aplicação como material adsorvente no tratamento de efluente. Os materiais zeolíticos derivados de três tipos diferentes de cinzas de carvão (cinzas manga, cinzas ciclone e cinzas pesadas) geradas na usina termelétrica de Figueira-PR foram usados para tratar o lixiviado do aterro de cinzas de carvão da mesma usina. As seguintes características das zeólitas foram determinadas: composição mineralógica, composição química, teor de carbono total, análise morfológica, área superficial específica, capacidade de troca catiônica (CTC), perda ao fogo, $\mathrm{pH}$, condutividade e densidade aparente. A fase zeolítica formada foi do tipo sodalita com as três amostras usadas como matéria prima após ativação hidrotérmica alcalina. O material zeolítico de cinzas manga apresentou a menor relação $\mathrm{SiO}_{2} / \mathrm{Al}_{2} \mathrm{O}_{3}(1,46)$, maior CTC $\left(2,36 \mathrm{meq} \mathrm{g}^{-1}\right)$ e área superficial específica $\left(69,5 \mathrm{~m}^{2} \mathrm{~g}^{-1}\right)$ e, consequentemente, maior capacidade de remoção dos íons do efluente. As concentrações de As e Cr estavam acima do padrão de lançamento de efluentes. As três amostras de materiais zeolíticos apresentaram uma remoção significativa de $\mathrm{Ni}, \mathrm{Cd}, \mathrm{Zn}$ e Co na dose de 10 g.L-1. Os materiais zeolíticos das cinzas manga e ciclone foram eficientes para reduzir a concentração de As abaixo do limite imposto pela legislação, enquanto a remoção do $\mathrm{Cr}$ não foi efetiva com nenhum dos materiais. Na segunda etapa do trabalho, as zeólitas foram modificadas com 0 surfactante brometo de hexadeciltrimetilamônio (HTDMA-Br) em concentrações de 1,8 e 20 mmol L-1. A modificação das zeólitas não melhorou a eficiência de remoção do As. A remoção do $\mathrm{Cr}$ usando a amostra de zeólita de cinzas manga modificada com HDTMA-Br 20 mmol L-1 resultou em uma concentração final muito próxima ao limite permitido pela legislação. 
Palavras-chave: Tratamento de efluente industrial; zeólita; lixiviado de cinzas de carvão. 


\section{ABSTRACT}

MIRANDA, C. S. da. Evaluation of treatment of coal ash landfill leachate produced in thermoelectric using zeolitic materials from coal combustion by-products. 2018. Dissertação (Mestrado) - Instituto de Pesquisas Energéticas e Nucleares -IPENCNEN/SP, São Paulo

The industries release various types of pollutants into to the environment. Among these pollutants are the liquid effluents containing toxic elements, they carry a high potential risk to human health and the environment. Some effluents can be treated by adsorbent materials, which can be made from industrial waste. One way to contribute significantly to the sustainability of an industry is to transform one of its residues into a value-added byproduct and use in the treatment of its own liquid effluents as a low cost adsorbent. The objective of this estudy was to synthesize and characterize coal ash zeolites and evaluate their application as adsorbent material in the treatment of effluent. Zeolite materials derived from three different types of coal ash (fly ashes, cyclone ashes and heavy ashes) generated at the Figueira-PR thermoelectric plant were used to treat leachate from the coal ash landfill of the same plant. The following zeolite characteristics were determined: mineralogical composition, chemical composition, total carbon content, morphological analysis, specific surface area, cation exchange capacity (CTC), fire loss, $\mathrm{pH}$, conductivity and bulk density. The zeolite phase formed with the three samples used as raw material after alkaline hydrothermal activation was sodalite. The zeolite material from fly ash had the lowest $\mathrm{SiO}_{2} / \mathrm{Al}_{2} \mathrm{O}_{3}$ ratio (1.46), higher CTC (2.36 meq g${ }^{-1}$ ) and specific surface area (69.5 $\mathrm{m}^{2} \mathrm{~g}^{-1}$ ) and, consequently, greater effluent removal capacity. The As and $\mathrm{Cr}$ concentrations were above the effluent discharge standard. The three samples of zeolitic materials showed a significant removal of $\mathrm{Ni}, \mathrm{Cd}, \mathrm{Zn}$ and $\mathrm{Co}$ in the dose of $10 \mathrm{~g} \mathrm{~L}^{-1}$. The zeolite materials from fly and cyclone ash were efficient to reduce As concentrations below the limit imposed by legislation, while removal of $\mathrm{Cr}$ was not effective with any of the materials. In the second stage of the study, the zeolites were modified with the surfactant hexadecyltrimethylammonium bromide (HTDMA-Br) in concentrations of 1.8 and 20 mmol.L $L^{-1}$.

The zeolite removal efficiency of As did not improve after its modification. Removal of $\mathrm{Cr}$ using the 20 mmol. $\mathrm{L}^{-1}$ modified HDTMA-Br modified fly ash zeolite sample resulted in a final concentration very close to the limit allowed by the legislation.

Key words: Treatment of industrial wastewater; zeolite; coal fly ash leachate. 
SUMÁRIO

1 INTRODUÇÃO

2 OBJETIVOS

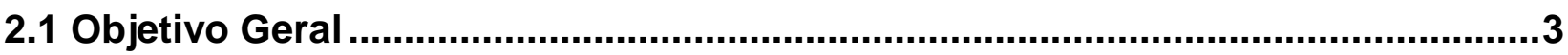

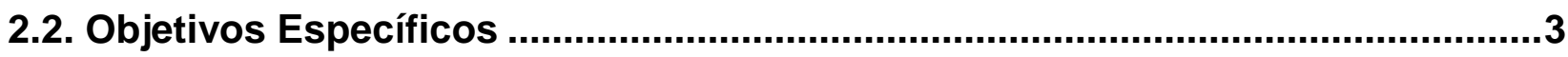

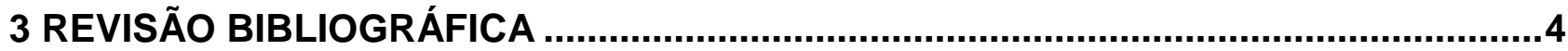

3.1 Geração de efluentes líquidos em termelétricas ..................................................

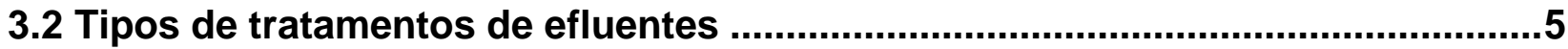

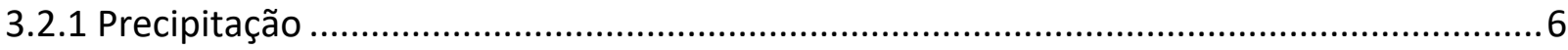

3.2.2 Coagulação e floculação ..............................................................................................

3.2.3 Membranas ......................................................................................................

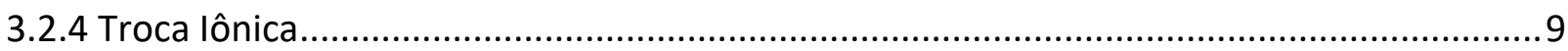

3.2.5 Eletrodeposição ………………………………………………………………....

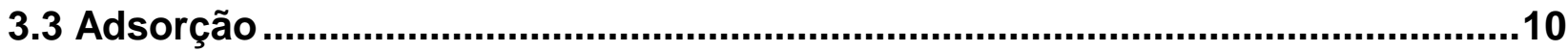

3.4 Tratamento de efluente usando zeólita ..........................................................12

3.4.1 Definição de zeólita ..................................................................................................12

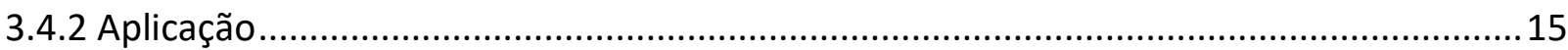

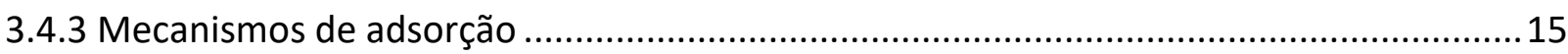

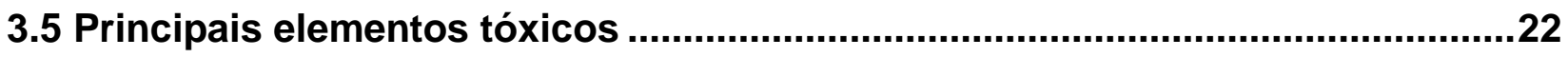

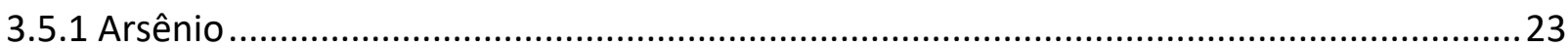

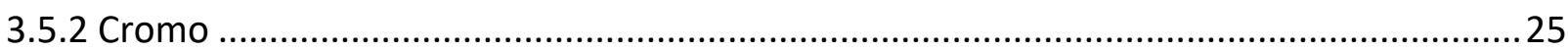

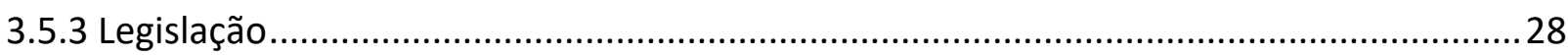

4. MATERIAIS E MÉTODOS

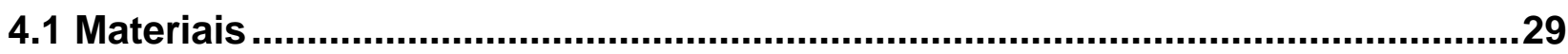

4.2 Síntese de zeólita a partir das cinzas de carvão................................................31

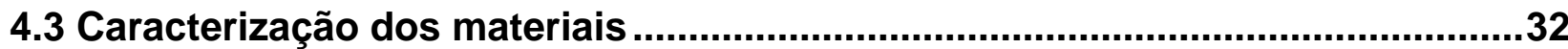

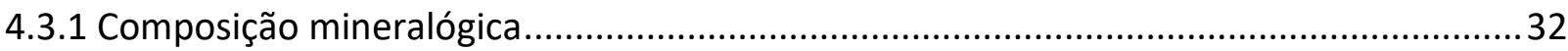

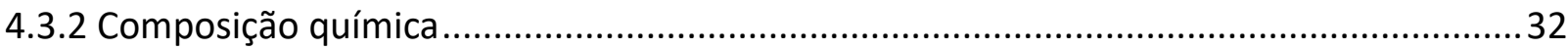

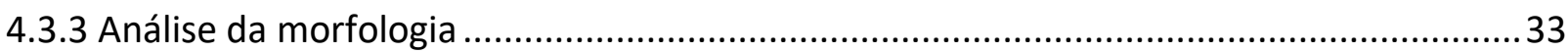

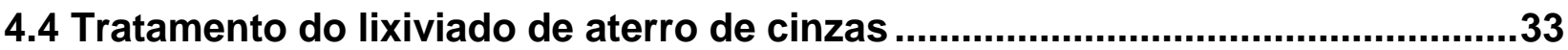

4.5 Síntese das zeólitas de cinzas de carvão modificadas por surfactante .............35 
4.6 Tratamento de efluente usando zeólitas modificadas por surfactante e zeólita

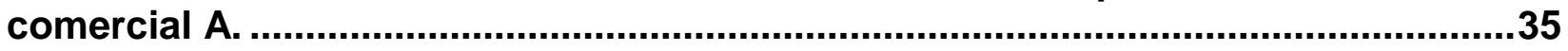

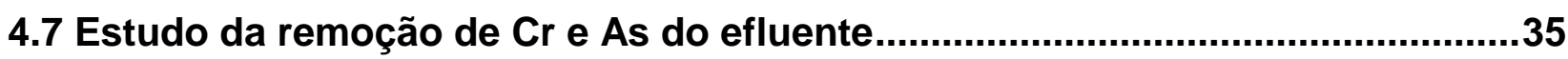

4.7.1 Tratamento com zeólita e acidificação prévia da solução aquosa ...................................36

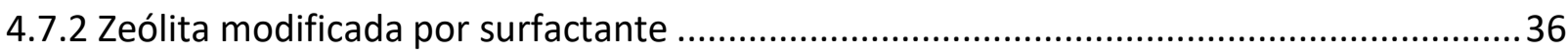

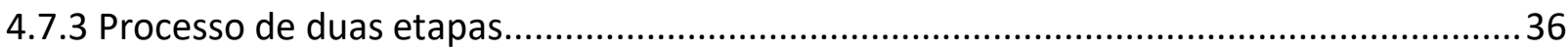

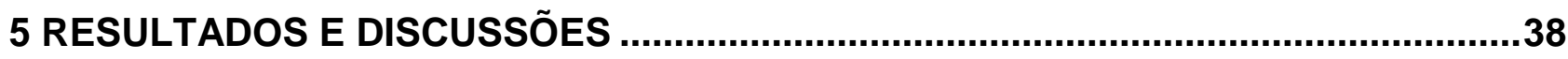

5.1 Características dos Materiais Zeolíticos .........................................................38

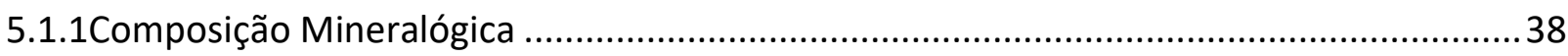

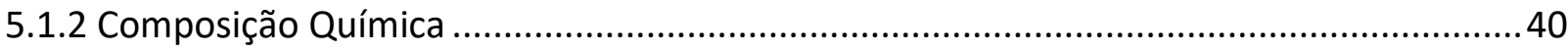

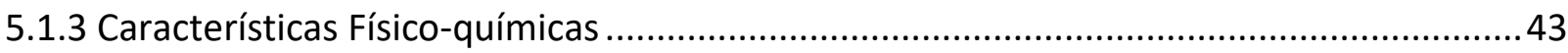

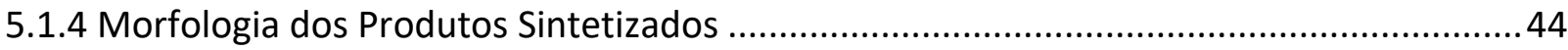

5.2 Tratamento de efluente usando materiais zeolíticos ........................................46

5.3 Tratamento de efluente usando zeólita modificada com surfactante ................51

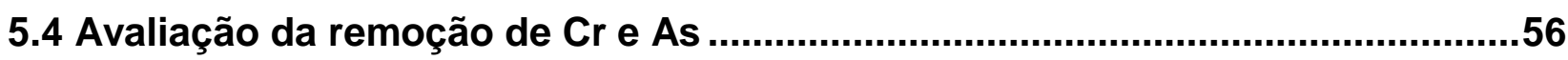

5.4.1 Tratamento com zeólita e acidificação prévia da solução aquosa ...................................56

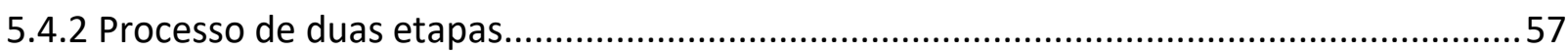

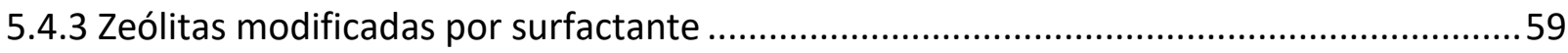

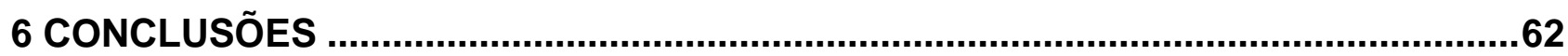

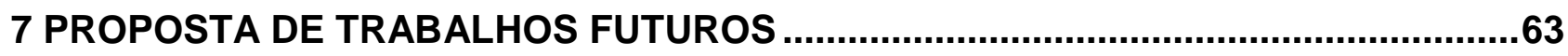

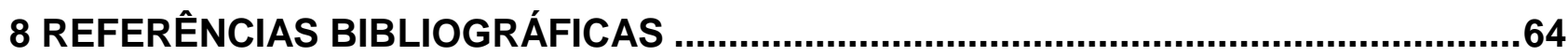

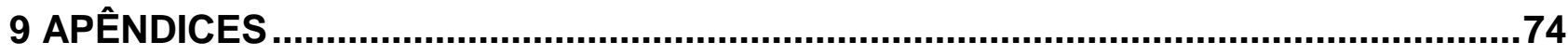




\section{LISTA DE TABELAS}

Página

Tabela 1 - Características das zeólitas mais comuns.

Tabela 2 - Composição química por FRX dos materiais zeolíticos obtidos das diferentes amostras de cinzas (\% massica)

Tabela 3 - Análise de carbono total das amostras de material zeolítico 43

Tabela 4 - Características físico-químicas das amostras de ZCP, ZCC e ZCM

Tabela 5 - Resultado da análise do lixiviado de aterro de cinzas (DA1) antes e depois do tratamento com ZCM usando diferentes doses e os parâmetros de lançamento

Tabela 6 - Resultado da análise do lixiviado de aterro de cinzas (DA1) antes e depois do tratamento com ZCC usando diferentes doses e os parâmetros de lançamento

Tabela 7 - Resultado da análise do lixiviado de aterro de cinzas (DA1) antes e depois do tratamento com ZCP usando diferentes doses e os parâmetros de lançamento.

Tabela 8 - Análise do efluente de aterro de cinzas antes e após tratamento com zeólitas modificadas com HDTMA-Br 1,8 $\mathrm{mmol} \mathrm{L}^{-1}$

Tabela 9 - Análise do efluente de aterro de cinzas antes e após tratamento com zeólita modificada com HDTMA-Br $20 \mathrm{mmol} \mathrm{L}^{-1}$ e zeólita comercial A

Tabela 10 - Valores de concentração do As e $\mathrm{Cr}$ e pH final do efluente após tratamento com ZCM em pH 4

Tabela 11 - Valores de concentraçãodo As e Cr do efluente após tratamento em duas etapas com ZCM

Tabela 12 - Valores de concentraçãodo As e Cr do efluente após tratamento em duas etapas com ZCM e zeólita magnética.

Tabela 13 - Valores de concentraçãodo As e Cr do efluente após tratamento com zeólitamodificada com HDTMA-Br 20 mmol.L-1 nadose $20 \mathrm{gL}^{-1}$ .59

Tabela 14 - Resultado da análise do efluente de aterro de cinzas na primeira e segunda coleta 


\section{LISTA DE FIGURAS}

Página

Figura 1 - Esquema das etapas envolvidas no processo de sorção .................................10

Figura 2 - Representações bi e tridimensionais da rede estrutural de zeólitas ...................13

Figura 3 - Estruturas das zeólitas: (a) natural faujasita ou zeólitas $X$ e Y sintéticas; (b) tipo

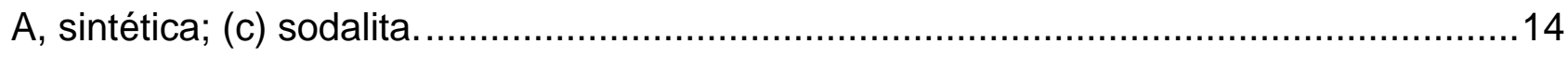

Figura 4 - Especiação de $\mathrm{Cr}(\mathrm{VI})$ e As (V) em água em função do pH ............................16

Figura 5 - Especiação dos grupos funcionais hidroxila em função do $\mathrm{pH}$........................17

Figura 6 - Estrutura química do brometo hexadeciltrimetilamônio ....................................19

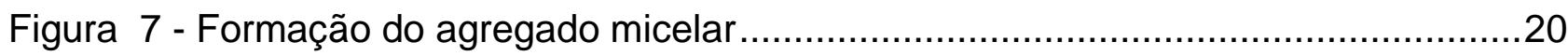

Figura 8 -Adsorção de surfactante na superfície da zeólita como:(a) monocamada; (b) monocamada/bicamada incompleta; (c) bicamada completa .........................................2.

Figura 9 -(a) diagrama das espécies de As em relação a Eh e pH; espécies de (b)

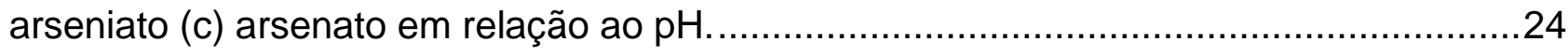

Figura 10- Diagrama de pH e Eh das espécies de cromo ………………………........26

Figura 11 - Localização da usina termelétrica de Figueira................................................29

Figura 12 - Ponto de coleta das diferentes cinzas de carvão, (1) fundo da caldeira, (2) filtro

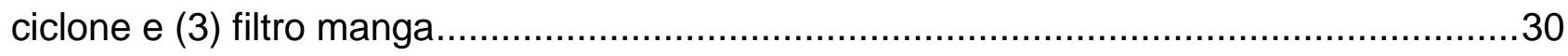

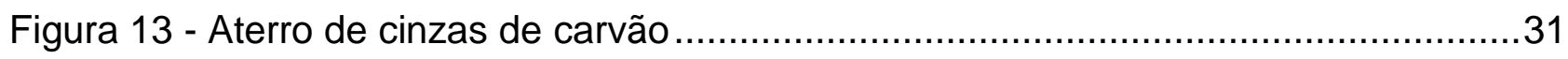

Figura 14 - Fluxograma das etapas do estudo de remoção dos elementos tóxicos presentes no efluente .34

Figura 15- Padrão de DRX do material zeolítico ZCP sintetizado por ativação hidrotérmica alcalina da cinza de carvão ( $\mathrm{Na}=$ Aluminossilicato de sódio, $\mathrm{Q}=$ Quartzo, $\mathrm{S}=$ Sodalita e $\mathrm{M}$ $=$ Mulita). 39

Figura 16- Padrão de DRX do material zeolítico ZCC sintetizado por ativação hidrotérmica alcalina da cinza de carvão $(\mathrm{Q}=$ Quartzo, $\mathrm{S}=$ Sodalita e $\mathrm{M}=$ Mulita $)$. .39

Figura17 - Padrão de DRX do material zeolítico ZCM sintetizado por ativação hidrotérmica alcalina da cinza de carvão $(Q=$ Quartzo, $S=$ Sodalita $e \mathrm{M}=$ Mulita) 
Figura 18- MEV do material zeolítico (ZCP) sintetizado a partir de cinzas de carvão por ativação hidrotérmica alcalina. 45

Figura 19- MEV do material zeolítico (ZCM) sintetizado a partir de cinzas de carvão por ativação hidrotérmica alcalina. .45

Figura 20- MEV do material zeolítico (ZCM) sintetizado a partir de cinzas de carvão por ativação hidrotérmica alcalina. .46 


\section{INTRODUÇÃO}

O desenvolvimento industrial acelerado ocorrente no mundo inteiro proporcionou diversos benefícios para a humanidade, porém seus efeitos negativos para meio ambiente também foram significativos e ainda influenciam na qualidade ambiental nos tempos atuais. As atividades industriais muitas vezes estão relacionadas com o detrimento ambiental devido as suas emissões de poluentes no ar, solo e água.

Segundo MARCHUK (1986), os limites máximos permitidos de substâncias tóxicas lançadas na natureza são excedidos diversas vezes pelas indústrias e associados a exploração elevada de recursos naturais, como extração de carvão mineral, têm resultado em altos níveis de degradação no planeta

Os ecossistemas aquáticos acabam tornando-se reservatórios temporários ou definitivos de grandes quantidades e variedades de poluentes que são lançados no ar, no solo ou diretamente nos corpos d'água. A poluição antropogênica aos ambientes aquáticos, causada de forma direta ou indireta pelo lançamento de substâncias inorgânicas ou orgânicas, pode acarretar em efeitos prejudiciais aos seres vivos, riscos à saúde e também as atividades (pesca, lazer etc.) e possíveis usos (industrial, agricultura, abastecimento etc.) (MEYBECK e HELMER, 1992).

A qualidade da água dos corpos hídricos é função do uso e ocupação do solo das bacias hidrográficas. Os centros urbanos são responsáveis pela geração e lançamento de efluentes sanitários e/ou industriais os quais são muitas vezes tratados inadequadamente ou lançados diretamente nos corpos d'água. Outra forma de contaminação destes ecossistemas inclui arraste de contaminantes pela chuva, assim como a lixiviação de substâncias nocivas de resíduos sólidos que entram em contato com as águas pluviais. Sendo assim, como descreve OLIVEIRA (2010), é de suma importância avaliar e quantificar os elementos que podem contaminar os recursos hídricos, para poder identificar os riscos e impactos ambientais decorrentes das diferentes atividades socioeconômicas que existem no território.

As indústrias lançam diversos poluentes no meio ambiente, destacando-se os efluentes com elementos tóxicos, pois apresentam maior periculosidade à saúde e ao ambiente, uma vez que podem gerar inúmeros efeitos nocivos à biota aquática e alteração dos parâmetros físico-químicos na água, diminuindo sua qualidade. 
De acordo com PINO (2005), questões ambientais vêm sendo mais abordadas e enfatizadas, a fim de provocar um aumento na conscientização e preocupação com as atividades de elevado impacto ambiental.

A geração de energia por usinas termelétricas de carvão mineral é uma atividade que possui elevado impacto ambiental, por serem indústrias que produzem grandes quantidades de resíduos sólidos, assim como, a geração e lançamento de efluentes líquidos. Portanto, a aplicação e valorização de resíduos sólidos provenientes da queima do carvão na síntese de um material alternativo podem contribuir para a redução dos impactos ambientais causados por sua destinação inadequada, sendo esse processo também apoiado pela Política Nacional de Resíduos Sólidos 꾸 12.305/10, que tem como uma de suas premissas os $3 \mathrm{Rs}$ (reduzir, reutilizar e reciclar).

A transformação de um resíduo em um produto de valor agregado e sua aplicação no tratamento dos efluentes líquidos in situ, da mesma usina, contribui de forma significativa com a sustentabilidade de usinas térmicas. Além disso, ressalta-se que a aplicação deste material adsorvente de baixo custo não se restringe ao uso da própria usina e pode ser utilizado em diversas aplicações, como o tratamento de efluentes contendo metais e/ou arsênio. 


\section{OBJETIVOS}

\subsection{Objetivo Geral}

O objetivo do trabalho foi sintetizar e caracterizar zeólitas a partir de três tipos dediferentes de cinzas de carvão geradas na usina termelétrica de Figueira e avaliar a aplicação como material adsorvente no tratamento de efluente da mesma usina.

\subsection{Objetivos Específicos}

- Determinar as concentrações dos elementos tóxicos presentes no efluente líquido da usina termelétrica de Figueira-PR;

- Sintetizar zeólitas a partir de diferentes tipos de cinzas de carvão;

- Caracterizar físico-quimicamente as diferentes zeólitas sintetizadas;

- Avaliar a remoção das substâncias tóxicas presentes no efluente líquido usando as zeólitas de cinzas de carvão como material adsorvente. 


\section{REVISÃO BIBLIOGRÁFICA}

\subsection{Geração de efluentes líquidos em termelétricas}

$\mathrm{Na}$ operação de usinas termelétricas a carvão é gerada uma série de efluentes líquidos, os quais são produzidos desde a extração do carvão mineral até a disposição dos resíduos gerados.

Os principais impactos ambientais produzidos durante as etapas de lavra e beneficiamento do carvão decorrem da disposição de resíduos sólidos estéreis e rejeitos, constituídos basicamente por materiais carbonosos e minerais (pirita e argilominerais) sem valor comercial, que são depositados em áreas próximas ao local de mineração (FUNGARO e IZIDORO, 2006).

Estes estéreis e rejeitos ricos em sulfetos de ferro oxidam-se em presença do ar, da água e da ação de bactérias Thiobacilus ferroxidans, desencadeando o processo de acidificação de drenagens e a dissolução de metais, que podem ocorrer em minas abandonadas ou em operação, originando a drenagem ácida de mina (DAM).

O nível de acidez, a concentração e a composição dos metais da DAM dependem do tipo e quantidade de sulfetos e da presença ou ausência de materiais alcalinos. Em consequência desse fenômeno, além do risco de contaminação de fontes de água superficiais e subterrâneas com a possível destruição do habitat aquático, a recuperação dessas áreas se torna mais onerosa devido à maior dificuldade de reflorestamento.

As reações químicas que explicam a oxidação da pirita e a produção de ácido in situ são representadas pelas Equações de 1 a 4.

$$
\begin{aligned}
& \mathrm{FeS}_{2(\mathrm{~s})}+7 / 2 \mathrm{O}_{2(\mathrm{~g})}+\mathrm{H}_{2} \mathrm{O}(\mathrm{l}) \leftrightarrow \mathrm{Fe}^{2+}{ }_{(\mathrm{aq})}+2 \mathrm{SO}_{4}{ }^{2-}(\mathrm{aq})+2 \mathrm{H}^{+}(\mathrm{aq}) \\
& \mathrm{Fe}^{2+}{ }_{(\mathrm{aq})}+1 / 2 \mathrm{O}_{2(\mathrm{~g})}+2 \mathrm{H}_{(\mathrm{aq})}^{+} \leftrightarrow \mathrm{Fe}^{3+}{ }_{(\mathrm{aq})}+\mathrm{H}_{2} \mathrm{O} \\
& \mathrm{Fe}^{3+}{ }_{(\mathrm{aq})}+3 \mathrm{H}_{2} \mathrm{O}(\mathrm{l}) \leftrightarrow \mathrm{Fe}(\mathrm{OH})_{3(\mathrm{~s})}+3 \mathrm{H}^{+}(\mathrm{aq}) \\
& \left.4 \mathrm{FeS}_{2(\mathrm{~s})}+15 \mathrm{O}_{2(\mathrm{~g})}+14 \mathrm{H}_{2} \mathrm{O}_{(\mathrm{l})} \leftrightarrow 4 \mathrm{Fe}(\mathrm{OH})_{3(\mathrm{~s})}+8 \mathrm{SO}_{4}{ }^{2-}{ }_{(\mathrm{aq})}+16 \mathrm{H}^{+}(\mathrm{aq})\right)
\end{aligned}
$$

O íon ferroso gerado na reação (equação 1) pode ser oxidado ao estado férrico (equação 2) que se hidrolisa gerando mais acidez (equação 3). As bactérias catalisam a reação de oxidação da etapa 2 . Os hidróxidos ferrosos e férricos, associados na reação 
química da equação 2, dão a cor vermelho-alaranjada que é característica da DAM e pode ser observada geralmente nos corpos d'água das áreas de mineração de carvão.

Os produtos da oxidação estão na solução, portanto, a etapa que determina a reação ácida é a oxidação do íon ferroso $\left(\mathrm{Fe}^{2+}\right)$ ao íon férrico $\left(\mathrm{Fe}^{3+}\right)$. Os produtos solúveis da oxidação da pirita são removidos pela água, consequentemente, na ausência de materiais alcalinos, as reações de produção de ácidos podem prosseguir por períodos de tempo indefinidos.

O outro efluente líquido, além da DAM, encontrado na área da usina termelétrica é proveniente do sistema de drenagem do aterro de cinzas de carvão. Estudos de pesquisadores como DEPOI et al. (2008) e QUISPE et al. (2012) mostraram que os resíduos de usinas a carvão possuem em sua composição química elementos tóxicos como As, Cd, Mo, Pb, Ti, U, Zn e Hg, que podem, ao lixiviar, contaminar o meio ambiente.

\subsection{Tipos de tratamentos de efluentes}

Os métodos tradicionais para tratar efluentes industriais, principalmente na remoção de elementos tóxicos de soluções aquosas,são: floculação, coagulação, precipitação, troca iônica, eletrodeposição, membranas, extração, cristalização, entre outros.Estas técnicas se tornam menos eficientes quando há reações heterogêneas com diversas substâncias e diferentes fases, além disso, apresentam maior consumo de energia e podem gerar lodo tóxico (ECCLES, 1999; PAGANA et al., 2008).

Outra técnica muito utilizada é a adsorção, que é uma alternativa de custo relativamente baixo e com elevada capacidade de remoção dos íons tóxicos. Exemplos de materiais adsorventes são: zeólita, carvão ativado, cinzas de carvão, materiais poliméricos, biomassa, entre outros (LEUNG et. al., 2000; PAGANA et al., 2008).

A seguir serão apresentadas resumidamente as principais técnicas de tratamento de efluentes industriais, sendo que uma descrição completa pode ser encontrada em artigos de revisão recentes (FU e WANG, 2011; GISI et al., 2016; KOSHY e SINGH, 2016). 


\subsubsection{Precipitação}

A precipitação química é largamente utilizada no processo de tratamento de efluentes industriais, devido ao baixo custo e a relativa simplicidade no processo. No tratamento de efluentes contendo metais tóxicos ocorre a reação química destes metais que formam precipitados insolúveis, podendo ser separados da solução aquosa por sedimentação ou filtração.

A precipitação de hidróxidos é a mais amplamente utilizada das técnicas, devido a relativa simplicidade, baixo custo e facilidade no controle do pH (HUISMAN et al., 2006). A solubilidade de grande parcela dos metais é minimizada na faixa de $\mathrm{pH}$ 8-11 e diversos hidróxidos podem ser usados na reação, porém sua escolha se baseia no custo e na facilidade de manipulação, o que torna a cal mais comumente utilizada nas configurações das industrias (BALTPURVINS et al., 1997).

A precipitação de metais com hidróxidos possui algumas limitações, como a grande geração de lodo, que necessita ser desidratado e devidamente disposto, além da baixa eficiência na remoção de metais pesados em baixas concentrações (FU e WANG, 2011).

\subsubsection{Coagulação e floculação}

A coagulação desestabiliza as partículas coloidais adicionando um coagulante, fazendo com que elas sedimentem (SHAMMAS, 2004). Para aumentar o tamanho de partícula, a coagulação é seguida pela floculação das partículas instáveis formando flocos (SEMERJIAN e AYOUB, 2003).

A floculação é o processo no qual partículas desestabilizadas entram em contato entre si, formando flocos maiores que podem ser removidos mais facilmente. O processo é geralmente acompanhado de uma mistura lenta das suspensões promovendo um maior tempo de contato entre as partículas, formando mais aglomerados. Os coagulantesfloculantes mais usados são $\mathrm{FeCl}_{3}, \mathrm{Fe}_{2}\left(\mathrm{SO}_{4}\right)_{3}, \mathrm{Al}\left(\mathrm{SO}_{4}\right)_{3}, \mathrm{FeSO}_{4}, \mathrm{Ca}(\mathrm{OH})_{2}$ (KURNIAWAN et al., 2006) 


\subsubsection{Membranas}

A tecnologia de membrana filtrante com diferentes tipos de membranas apresenta alta remoção de metais pesados em solução aquosa e sua eficiência está também vinculada ao menor espaço requerido na instalação e sua operação simples. Os tipos utilizados em processos de tratamento destes poluentes efluentes são as membranas ultra filtrantes, osmose reversa, nanofiltros e eletrodiálise (FU e WANG, 2011).

\subsubsection{Ultrafiltração}

A membrana ultra filtrante (UF) é a técnica que trabalha com menor pressão no sistema para a remoção materiais dissolvidos e coloidais. Os poros das UF são maiores que os íons de metais dissolvidos quando em forma de hidróxido ou com menores moléculas de complexos mais pesados, quando fora destas condições os íons acabam passando facilmente pelas membranas. A técnica possui dois complementos alternativos que são empregadas para aumentar a eficiência na remoção, sendo estas a micellar enhanced ultrafiltration (MEUF) e polymer enhanced ultrafiltration (PEUF) (FU e WANG, 2011).

Na técnica MEUF, adiciona-se um surfactante no efluente e quando a concentração do surfactante chega ao ponto crítico de concentração micelar, as moléculas do surfactante que agregaram as micelas, captam os íons de metais na forma de grandes estruturas metal-surfactante. As micelas contendo íons metálicos são retidas nos poros das membranas UF e os íons que não foram retidos nas micelas do surfactante acabam passando pelos poros.

Os surfactantes de cargas opostas são utilizados para obter maior retenção. A eficiência do processo é dependente da concentração dos metais e do surfactante, do $\mathrm{pH}$, força dos íons e parâmetros relacionados a operação da membrana. O surfactante pode ser o maior gasto da operação, sendo essencial a recuperação e o reuso do mesmo, caso isso não ocorra, o surfactante deve ser destinado adequadamente para não originar poluição secundária (FU e WANG, 2011).

Na técnica PEUF emprega-se um polímero solúvel em água para complexar os íns metálicos e formar macromoléculas, a fim de aumentar o peso molecular. Os complexos retidos podem ser tratados para recuperação dos íons metálicos e posteriormente, reutilização dos polímeros (TRIVUNAC e STEVANOVIC, 2006). Os 
parâmetros importantes para melhor eficiência no processo são as concentrações dos metais e polímeros, o pH e os tipos de metais em solução, uma vez que esses fatores têm influência na solubilidade e tamanho das substâncias que irão passar pelas membranas.

\subsubsection{Osmose reversa}

A osmose reversa (OR) é um processo que utiliza membranas semipermeáveis, permitindo que o fluído que está sendo purificado passe, enquanto os contaminantes ficam retidos. Esta técnica pode remover uma gama de espécies dissolvidas em água e é responsável por $20 \%$ da capacidade mundial de dessalinização de água do mar (SHAHALAM et al., 2002). As desvantagens da osmose reversa são o alto consumo de energia elétrica e a troca constante das membranas.

\subsubsection{Nanofiltração}

A nanofiltração (NF) é um processo intermediário entre UF e OR. Esta é uma técnica que vem sendo empregada com êxito na remoção de elementos tóxicos em efluentes como níquel (MURTHY e CHAUDHARI, 2008), cromo (MUTHUKRISHNAN e GUHA, 2008), cobre (CSÉFALVAY et al., 2009; AHMAD e OOI, 2010) e arsênio (NGUYEN et al., 2009; FIGOLI et al., 2010)

FIGOLI et al. (2010) constataram que aumentando o pH, diminuindo a temperatura de operação e com baixas concentrações de As, há uma maior eficiência das membranas.

LIU et al. (2008) estudaram a performance de diferentes NF e OR no tratamento de efluentes de metalúrgicas contendo metais tóxicos. Ambas as técnicas com membranas obtiveram resultados satisfatórios, conseguindo alcançar qualidade do efluente para reuso de água, porém a NF, apresentou ser mais adequada para indústrias de larga escala, uma vez que esta mantém o fluxo mais contínuo e demanda menor pressão em sua operação.

\subsubsection{Eletrodiálise}

A eletrodiálise (ED) é outro processo de membrana para separação de íons, através de membranas carregadas, de uma solução para outra usando campo elétrico com força motriz. A maior parte dos processos de ED utilizam membranas com íons de 
troca, sendo basicamente de dois tipos as membranas catiônicas e aniônica (FU e WANG, 2011).

NATARAJ et al. (2007) testaram a técnica para remoção de cromo hexavalente obtendo resultados satisfatórios para o limite máximo permitido de $0,1 \mathrm{mg} \mathrm{L}^{-1}$ de cromo estipulado pela World Health Organization (WHO). MOHAMMADI et al. (2004) estudaram a eficiência na separação dos íons de $\mathrm{Pb}^{+2}$ em efluentes usando ED. Os resultados mostraram que aumentando a voltagem e a temperatura há uma melhora na separação, porém, esta diminui com o aumento do fluxo e com concentrações superiores a $500 \mathrm{mg} \mathrm{L}$ 1.

\subsubsection{Troca lônica}

O processo de troca iônica vem sendo largamente utilizado na remoção de metais pesados, em efluentes, devido às muitas vantagens, como a alta capacidade de tratamento, a eficiência na remoção e a cinética rápida (KANG et al., 2004). As resinas de troca iônica, sintéticas ou naturais, têm capacidades específicas de troca de seus cátions com os metais presentes no efluente. As resinas sintéticas geralmente são utilizadas para remoção de metais pesados em solução (ALYÜZ e VELI, 2009).

A absorção de íons de metais pesados pelas resinas de troca iônica é afetada pelos seguintes fatores: $\mathrm{pH}$, temperatura, concentração inicial dos metais e o tempo de contato (GODE e PEHLIVAN, 2006). Assim como outro fator importante nesse processo é a carga iônica (FU e WANG, 2011).

\subsubsection{Eletrodeposição}

A recuperação eletrolítica é uma tecnologia muito usada para remover metais em tratamento de água. Este processo utiliza uma placa catódica e um ânodo insolúvel para gerar correntes elétricas que passam através de uma solução contendo metais. Os íons metálicos carregados positivamente aderem aos cátodos carregados negativamente, depositando os metais que são removidos e recuperados posteriormente. A corrosão dos eletrodos é uma desvantagem, pois leva a constante substituição dos mesmos (KURNIAWAN et al., 2006). 


\subsection{Adsorção}

Este tratamento será descrito com mais detalhes por ser o foco do estudo.

Dentre os processos físicos de tratamento de efluentes, a adsorção tem sido considerada superior a outras técnicas em termos de flexibilidade, custo inicial relativamente baixo, simplicidade no projeto e facilidade de operação.

A adsorção é um dos métodos mais conhecidos para remoção de contaminantes e pode ser empregada como uma etapa de pré-tratamento ou polimento do efluente final.

Os materiais adsorventes são substâncias naturais ou sintéticas, cuja superfície interna dos poros é acessível a uma combinação seletiva entre o sólido e o soluto. Basicamente, a adsorção é um processo de transferência de massa de uma fase líquida ou gasosa para a superfície de um sólido, sendo que a espécie química que é adsorvida é conhecida como adsorbato e o material no qual ocorre a adsorção é denominado adsorvente (BARAKAT, 2011; BERTOLINI, 2014). .A Figura 1 ilustra as etapas que fazem parte do processo de adsorção.

Figura 1 - Esquema das etapas envolvidas no processo de sorção

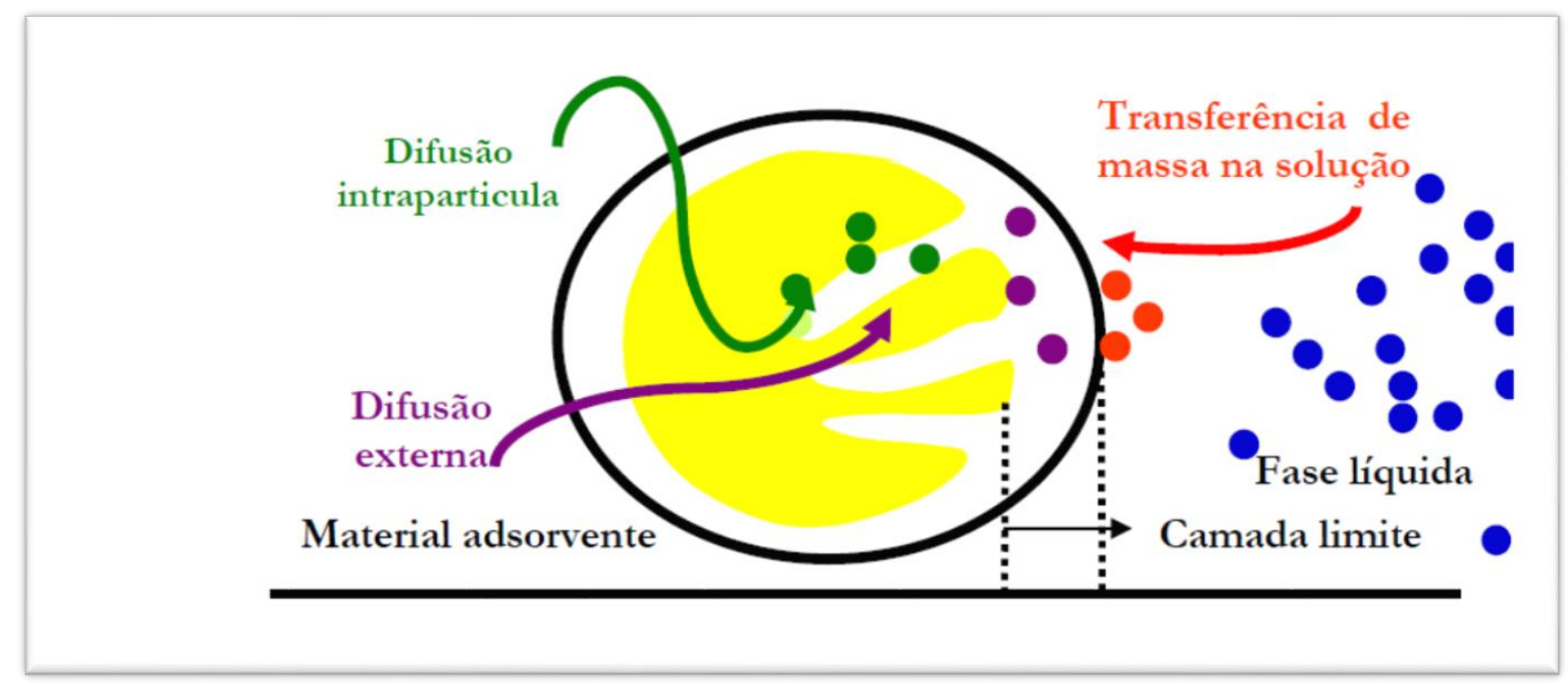

Fonte: OLIVEIRA, 2007. 
O processo de adsorção pode ser classificado em dois tipos, com base na interação (física ou química) que ocorre entre o adsorvente e o adsorbato. Quando há interação física, a adsorção é classificada como fisiossorção, estas apresentam reversibilidade no processo, devido à atração relativamente fraca. Nesta interação as moléculas presentes no adsorbato são retidas na superfície do sólido por diversos tipos de forças intermoleculares (forças de Van der Waals, ligações de hidrogênio, interações de dipolos, entre outros).

As interações de natureza química, denominadas quimissorção, ao contrário da física, apresentam-se fortes e, geralmente, não são reversíveis. Neste processo as moléculas ou átomos interagem com a superfície do sólido, devido as ligações químicas, como por exemplo, ligações iônicas e covalentes (ROVANI, 2015; BERTOLINI, 2014). Tanto as interações físicas quanto químicas podem ocorrer ao mesmo tempo, estas interações simultâneas acontecem dependendo das condições do processo (ZUIM, 2010; GRASSI, 2012).

Os fatores que influenciam o processo de adsorção são: acidez, o pH da solução, a área de superfície, o tamanho dos poros; a temperatura em que ocorre o processo, assim como as características e concentrações do adsorvente e do adsorbato (GRASSI, 2012; ATIKINS, 2004).

O material que apresenta alta capacidade de adsorção e que é amplamente utilizado para o tratamento de efluentes, é o carvão ativado. Entretanto, devido às perdas durante o processo de recuperação do adsorvente sua utilização torna-se onerosa, sendo esta uma desvantagem do processo de adsorção. Assim, existe um crescente interesse pela busca de materiais alternativos de baixo custo que possam ser utilizados como adsorventes em substituição ao carvão ativado, sendo a zeólita sintetizada a partir de um resíduo,um material promissor (GUPTA et al., 2009a, 2009b; AHMARUZZAMAN, 2011). 


\subsection{Tratamento de efluente usando zeólita}

\subsubsection{Definição de zeólita}

A palavra zeólita vem do grego zeo (que ferve) e lithos (pedra). Este material foi descoberto pela primeira vez pelo mineralogista sueco Alex Fredrik Cronstedt, há 250 anos. Porém, décadas depois Barrer e Milton produziram em laboratório a primeira zeólita sintética (GIANNETTO, 1990; COOMBS et al., 1998; MASTERS e MASCHMEYER, 2011).

As zeólitas podem ser de origem sintética ou mineral, com diversos tipos produzidos em laboratório, enquanto que somente quarenta tipos são encontrados na natureza (GUISNET e RIBEIRO, 2004). Alguns exemplos de zeólitas sintéticas são as zeólitas tipo $A, X, Y, P, L, F, N a-P 1$ e sodalita, estas são amplamente usadas pelas indústrias, sendo a zeólitas X e A com maior utilização industrial (IZIDORO, 2013; JHA e SINGH, 2011). Algumas características das zeólitas mais comuns são descritas na Tabela 1.

Tabela 1- Características das zeólitas mais comuns

\begin{tabular}{|c|c|c|c|}
\hline Zeólita & JCPDS* & Razão Si/Al & Formula Química \\
\hline Na-P1 & $39-0219$ & $\sim 1,00$ & $\mathrm{Na}_{6} \mathrm{Al}_{6} \mathrm{Si}_{10} \mathrm{O}_{32} \bullet 12 \mathrm{H}_{2} \mathrm{O}$ \\
\hline A & $43-0142$ & $1,00-1,50$ & $\mathrm{NaAISi}_{1.1} \mathrm{O}_{4.2} \cdot 2.25 \mathrm{H}_{2} \mathrm{O}$ \\
\hline$X$ & $39-0218$ & $1,00-1,20$ & $\mathrm{NaAISi}_{1.23} \mathrm{O}_{4.46} \bullet 3.07 \mathrm{H}_{2} \mathrm{O}$ \\
\hline Sodalita & $31-1271$ & - & $\mathrm{Na}_{1.08} \mathrm{Al}_{2} \mathrm{Si}_{1.68} \mathrm{O}_{7.44 \bullet 1.8 \mathrm{H}_{2} \mathrm{O}}$ \\
\hline
\end{tabular}

* Joint Committee of Powder Diffraction Standard

Fonte: IZIDORO, 2013; QIU e ZHENG, 2009;

As zeólitas naturais são geralmente encontradas em regiões vulcânicas, associadas com a ativação alcalina das rochas. Dentre os 40 tipos de zeólita naturais, 
apenas sete são considerados fontes minerais viáveis, por terem quantidades suficientes para extração (IZIDORO, 2008; ZAMZOW et al., 1990).

As zeólitas são aluminosilicatos hidratados de cátions de metais alcalinos e alcalinos terrosos. Este material possui estrutura em redes cristalinas tridimensionais,compostas de tetraedros do tipo $\mathrm{TO}_{4}(\mathrm{~T}=\mathrm{Si}, \mathrm{Al}, \mathrm{Ga}, \mathrm{Ge}, \mathrm{Fe}, \mathrm{B}, \mathrm{P}, \mathrm{Ti}$ etc) ligados aos vértices através de átomos de oxigênio (BRECK, 1984; GHOBARKAR et al., 1999; SMART et al., 1992).

As estruturas das zeólitas, em geral, são formadas por dois tipos de unidades de construção denominadas de unidade primária e secundária. As unidades de construções primárias são constituídas principalmente de $\mathrm{SiO}_{4}^{4-}$ e $\mathrm{AlO}_{4}^{5-}$ as quais se apresentam dispostas de tal maneira que os quatro cantos do tetraedro são ocupados por átomos de oxigênio em volta de um íon central (de $\mathrm{Si}^{4+}$ ou $\mathrm{Al}^{3+}$ ) (MARUI et al., 2002).

A Figura 2 ilustra como são estas estruturas, sendo que a a-cavidade é um cubooctaedro truncado e a $\beta$-cavidade é um octaedro truncado, também denominada cavidade sodalita (MASCARENHAS, OLIVEIRA e PASTORE, 2001).

Figura 2 - Representações bi e tridimensionais da rede estrutural de zeólitas

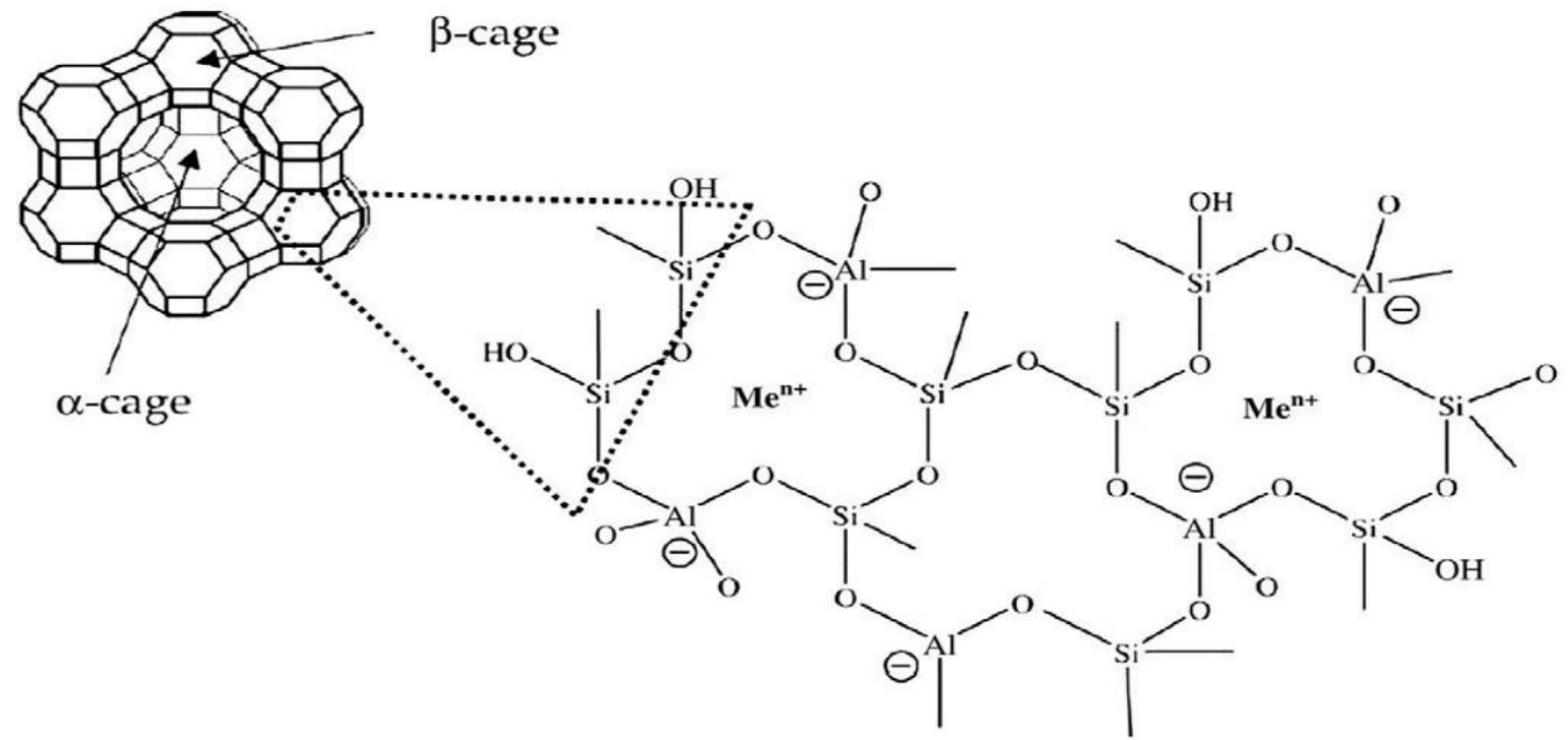

Fonte: FOO e HAMEED, 2011 
As estruturas secundárias são formadas a partir de ligações das estruturas primárias, que formam combinações mais complexas e diferentes tipos de poliedros (MAINGANYE, OJUMO e PETRIK, 2013).A Figura 3 ilustra três tipos de zeólitas que apresentam diferentes formas de poliedros.

Figura 3 - Estruturas das zeólitas: (a) natural faujasita ou zeólitas X e Y sintéticas; (b) tipo A, sintética; (c) sodalita

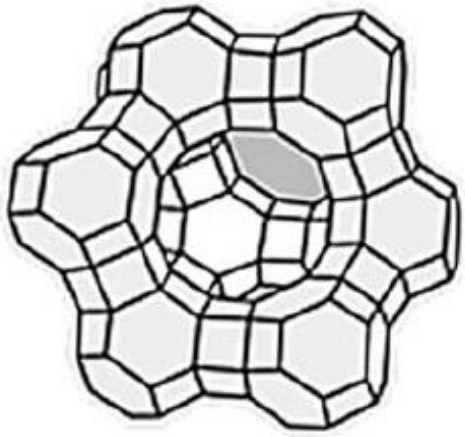

(a)

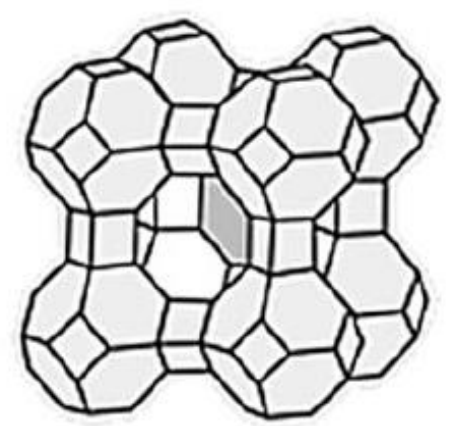

(b)

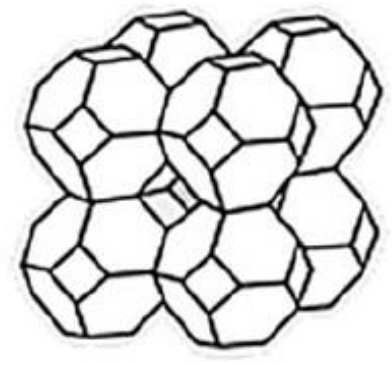

(c)

Fonte: LACERDA, 2015

As zeólitas podem ser representadas pela fórmula empírica

$$
\mathrm{M} \times n\left[\left(\mathrm{AlO}_{2}\right)_{x}\left(\mathrm{SiO}_{2}\right)_{y}\right] \cdot \mathrm{wH}_{2} \mathrm{O}
$$

Sendo que $n$ representa a valência do cátion de compensação $M, x$ e y é o número de tetraedros por célula unitária, sendo x+y o número total de tetraedros de $\mathrm{SiO}_{4}$ e $\mathrm{AlO}_{4}$, w é o número de moléculas de água e y/x é a razão Si/AI (GUISNET e RIBEIRO, 2004; BRECK, 1984).

As zeólitas são ótimos trocadores de cátions inorgânicos. Elas podem competir com resinas de troca iônica no processo de purificação de água e no tratamento de efluentes, além de demonstrarem uma alta resistência à temperatura e às radiações ionizantes. Este material pode ser utilizado como adsorvente seletivo e como catalisador (CORELLA, 1996). 


\subsubsection{Aplicação}

A zeólita pode ser utilizada no tratamento de diversos tipos de efluentes com características distintas. Alguns estudos demonstram que a zeólita pode ser aplicada no tratamento de drenagem ácida de mina, na remoção de íons metálicos em água e em efluentes de galvanoplastia, na remoção de corantes em solução aquosa, entre outras (BERTOLINI, 2014).

A utilização das zeólitas como catalisadores é empregada de forma eficiente, e isto ocorre devido à aproximação forçada entre moléculas dos reagentes sob a influência dos fortes potenciais eletrostáticos no interior das cavidades da zeólita, provocando a diminuição da energia de ativação necessária para o fenômeno da catálise (BOND, 1987). A grande parte das aplicações das zeólitas nas indústrias envolve a reação de catálise ácida, denominada cracking, que é a quebra de moléculas volumosas, em moléculas menores. Atualmente, as zeólitas são muito utilizadas no craqueamento do petróleo, tendo papel importante como catalisador nas indústrias químicas e petroquímicas (GUISNET e RIBEIRO, 2004; CORMA, 1997; LIMA, 2015).

\subsubsection{Mecanismos de adsorção}

A adsorção dos metais pela zeólita ocorre devido à interação do adsorbato com a superfície do adsorvente, esta interação pode ser forte ou fraca, dependendo do tipo de adsorção (física e/ou química) (WESTHOLM, REPO e SILLANPÄÄ, 2014).

PRASAD e MORTIMER(2011) sugerem que os sítios superficiais são os principais mecanismos de remoção, devido à elevada capacidade de troca catiônica das zeólitas sintéticas. A remoção de $\mathrm{Cr}(\mathrm{VI})$ e As (V) em solução aquosa, por exemplo, é altamente dependente do $\mathrm{pH}$ da solução, pois este afeta a carga superficial do adsorvente e o grau de ionização, além da especiação do adsorbato (Figura 4). 
Figura 4- Especiação de $\mathrm{Cr}(\mathrm{VI})$ e As (V) em água em função do pH
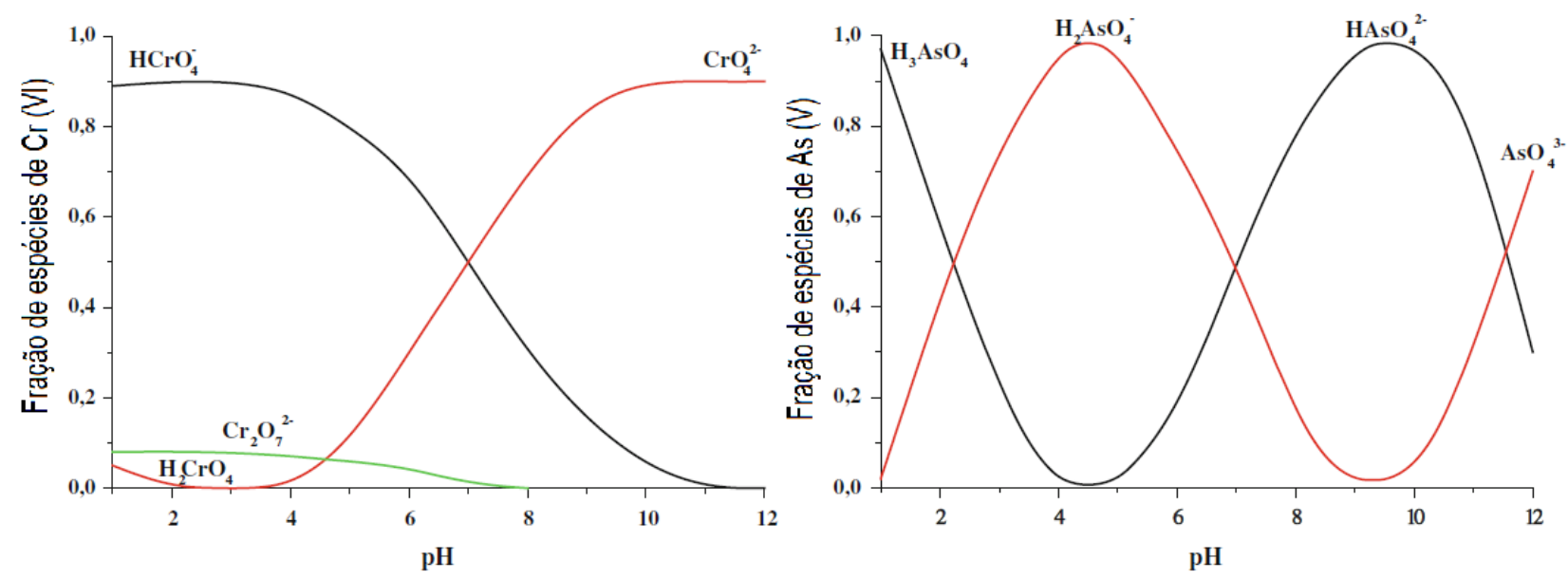

Fonte: JACHUŁA e HUBICKI, 2013

A zeólita possui sítios negativos em sua superfície, o que dificulta a adsorção de ânions em solução. Estudos realizados por WENG et al. (2008) identificaram que há a possível adsorção de íons aniônicos de $\mathrm{Cr}(\mathrm{VI})$ e As (V) por complexação, devido aos grupos funcionais hidroxila presentes na superfície do material. De acordo com RAl et al. (1989), os íons cromato podem ser adsorvidos por minerais sólidos que apresentam grupos hidroxila em sua superfície.

$\mathrm{Na}$ Figura 5, é ilustrado o comportamento dos grupos funcionais em relação ao $\mathrm{pH}$, sendo que a é a fração positiva, neutra e negativa, e $\underline{S}$ representa os sítios superficiais $\mathrm{Si}$ ou Al-. Estes grupos funcionais foram identificados como os sítios superficiais ativos de alguns minerais sólidos, sendo constituídos principalmente por $\mathrm{SiO}_{2}$ e $\mathrm{Al}_{2} \mathrm{O}_{3}$ (WENG et al., 2001; QUIO e ZHENG, 2007). 
Figura 5- Especiação dos grupos funcionais hidroxila em função do pH

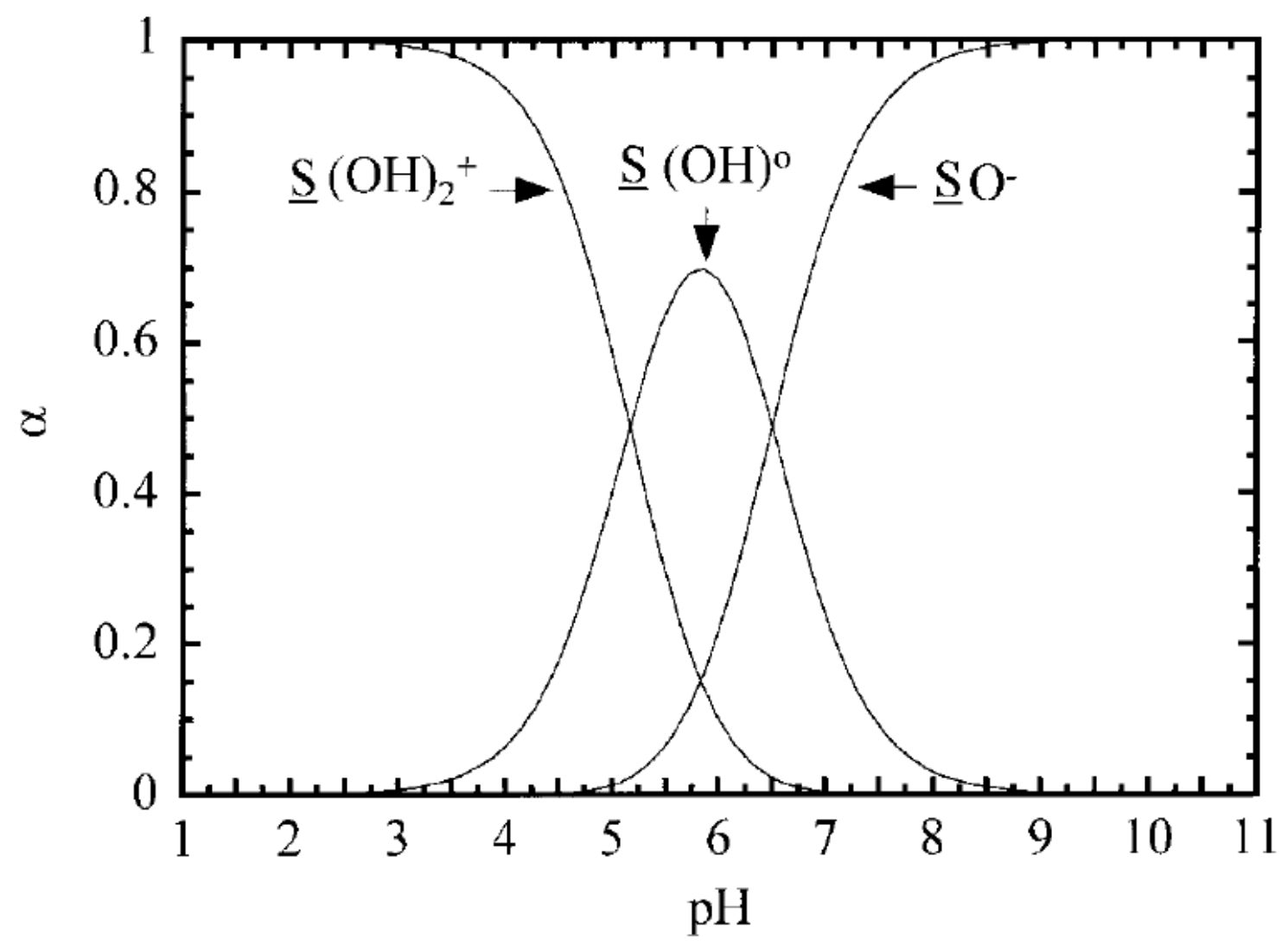

Fonte: WENG et al. (2001)

\subsubsection{Zeólitas modificadas}

\subsubsection{Zeólita Magnética}

A zeólita magnética pode ser produzida a partir da incorporação de magnetita na zeólita durante sua síntese.

A magnetita $\left(\mathrm{Fe}_{3} \mathrm{O}_{4}\right)$ é um compósito magnético formado por íons $\mathrm{Fe}^{2+} \mathrm{e} \mathrm{Fe}^{3+}$. Esta possui uma estrutura cristalina cúbica denominada spinel invertido, sendo que são formados por sítios tetraédricos ocupados pelos cátions $\mathrm{Fe}^{3+}$ e sítios octaédricos ocupados por ambos os íons de ferro (ARANTES, 2010). Os compósitos podem ser definidos como materiais formados por dois ou mais elementos, possuindo uma fase matriz (fase contínua) e uma fase dispersa (partícula), sendo que as propriedades finais do material são dependentes da combinação dos elementos, da morfologia e das 
características interfaciais, não necessariamente sendo resultante das propriedades individuais de cada elemento (CRAESMEYER, 2013).

Alguns estudos demonstram que a zeólita magnética pode ser utilizada para diversas finalidades como na remoção de corantes, íons metálicos em meio aquoso (FUNGARO et al., 2011, 2012), remoção do U(VI) de solução aquosa (CRAESMEYER, 2013), remoção de cromo hexavalente (YUAN et al., 2009; WANG et al., 2017) e utilização como catalisador (YUAN et al, 2009, 2010).

Segundo WANG et al. (2017) os mecanismos de adsorção de Cr (VI) pela zeólita magnética podem ocorrer devido algumas peculiaridades. $\mathrm{O} \mathrm{Fe}_{3} \mathrm{O}_{4}$ presente na zeólita reduz o cromo hexavalente para trivalente na solução aquosa. Assim, a zeólita pode remover o $\mathrm{Cr}$ (III) através de dois mecanismos, sendo o primeiro por troca iônica, uma vez que este material possui sítios negativos em sua superfície, e o outro menos provável é devido a sua elevada área superficial.

\subsubsection{Zeólita modificada com surfactante}

As zeólitas possuem sítios negativos na sua superfície que são resultantes da substituição isomórfica de cátions na estrutura cristalina, sendo estas hidrofílicas. Estas características agregam alta capacidade de troca catiônica e baixa afinidade por espécies aniônicas, assim como compostos orgânicos (ALCANTARA, 2016).

Os surfactantes (do inglês surface active), também conhecidos como agentes tenso-ativos, são compostos que tem atividade na superfície da interface entre duas fases podendo ser esta água, óleo-água, e na superfície de sólidos. Estes compostos têm como característica, duas regiões diferentes na mesma molécula: uma região polar (hidrofílica) e outra região não-polar (hidrofóbica) (Figura 6b) (BERTOLINI, 2014). 
Figura 6- Estrutura química do brometo hexadeciltrimetilamônio

(a)

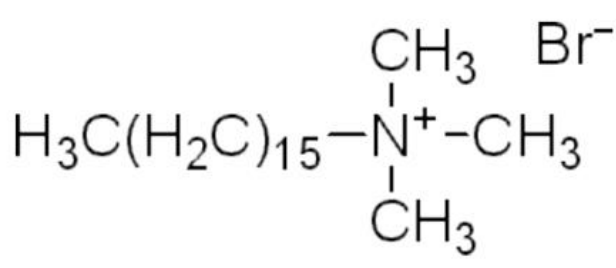

(b)

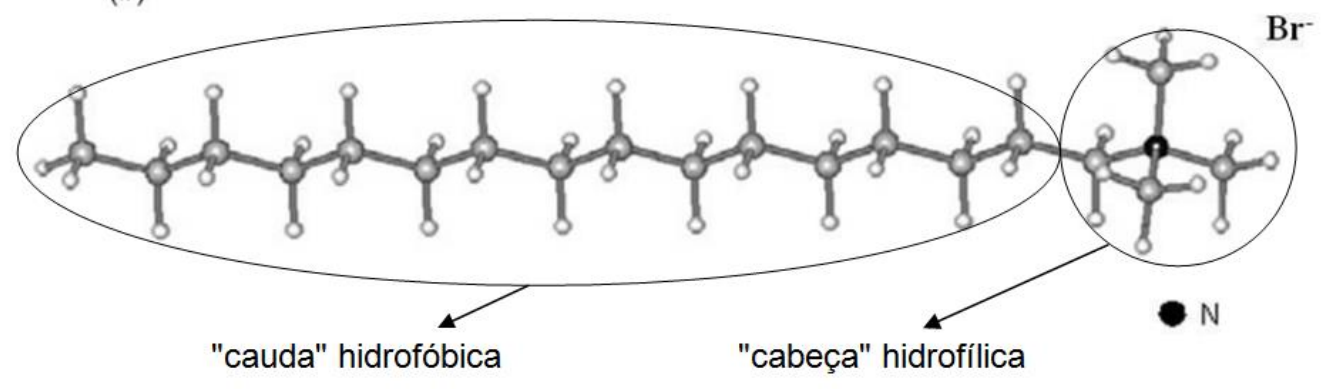

Fonte: modificado de BERTOLINI, 2014 e ALCANTARA, 2016

Todos os surfactantes têm a capacidade de formar agregados (micelas) em solução aquosa a partir de uma determinada concentração. A concentração onde inicia o processo de formação de agregados (micelização) é denominada, concentração crítica micelar (CMC), que é uma propriedade intrínseca e característica do surfactante que está predominantemente na forma de monômeros. O equilíbrio dinâmico entre monômero e micela está ilustrado na Figura 7, a concentração ainda está abaixo, no entanto, próxima da CMC (MANISSAO, 2001).

Figura 7- Formação do agregado micelar

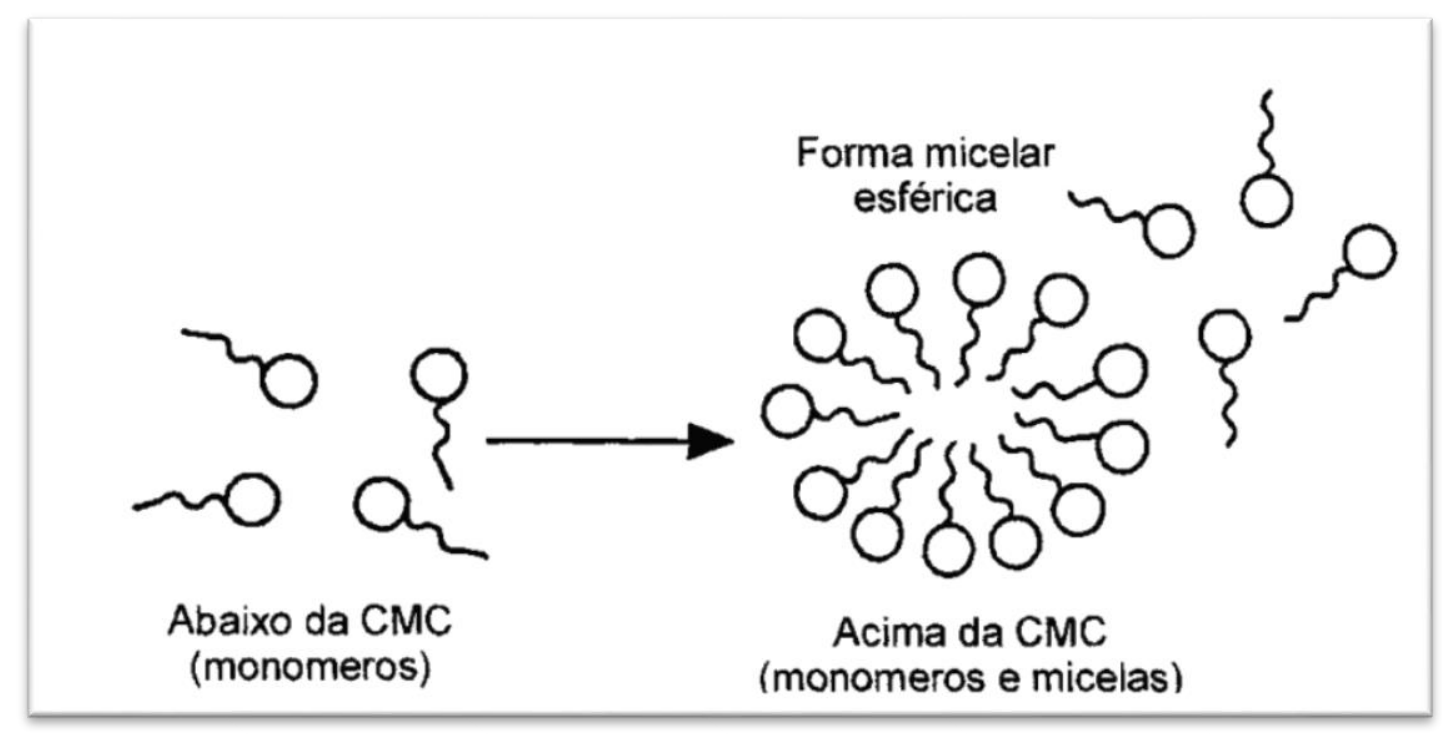

Fonte: MANISSAO, 2001 
Existem diferentes tipos de surfactantes utilizados pelas indústrias para finalidades distintas como, por exemplo, os catiônicos, aniônicos, não iônicos e anfóteros (MANISSAO, 2001). Os surfactantes catiônicos mais utilizados na modificação de zeólitas são as aminas quaternárias de cadeia alquílica longa, sendo estes compostos com carga permanente positiva de nitrogênios pentavalentes e alto grau de hidrofobicidade (HAGGERLY e BOWMAN, 1994; BOWMAN, 2003). O brometo de hexadeciltrimetilamônio (HDTMA-Br) é atualmente o mais utilizado para modificar zeólitas devido a sua disponibilidade e baixo custo (Figura 6).

A zeólita quando misturada com o surfactante em concentrações menores que a CMC, ocorre a formação, via troca iônica, de uma monocamada das moléculas catiônicas do surfactante na superfície externa da zeólita carregada negativamente (Figura 8a). Em concentrações acima da CMC, uma bicamada via interações hidrofóbicas é formada entre as caudas do surfactante, por causa das forças coercivas fracas de Van der Waals (Figura 8b). Frequentemente, pode-se observar a formação de monocamada e/ou bicamada incompleta antes de ocorrer a formação da bicamada completa (SULLIVAN et al. 1997; ROZIC et al.,2009). A Figura 8 apresenta a adsorção de surfactante na superfície da zeólita (LI e BOWMAN, 1997) 
Figura 8 - Adsorção de surfactante na superfície da zeólita como: (a) monocamada; (b) monocamada/bicamada incompleta; (c) bicamada completa

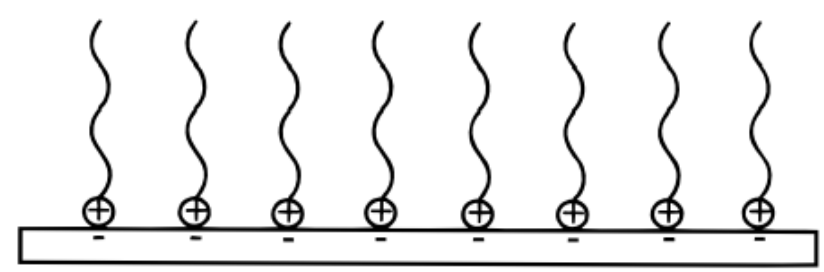

(a)

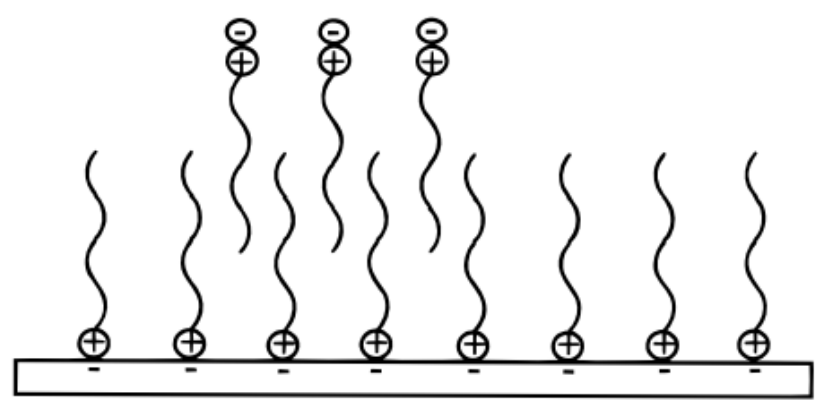

(b)

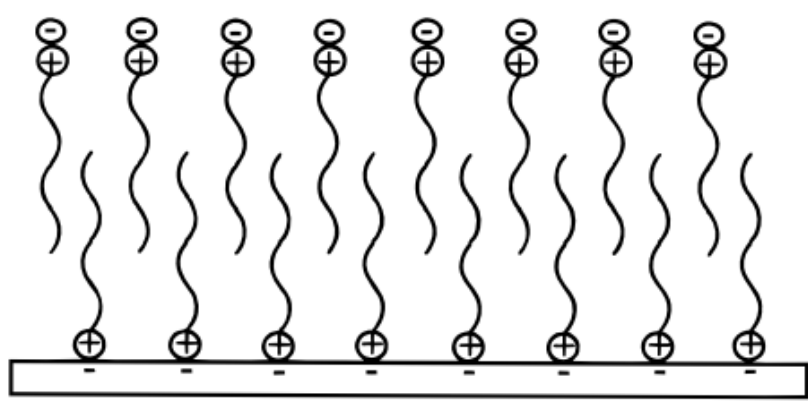

(c)

Fonte: LI e BOWMAN, 1997

A zeólita modificada com surfactante é capaz de adsorver diferentes classes de contaminantes em água como: ânions, cátions, substâncias orgânicas e disruptores endócrinos simultaneamente. Este fenômeno ocorre porque o surfactante possui moléculas maiores que os poros da zeólita e, portanto, os sítios de troca internos permanecem disponíveis para remoção de cátions. Além disso, a bicamada do surfactante eleva a quantidade de carbono orgânico total da zeólita fazendo com que o meio fique similar a um solvente, o qual compostos orgânicos acabam dissolvendo (BERTOLINI, 2014; MAGDALENA, 2015). 


\subsection{Principais elementos tóxicos}

No presente estudo, os principais elementos tóxicos são o arsênio e o cromo, devido as altas toxicidades e suas peculiaridades que dificultam o tratamento em solução aquosa.

A problemática em relação à alta concentração de arsênio encontrada em amostras de carvão e cinzas provenientes da atividade carbonífera da usina termelétrica de Figueira e de amostras ao redor da mesma foi identificada em estudos anteriores.

A alta concentração de arsênio é atribuída à presença significativa de pirita no carvão do Paraná (FUEL et al., 2013; FLUES et al., 2008) Em estudos de DEPOl et al, 2008 foram observadas 35\% e 19\% de As no extrato de água obtido a partir das cinzas leves e pesadas, respectivamente. Enquanto para o $\mathrm{Cr}$, a extração foi de 0,8 e 0,3\% para as cinzas leves e pesadas, respectivamente. Além disso, foi observado que o arsênio estava entre os elementos que apresentavam concentração mais alta no carvão e nas cinzas na usina termelétrica de Figueira do que nas outras usinas brasileiras.

Os elementos traço foram determinados em amostras de carvão e cinzas da usina da Figueira coletadas durante um ano. No geral, as concentrações dos elementos foram: $\mathrm{Zn}>\mathrm{As}>\mathrm{Mn} \geq \mathrm{Pb} \geq \mathrm{V}>\mathrm{Cr}>\mathrm{Ni} \geq \mathrm{Mo}>\mathrm{Cu}>\mathrm{Cd}>\mathrm{Co}$. O arsênio foi o elemento que apresentou a maior porcentagem de disponibilidade nas cinzas (> 40\%), enquanto o $\mathrm{Cr}$ apresentou baixa disponibilidade (<5\%). A disponibilidade representa a quantidade de metal que pode ser lixiviada das cinzas para o meio ambiente.O As também apresentou o maior fator de enriquecimento nas cinzas do filtro manga em relação ao carvão. A sequência no fator de enriquecimento foi: $\mathrm{As} \geq \mathrm{Pb} \geq \mathrm{Zn}>\mathrm{Mn}>\mathrm{Mo}>\mathrm{Cu}>\mathrm{Cr}>\mathrm{Cd}>\mathrm{Ni}$ (FLUES et al., 2013).

A concentração de elementos traço presentes em amostras de solo coletadas em 50 pontos ao redor da usina foi determinada. Os elementos considerados contaminantes foram As, Cd, Mo, $\mathrm{Pb}$ e $\mathrm{Zn}$, sendo que o As foi considerado o elemento mais crítico, pois apresentou uma concentração parcial em 10 pontos amostrados acima do valor de intervenção estabelecido pela CETESB (FLUES et al., 2008).

Nos estudos sobre amostras de solo coletadas em torno da usina de Figueira foi constatado que $\mathrm{Co}, \mathrm{Cr}, \mathrm{Cu}, \mathrm{Ni}$ e Sc eram de origem litogênica, enquanto As, Cd, Hg, Mo, $\mathrm{Pb}, \mathrm{Sb}, \mathrm{U}$ e $\mathrm{Zn}$ apresentaram origem no carvão e nas fontes de cinzas da área (CAMPANER, 2013). 
A contaminação de dois tipos de solo diferentes pela lixiviação de As das cinzas de carvão coletadas em Figueira foi avaliada por estudos em coluna com percolação de chuva ácida simulada. A alta mobilidade desse elemento foi observada por LANGE (2012) e SILVA (2013).

Concentrações elevadas de arsênio no carvão, cinzas e plantas coletadas ao redor da usina de Figueira foram registradas na avaliação de impacto ambiental realizada por KALKREUTH et al. (2014).

O comportamento da lixiviação do As de cinzas é pouco compreendido na natureza. Portanto, pesquisas têm sido realizadas em laboratório para melhor entendimento desse comportamento. Mesmo assim, resultados discrepantes de concentrações de As têm sido observados em diferentes amostras de cinzas (PANDEY, 2011).

\subsubsection{Arsênio}

O arsênio é um poluente muito conhecido pela sua alta toxicidade e por ser carcinogênico, além de ser muito encontrado em águas para consumo em diversas regiões (DRIEHAUS et al., 1995; PAGANA et al., 2008). Este elemento apresenta diversas espécies em água variando com o pH, potencial redox (Eh) (Figura 9a) e outros fatores. A maioria dos oxiânions, incluindo o arsenato, tende a diminuir sua solubilidade com o aumento do $\mathrm{pH}$ (DZOMBAK e MOREL, 1990).

Em relação aos oxiânions presentes no meio ambiente, o As está entre os mais problemáticos, por causa da sua alta mobilidade em uma ampla faixa de potencial redox (SMEDLEY e KINNIBURGH, 2002). Em Eh baixo (<600), a espécie principal é As (III) o qual apresenta predominantemente, em pH menor que 9,2, a forma $\mathrm{H}_{3} \mathrm{AsO}_{3}{ }^{0}$ (Figura 9b). Já em Eh alto (> 600), a espécie principal é As (V), sendo a forma $\mathrm{H}_{2} \mathrm{AsO}_{4}{ }^{-}$predominante em $\mathrm{pH}$ inferior a 6,9 e a $\mathrm{HAsO}_{4}{ }^{2-} \mathrm{em} \mathrm{pH}$ mais elevado. Já as formas $\mathrm{H}_{3} \mathrm{AsO}_{4}{ }^{0}$ e $\mathrm{AsO}_{4}{ }^{3-}$ podem estar presentes em condições extremamente ácidas e alcalinas, respectivamente (Figura 9c) (BROOKINS, 1988; YAN et al., 2000). 
Figura 9- (a) diagrama das espécies de As em relação a Eh e pH; espécies de (b) arseniato (c) arsenato em relação ao pH.

(a)

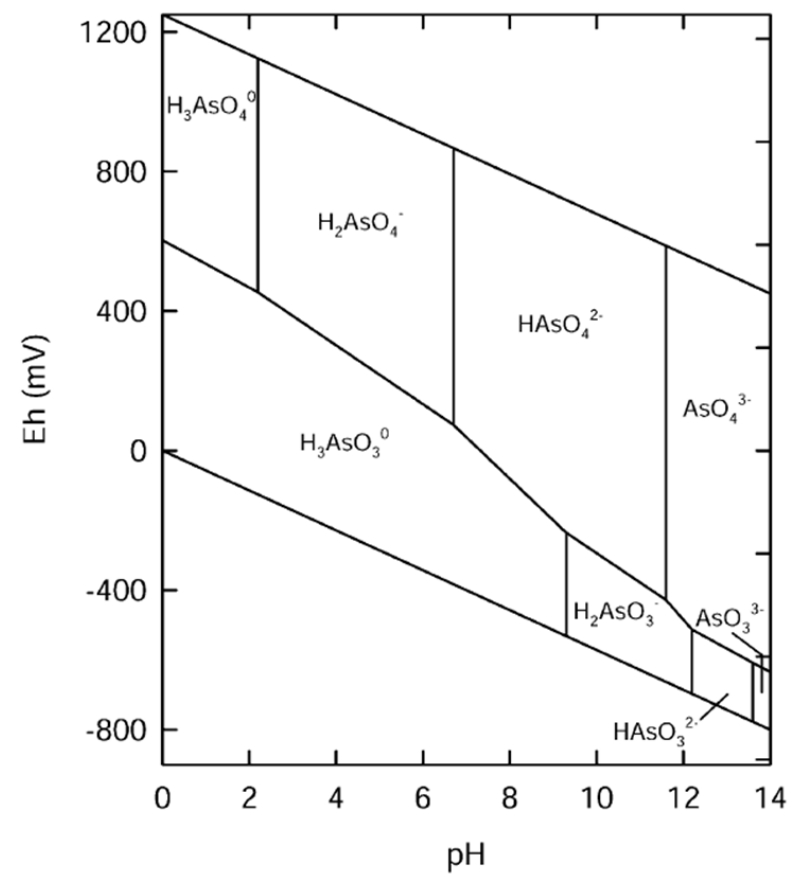

(b)

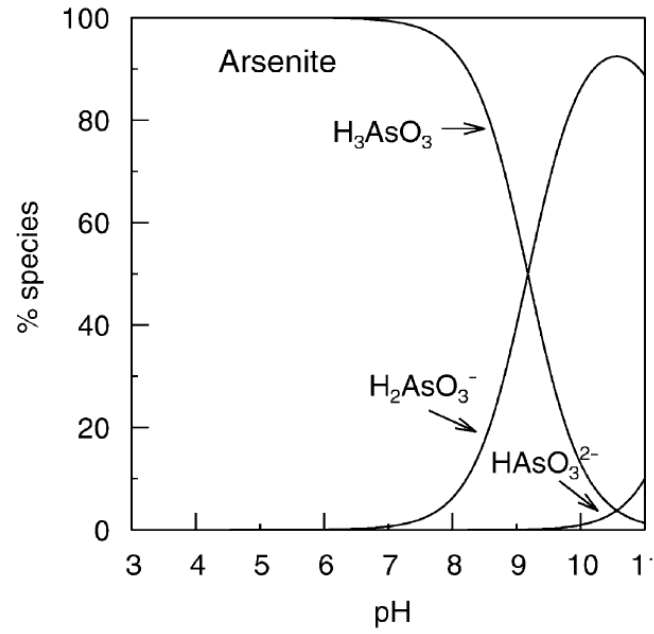

(c)

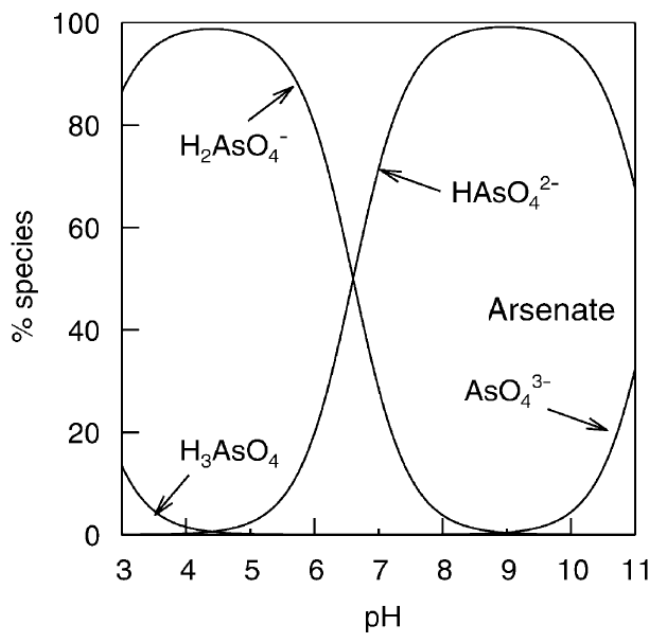

Fonte: modificado de SMEDLEY e KINNIBURGH, 2002

Os compostos de arsênio são muito utilizados nas indústrias e na agricultura, incluindo pesticidas, herbicidas, indústrias de vidro, semicondutores, pigmentação e preservantes de madeira. Na biomassa este elemento aparece principalmente como espécies orgânicas na forma de metil compostos, sendo que os encontrados em água normalmente são espécies inorgânicas. As espécies orgânicas como ácidos monometilarsônico (MMA) e o dimetilarsénico (DMA) apresentam baixa toxicidade, enquanto que arseniobetaína e arseniocolina não são tóxicas.No entanto, as espécies inorgânicas como o As (III) e As (V) possuem alta toxicidade, sendo a forma trivalente a 
mais tóxica solubilizada em água. Estudos apontam que este elemento pode causar câncer em seres humanos (MARTINEZ-BRAVO et al., 2001;AGRAFIOTI et al., 2014) e efeitos no desenvolvimento embrionário. De acordo com SMITH e STEINMAUS(2009), arsênio pode causar baixa de peso em embriões e em alguns provoca abortos espontâneos.

O aumento da mortalidade infantil e a diminuição das funções cognitivas das crianças são outros fatores correlacionados com a exposição ao arsênio (SMITH e STEINMAUS, 2009).

Os organismos aquáticos podem acumular arsênio de modo mais eficiente em relação aos organismos terrestres. Por exemplo, as algas marinhas absorvem a forma predominante do arsênio no mar (os arseniatos) e os transformam em diferentes ribosídeos contendo arsênio, alterando de arsênio inorgânico para orgânico, como MMA e DMA. Os organismos marinhos provavelmente adquirem arsênio pela cadeia alimentar (BARRA et al., 2000).

Em rios, o lançamento de efluentes com concentrações de As a partir de 0,21 mg.'-

1, faz com que apenas microorganismos do tipo diatomáceas sobrevivam. Por outro lado, os peixes não morrem, porém bioacumulam este elemento (PANDEY, 2011).

Os efeitos tóxicos do As têm sido muito estudados, tanto por países desenvolvidos como pelos subdesenvolvidos. Esse elemento tóxico é cancerígeno, mutagênico e pode causar riscos aos sistemas respiratórios, digestivos e mesmo aos dermatológicos. 0 envenenamento crônico pelo As, como já citado anteriormente, pode causar efeitos graves também à saúde incluindo câncer, melanoma, gangrena, diabetes, hipertensão e afetar o sistema imunológico. Em alguns estudos, foi possível observar que trabalhadores diretamente envolvidos com as cinzas contendo As, apresentaram elevados danos ao DNA (USPHS, 2000; 2001)

\subsubsection{Cromo}

O Cr apresenta diversos estados de oxidação na água, porém na natureza são encontrados principalmente o $\mathrm{Cr}^{+3}$ e o $\mathrm{Cr}^{+6}$ por serem mais estáveis (SHUPAK, 1991).

As espécies do Cr têm características distintas, uma vez que $\mathrm{Cr}(\mathrm{VI})$ é mais solúvel em água, apresentando maior mobilidade e biodisponibilidade. Além disso, pode causar reações alérgicas na pele e até mesmo câncer, portanto é uma espécie altamente tóxica. 
Já sua forma reduzida, o $\operatorname{Cr}(\mathrm{III})$, é trezentas vezes menos tóxica que a hexavalente e é essencial para saúde de plantas e animais, assim como no metabolismo humano, sendo responsável pela redução dos níveis de glicose e colesterol no sangue, podendo estar relacionado ao controle da diabete (PAGANA et. al., 2008; MARTINEZ-BRAVO et al., 2001; AGRAFIOTI et al., 2014; PANTSAR-KALLIO e MANNINEN 1997; GUOCHENG et al., 2014; MIRETZKY e CIRELLI, 2010)

Estudos indicam que o consumo de água contendo cromo hexavalente pode causar câncer de estômago, aumentando os riscos da população que vive em regiões contaminadas com esse poluente (SMITH e STEINMAUS, 2009). Assim como o As, a especiação do Cr é altamente dependente do pH e do Eh, como mostra a Figura 10.

Figura 10- Diagrama de pH e Eh das espécies de cromo

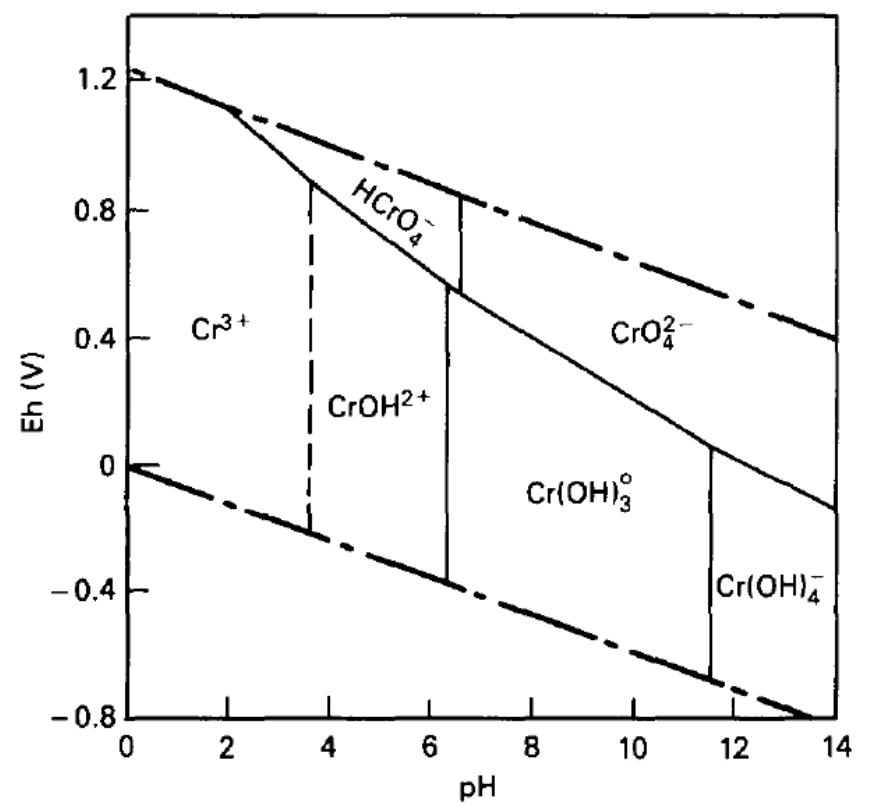

Fonte: RAI, EARY, ZACHARA, 1989

As principais espécies do cromo (III), encontradas no meio ambiente, ocorrem em baixo potencial redox, sendo estas o $\mathrm{Cr}^{3+}, \mathrm{Cr}(\mathrm{OH})^{2+}, \mathrm{Cr}(\mathrm{OH}) 3^{0} \mathrm{e} \mathrm{Cr}(\mathrm{OH}) 4^{-}(\mathrm{MIRETZKY} \mathrm{e}$ CIRELLI, 2010).

$\mathrm{O}$ cromo $(\mathrm{VI})$ pode apresentar diferentes espécies em soluções aquosas variando de acordo com $\circ \mathrm{pH}$, estas são: o cromato $\left(\mathrm{CrO}_{4}^{2-}\right)$, dicromato $\left(\mathrm{Cr}_{2} \mathrm{O}_{7}{ }^{2-}\right)$, cromato de hidrogênio $\left(\mathrm{HCrO}_{4}^{-}\right)$, ácido crômico $\left(\mathrm{H}_{2} \mathrm{CrO}_{4}\right)$, dicromato de hidrogênio $\left(\mathrm{HCr}_{2} \mathrm{O}_{7}^{-}\right)$, 
tricromato $\left(\mathrm{Cr}_{3} \mathrm{O}_{10^{2}}{ }^{2-}\right)$, tetracromato $\left(\mathrm{Cr}_{4} \mathrm{O}_{13^{2}}{ }^{2-}\right)$. A forma hexavalente, diferentemente do $\mathrm{Cr}^{3+}$, não é encontrada na forma de cátions livres.

As espécies de $\mathrm{Cr}(\mathrm{VI})$ se distinguem em três principais faixas de $\mathrm{pH}$. $\mathrm{Em} \mathrm{pH} \leq 2$, 0 $\mathrm{H}_{2} \mathrm{CrO}_{4}$ é a forma que mais aparece em solução, enquanto que na faixa de $\mathrm{pH} 2-6$ as espécies que mais estão presentes são o $\mathrm{HCrO}_{4}^{-}$e o $\mathrm{Cr}_{2} \mathrm{O}_{7}^{2-}$. Por fim, em $\mathrm{pH}>6,0 \mathrm{CrO}_{4}^{2-}$ é predominante (TANDON et al., 1984; KIMBROUGH et al., 2010). Como pode ser observado todas as espécies do $\mathrm{Cr}^{6+}$ são aniônicas, o que dificulta sua adsorção por meio da zeólita, uma vez que esta possui sítios negativos.

Segundo KIM et al. (2016) existem diversas formas de remoção do $\mathrm{Cr}$ (VI) em solução aquosa, sendo estes divididos em três categorias: (1) tratamentos físicos, dentre eles adsorção, troca iônica e membrana filtrante; (2) tratamentos químicos, como oxidação química, degradação eletroquímica e uso de ozonização; (3) degradação biológica. Dentre todos os métodos, a adsorção se destaca pelo custo relativamente menor e sua alta eficiência no tratamento. Alguns exemplos, de materiais adsorventes, são dolomita, celulose, carvão ativado, ferro zero valente, zeólita, entre outros.

A geração de efluente, contendo este metal, pode vir de diversas empresas como na extração de metais, indústrias têxteis, de tintas e de pigmentação, manufatura de baterias, curtumes, entre outras. Há uma preocupação também no lançamento do $\mathrm{Cr}$ (III) no meio ambiente, pois este é facilmente oxidável, o que pode acarretar na mudança para Cr (VI) (PAGANA et. al., 2008; AGRAFIOTI et al., 2014)

YUSOF et al. (2009) observaram que a maior capacidade de remoção do Cr (VI) utilizando zeólita modificada com surfactante foi em pH 3. Em pH baixo, as espécies de cromo hexavalente são principalmente na forma univalente $\left(\mathrm{HCrO}_{4}{ }^{-}\right)$, portanto requer um sítio de troca do adsorvente para uma molécula da espécie do adsorbato. Em contrapartida, em pH elevado as formas divalentes das espécies $\left(\mathrm{Cr}_{2} \mathrm{O}_{7}{ }^{2-}, \mathrm{CrO}_{4}{ }^{2-}\right)$ estão principalmente presentes e necessitam de dois sítios de troca para a adsorção ocorrer. Além disso, a baixa eficiência na sorção do cromo em pH 10 pode ser devido à forte competição do $\mathrm{OH}^{-}$com o $\mathrm{Br}^{-}$ou a maior quantidade de íons $\mathrm{OH}^{-}$que competem com os ânions cromato nesta faixa de $\mathrm{pH}$. Estudos como de Li (2004) também apresentaram resultados similares sendo que em $\mathrm{pH} 11$ houve uma maior afinidade com $\circ \mathrm{Cl}^{-}$do que com o cromo. 


\subsubsection{Legislação}

A Agência de Proteção Ambiental (Environmental Protection Agency- EPA) dos EUA, estabelece que o limite de concentração do arsênio e do cromo em água para consumo é 0,01 ppm e 0,1 ppm, respectivamente. Enquanto que limites mais restritivos, apenas para o $\mathrm{Cr}$, são impostos pela Comunidade Européia e pela WHO, sendo 0,05 ppm. No Brasil, a legislação federal utilizada para lançamento de efluentes é a resolução CONAMA 430 que estipula um limite máximo de concentração de arsênio em 0,5 ppm e 0,1 ppm para o cromo, os padrões devem ser atendidos para que o efluente possa ser lançado no corpo d'água minimizando os impactos à saúde e ao meio ambiente (PAGANA et. al. 2008; AGRAFIOTI et al. 2014; BRASIL, 2011, AHMARUZZAMAN, 2011). 


\section{MATERIAIS E MÉTODOS}

\subsection{Materiais}

Todos os reagentes usados no estudo experimental são de grau analítico. As amostras de cinzas de carvão coletadas são provenientes da usina termelétrica de Figueira localizada no estado do Paraná (Figura 11).

Figura 11- Localização da usina termelétrica de Figueira

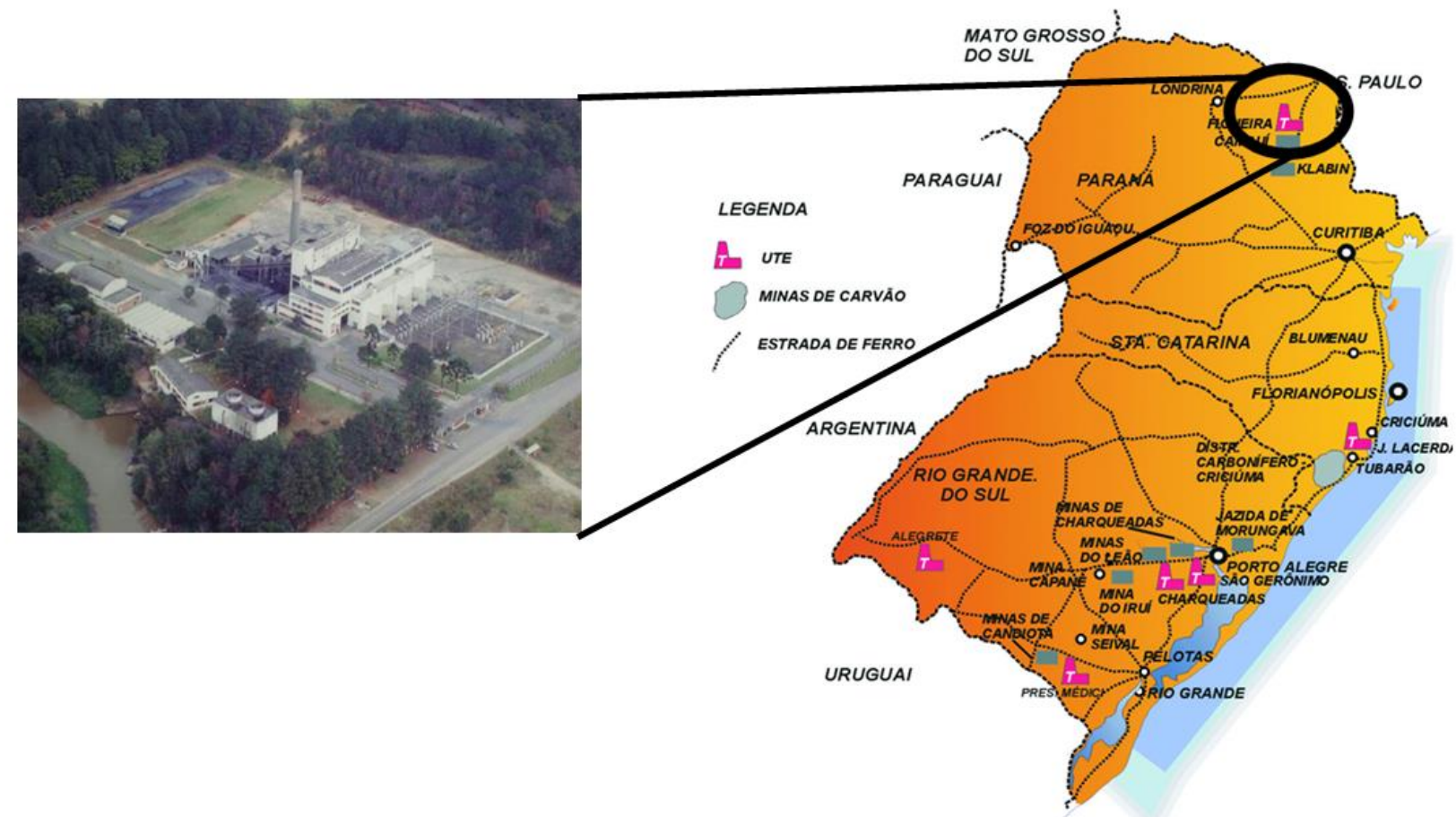

Fonte: modificado de BRUNO, 2008

$\mathrm{Na}$ usina termelétrica, o carvão é pulverizado e colocado para queimar nas fornalhas das caldeiras, sendo coletadas as cinzas pesadas (CP) no fundo da caldeira. Após a queima, os gases são enviados para o tratamento dos poluentes atmosféricos passando pelo filtro ciclone e filtro manga, onde são coletadas as cinzas ciclone (CC) e cinzas manga $(\mathrm{CM})$, respectivamente. Os pontos de coleta da usina podem ser observados na Figura 12. 
Figura 12- Ponto de coleta das diferentes cinzas de carvão, (1) fundo da caldeira, (2) filtro ciclone e (3) filtro manga.
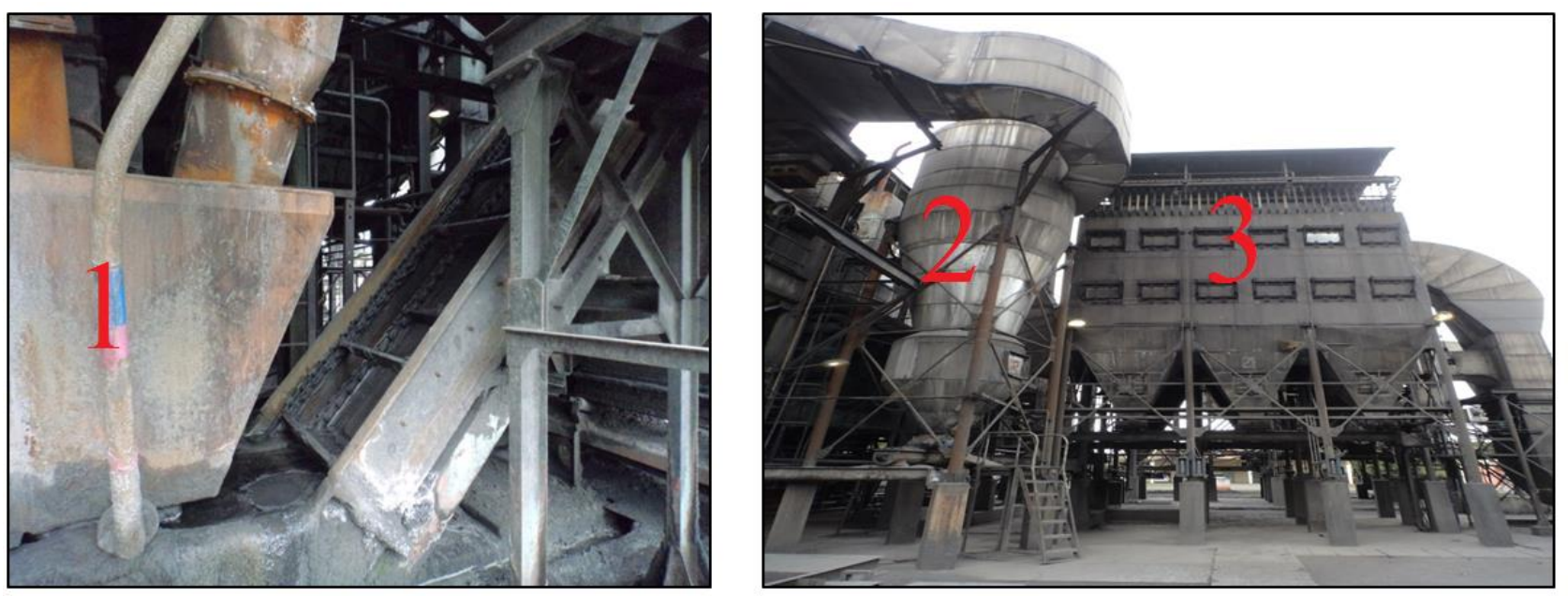

Fonte: elaborado pelo autor da dissertação

Estas amostras de cinzas, embora sejam da queima do mesmo lote de carvão mineral, apresentam tamanhos de partículas e características físico-químicas diferentes. As caracterizações das amostras que são significativas para o presente trabalho estão apresentadas nos Apêndices.

Na primeira coleta, o efluente líquido utilizado neste estudo foi rotulado como DA1 (drenagem de aterro de cinzas) e é proveniente do aterro de cinzas onde a usina dispõe seus resíduos (a mesma usina na qual foram coletadas as amostras de cinzas). A Figura 13 apresenta esquematicamente a forma com que a usina dispõe suas cinzas. 
Figura 13- Esquema do aterro de cinzas de carvão

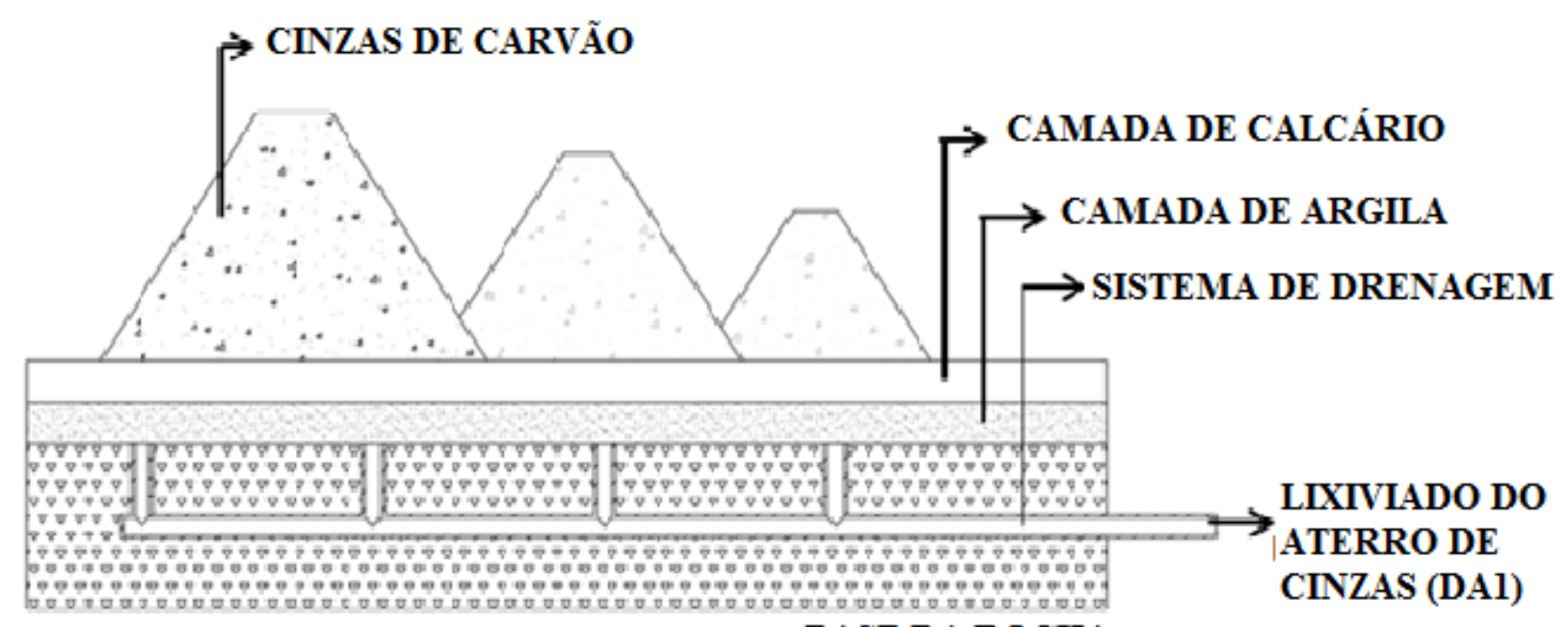

BASE DA ROCHA

Fonte: modificado de IZIDORO et al., 2018

A segunda coleta do efluente líquido (DA2), também proveniente do aterro de cinzas, foi realizada em julho de 2017, sendo que não chovia a 40 dias na região. Posteriormente, a amostra foi caracterizada e comparada com a primeira.

\subsection{Síntese de zeólita a partir das cinzas de carvão}

Os materiais zeolíticos foram sintetizados a partir das três amostras de cinzas de carvão, as quais foram coletadas do filtro manga, filtro ciclone e cinzas de fundo. Assim, as amostras foram nomeadas no presente estudo como ZCM, ZCC e ZCP, respectivamente. Os materiais adsorventes foram preparados por ativação hidrotérmica alcalina de $20 \mathrm{~g}$ de cinzas com 160mL de $\mathrm{NaOH} 3,5 \mathrm{~mol} \mathrm{~L}^{-1}$ (HENMI, 1987). A mistura foi aquecida em estufa à $100^{\circ} \mathrm{C}$ por $24 \mathrm{~h}$. As zeólitas foram lavadas com água deionizada para remover o excesso de hidróxido de sódio até obter o $\mathrm{pH} \sim 10$, e o produto sólido foi seco em estufa a $80^{\circ} \mathrm{C}$ por $12 \mathrm{~h}$. 


\subsection{Caracterização dos materiais}

\subsubsection{Composição mineralógica}

As amostras de cinzas e os materiais zeolíticos foram inseridos em um porta amostra de vidro e analisadas em um difratômetro de raio $X(D R X)$ Rigaku modelo Mutiflex com monocromador e com radiação $\mathrm{Cu} K-\alpha$, gerada a $40 \mathrm{kV}$ e $20 \mathrm{~mA}$. A velocidade de varredura era de $0,02 \%$ e com $2 \theta$ variando entre 5 e 80 graus.

A identificação das fases cristalinas foi realizada com o auxílio do programa de computador Search-Match e do banco de dados de padrões de difração do International Centre for Diffraction Data (ICDD)/Joint Committeeon Power Diffraction Standards (JCPDS). Essa análise foi realizada no Centro de Células a Combustível e Hidrogênio $(\mathrm{CCCH})$ do Instituto de Pesquisas Energéticas e Nucleares (IPEN).

\subsubsection{Composição química}

Para analisar a composição química das cinzas e dos materiais zeolíticos sintetizados, foi utilizado um espectrômetro de fluorescência de raio X (FRX) modelo S8 Tiger, da marca Bruker do Laboratório de Caracterização Tecnológica do Departamento de Engenharia de Minas e de Petróleo da Escola Politênica da Universidade de São Paulo. A análise de perda ao fogo (PF) foi efetuada a $1.020^{\circ} \mathrm{C}$ por $2 \mathrm{~h}$.

O carbono total foi determinado pelo LECO equipamento analítico (modelo CS-400) com um forno de rádio frequência (modelo HF- 400A).

$\mathrm{O} \mathrm{pH}$ e a condutividade das suspensões dos materiais zeolíticos foram analisados como se segue: foi inserido $0,25 \mathrm{~g}$ da amostra em $25 \mathrm{~mL}$ de água deionizada e a mistura foi agitada durante 24 h num agitador a 120 rpm (Ética - Mod 430). Após a filtração, o pH das soluções e a condutividade foram determinados com um pHmetro (MSTecnopon Mod MPA 210) e um condutivímetro (BEL Engineering - Mod W12D), respectivamente. O $\mathrm{pH}$ e a condutividade das amostras de efluentes não tratadas e tratadas foram determinados pelos mesmos equipamentos, conforme descrito por IZIDORO (2013).

A densidade aparente das amostras de materiais zeolíticos foi calculada a partir do peso de cada amostra dividido pelo volume de $35 \mathrm{~mL}$ ocupado por ela em um béquer. $\mathrm{A}$ 
área superficial específica das amostras de materiais zeolíticos foi determinada por um analisador de adsorção BET Micromeritics (ASAP 2010) no Centro de Ciência e Tecnologia de Materiais - CCTM - IPEN. Antes da determinação da área superficial específica, as amostras foram aquecidas a $120^{\circ} \mathrm{C}$ durante $8 \mathrm{~h}$ para desgaseificação sob condições de vácuo. As áreas específicas BET foram obtidas aplicando a equação BET aos dados de adsorção de nitrogênio.

Nas medidas de capacidade de troca cationica (CTC), as amostras foram saturadas com solução de acetato de sódio $\left(1 \mathrm{~mol} \mathrm{~L}^{-1}\right)$, lavadas com água destilada ( $\left.1 \mathrm{~L}\right)$ e depois misturadas com solução de acetato de amônio (1 mol L-1). A concentração de íons de sódio da solução resultante foi determinada por espectrometria de emissão óptica com plasma de argônio- ICP-OES (Spectro-Arcos) (IZIDORO, 2013).

\subsubsection{Análise da morfologia}

As partículas das diferentes amostras foram primeiramente desagregadas com isopropanol usando almofariz e pistilo para então a observação de sua morfologia ser realizada. As amostras foram revestidas com ouro. As micrografias foram obtidas usando o microscópio eletrônico de varredura (MEV) de alta resolução JEOL JSM-6701F (Emissão de campo) no Centro de Ciência e Tecnologia de Materiais - CCTM - IPEN.

\subsection{Tratamento do lixiviado de aterro de cinzas}

O efluente líquido escolhido para o presente estudo foi coletado diretamente da saída dos drenos do aterro de cinzas da usina térmica a carvão. $\mathrm{O} \mathrm{pH}$ do efluente foi determinado pelo pHmetro MS Tecnopon - Mod. MPA 210 e a condutividade foi determinada pelo condutivímetro Orion - Modelo 150. O agitador mecânico Ética - Mod 430 foi utilizado em todos os experimentos em batelada.

As amostras de 0,5 e $1 \mathrm{~g}$ de ZCM, ZCC e ZCP foram colocadas em contato com alíquotas de $50 \mathrm{~mL}$ do efluente DA1, o que corresponde as doses de $10 \mathrm{~g} \mathrm{~L}^{-1}$ e $20 \mathrm{~g} \mathrm{~L}^{-1}$, respectivamente. As suspensões foram agitadas a $120 \mathrm{rpm}$ por $24 \mathrm{~h}$. Após esse período, a fase líquida foi separada por filtração. Posteriormente $10 \mathrm{~mL}$ do sobrenadante foi separado para a análise de $\mathrm{pH}$ e condutividade, enquanto que o restante da alíquota foi 
enviado para a determinação de concentração por meio da técnica de espectrometria de emissão óptica com plasma de argônio (ICP-OES) após a acidificação, com $\mathrm{HNO}_{3}$ concentrado (MORENO et al., 2001; PRASAD e MORTIMER, 2011).

A concentração de arsênio presente no efluente foi determinada por meio da técnica de espectrofotometria de absorção atômica com atomização por forno de grafita (GF-AAS), enquanto que as concentrações de todos os outros elementos foram determinadas por espectrometria de emissão óptica com plasma de argônio (ICP-OES Spectro - Arcos)

$\mathrm{Na}$ Figura 14 pode ser observado o modelo base de como foi realizado o ensaio de tratamento do efluente do presente estudo. Em alguns processos, o material adsorvente, a dose e o tempo de agitação foram variados.

Figura 14- Fluxograma das etapas do estudo de remoção dos elementos tóxicos presentes no efluente

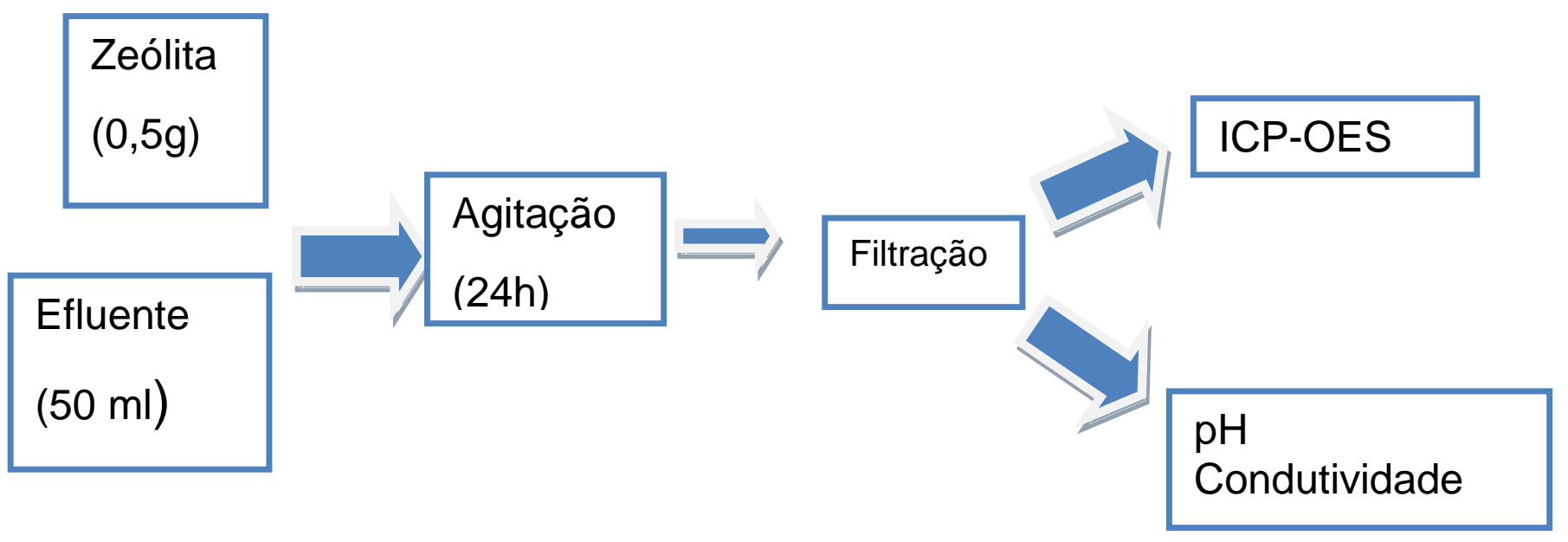

Fonte: autor da dissertação 


\subsection{Síntese das zeólitas de cinzas de carvão modificadas por surfactante}

O procedimento para a preparação das zeólitas modificadas com surfactante foi realizado pela mistura da zeólita de cinzas de carvão com HDTMA-Br 1,8 mmol L-1, na razão massa de zeólita/volume de HDTMA-Br de 0,05 $\mathrm{g} \mathrm{mL}^{-1}$ (FUNGARO e BORRELY, 2012). A mistura foi agitada por $7 \mathrm{~h}$ a $120 \mathrm{rpm}$ em temperatura ambiente com agitador mecânico (Ética - Mod 430). A suspensão foi filtrada e o sólido foi seco em estufa a $50^{\circ} \mathrm{C}$. Os materiais obtidos foram denominados ZMM para a zeólita modificada preparada com as cinzas leves do filtro manga, ZMC para a zeólita modificada preparada com as cinzas leves do filtro ciclone e ZMP para a zeólita modificada preparada com as cinzas pesadas. Um segundo material foi preparado usando uma concentração maior de surfactante (20 mmol $L^{-1}$ de HDTMA-Br) na zeólita de cinzas leves do filtro manga e a amostra foi denominada ZMM-20.

\subsection{Tratamento de efluente usando zeólitas modificadas por surfactante e zeólita comercial A.}

As amostras ZMM, ZMC e ZMP foram colocadas em contato com alíquotas de 50 $\mathrm{mL}$ do efluente DA1 e dose de $10 \mathrm{~g} \mathrm{~L}^{-1}$. As suspensões foram agitadas a $120 \mathrm{rpm}$ por $1 \mathrm{~h}$. Após esse período, a fase líquida foi separada por filtração. Posteriormente $10 \mathrm{~mL}$ do sobrenadante foi separado para a análise de $\mathrm{pH}$ e condutividade, enquanto que o restante da alíquota foi enviado para a determinação de concentração por meio da técnica de espectrometria de emissão óptica com plasma de argônio (ICP-OES) após a acidificação, com $\mathrm{HNO}_{3}$ concentrado. O mesmo procedimento foi usado com tempo de agitação de 24 h para a amostra ZMM-20 e zeólita comercial A (ZA). O ensaio do "Branco" (BR) consistiu na agitação da amostra ZMM-20 apenas com água.

\subsection{Estudo da remoção de Cr e As do efluente}

No estudo de remoção dos elementos $\mathrm{Cr}$ e As foram realizados quatro experimentos: 1) zeólita e acidificação prévia da solução aquosa; 2) zeólita modificada por surfactante e 3) processo em duas etapas, com adição de zeólita e posterior adição de zeólita novamente (em 3.1) e zeólita magnética (em 3.2). 


\subsubsection{Tratamento com zeólita e acidificação prévia da solução aquosa}

A amostra ZCM foi colocada em contato com alíquotas de $50 \mathrm{~mL}$ do efluente DA1 nas doses de $10 \mathrm{~g} \mathrm{~L}^{-1}$ e $20 \mathrm{~g} \mathrm{~L}^{-1}$. $\mathrm{O} \mathrm{pH}$ das misturas foi medido e ajustado a 4, utilizando $\mathrm{HNO}_{3}$ concentrado. As suspensões foram agitadas a $120 \mathrm{rpm}$ por $1 \mathrm{~h}$. Após esse período, a fase líquida foi separada por filtração. Posteriormente $10 \mathrm{~mL}$ do sobrenadante foi separado para a análise de $\mathrm{pH}$, enquanto que o restante da alíquota foi enviado para a determinação de concentração por meio da técnica de espectrometria de emissão óptica com plasma de argônio (ICP-OES) após a acidificação, com $\mathrm{HNO}_{3}$ concentrado

\subsubsection{Zeólita modificada por surfactante}

A amostra ZMM-20 foi colocada em contato com alíquotas de $50 \mathrm{~mL}$ do efluente DA1 e dose de $20 \mathrm{~g} \mathrm{~L}^{-1}$. As suspensões foram agitadas a $120 \mathrm{rpm}$ por $24 \mathrm{~h}$. Após esse período, a fase líquida foi separada por filtração. Posteriormente $10 \mathrm{~mL}$ do sobrenadante foi separado para a análise de $\mathrm{pH}$, enquanto que o restante da alíquota foi enviado para a determinação de concentração do As e do Cr por meio da técnica de espectrometria de emissão óptica com plasma de argônio (ICP-OES) após a acidificação, com $\mathrm{HNO}_{3}$ concentrado.

\subsubsection{Processo de duas etapas}

$\mathrm{Na}$ primeira etapa, amostras de $0,5 \mathrm{~g}$ de material zeolítico de cinzas manga sintetizadas pelo método convencional (ZCM-1 e ZCM-2) foram colocadas em contato com $50 \mathrm{~mL}$ do lixiviado (DA1) e agitadas a $120 \mathrm{rpm}$ em tubo falcon de $250 \mathrm{ml}$, correspondendo à dosagem de adsorvente de $10 \mathrm{~g} \mathrm{~L}^{-1}$. Após $24 \mathrm{~h}$ de agitação, as misturas foram filtradas, separando-se $50 \mathrm{ml}$ do sobrenadante de cada amostra para realizar a segunda etapa. O sobrenadante restante foi analisado quanto ao $\mathrm{pH}$ e em seguida foi acidificado a pH menor que 2, utilizando ácido nítrico concentrado, a fim de determinar as concentrações de As e Cr em ICP-OES. 
As amostras de zeólita magnética (MZCM) e ZCM foram colocadas em contato com alíquotas de $50 \mathrm{~mL}$ do efluente remanescente da primeira etapa. As suspensões foram agitadas a 120 rpm por 24 h. Após esse período, a fase líquida foi separada por filtração. Posteriormente $10 \mathrm{~mL}$ do sobrenadante foi separado para a análise de $\mathrm{pH}$, enquanto que o restante da alíquota foi enviada para determinação das concentrações de As e $\mathrm{Cr}$ em ICP-OES, após sua acidificação com $\mathrm{HNO}_{3}$ concentrado. 


\section{RESULTADOS E DISCUSSÕES}

\subsection{Características dos Materiais Zeolíticos}

5.1.1Composição Mineralógica

Os padrões de difração de raios $X$ da ZCP, ZCC e ZCM estão apresentados nas Figuras 15, 16 e 17. A formação de zeólita sodalita pode ser observada em todas as amostras. Esta formação confirma que as cinzas de carvão podem ser utilizadas na síntese de zeólita, que é um material com alta eficiência na remoção de poluentes.

Todas as amostras apresentaram quantidades remanescentes de quartzo do material precursor. Estes resultados estão de acordo com os padrões de DRX apresentados por outros autores que utilizaram da mesma metodologia de ativação hidrotérmica alcalina para as cinzas volantes (QUEROL et al., 1997; MORIYAMA et al., 2005; IZIDORO, 2012; FUNGARO e MAGDALENA, 2014).

A amostra de ZCP apresentou também uma fase cristalina de aluminiossilicato de sódio próxima à fase da zeólita sodalita. Este fato ocorreu devido a menor proporção de sílica e alumina nesta amostra, não sendo suficiente para a completa formação de zeólita (Tabela 1). Além disso, a amostra de ZCP foi sintetizada a partir das cinzas de fundo da usina, o qual tem menor tempo de exposição aos gases de combustão da queima de carvão quando comparado as outras amostras, e portanto apresenta características diferentes das amostras de cinzas leves usadas neste estudo. 
Figura 15- Padrão de DRX do material zeolítico ZCP sintetizado por ativação hidrotérmica alcalina da cinza de carvão ( $\mathrm{Na}=$ Aluminossilicato de sódio, $\mathrm{Q}=$ Quartzo, $\mathrm{S}=$ Sodalita e $\mathrm{M}$ = Mulita).

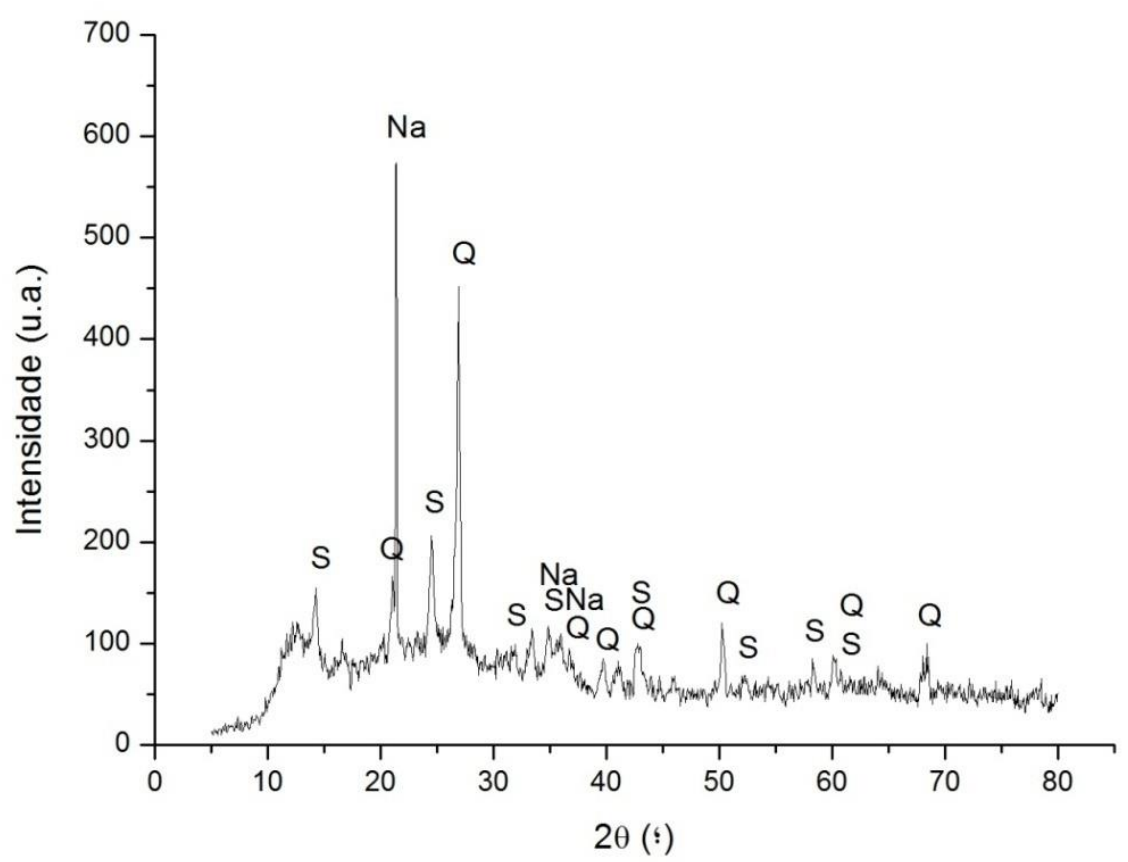

Fonte: autor da dissertação

Figura 16- Padrão de DRX do material zeolítico ZCC sintetizados por ativação hidrotérmica alcalina da cinza de carvão $(Q=$ Quartzo, $S=$ Sodalita e $M=$ Mulita).

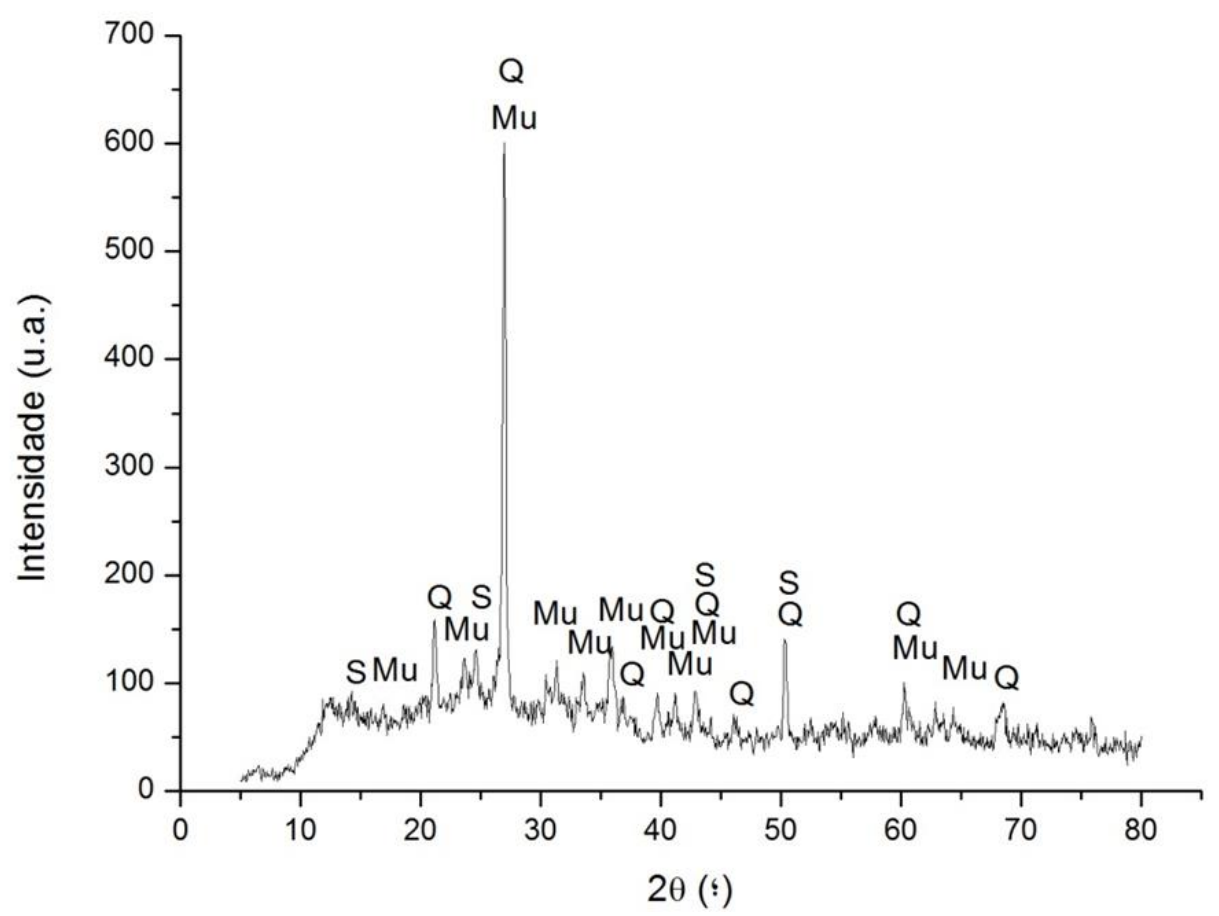

Fonte: autor da dissertação 
Figura 17- Padrão de DRX do material zeolítico ZCM sintetizado por ativação hidrotérmica alcalina da cinza de carvão $(\mathrm{Q}=$ Quartzo, $\mathrm{S}=$ Sodalita e $\mathrm{M}=$ Mulita $)$.

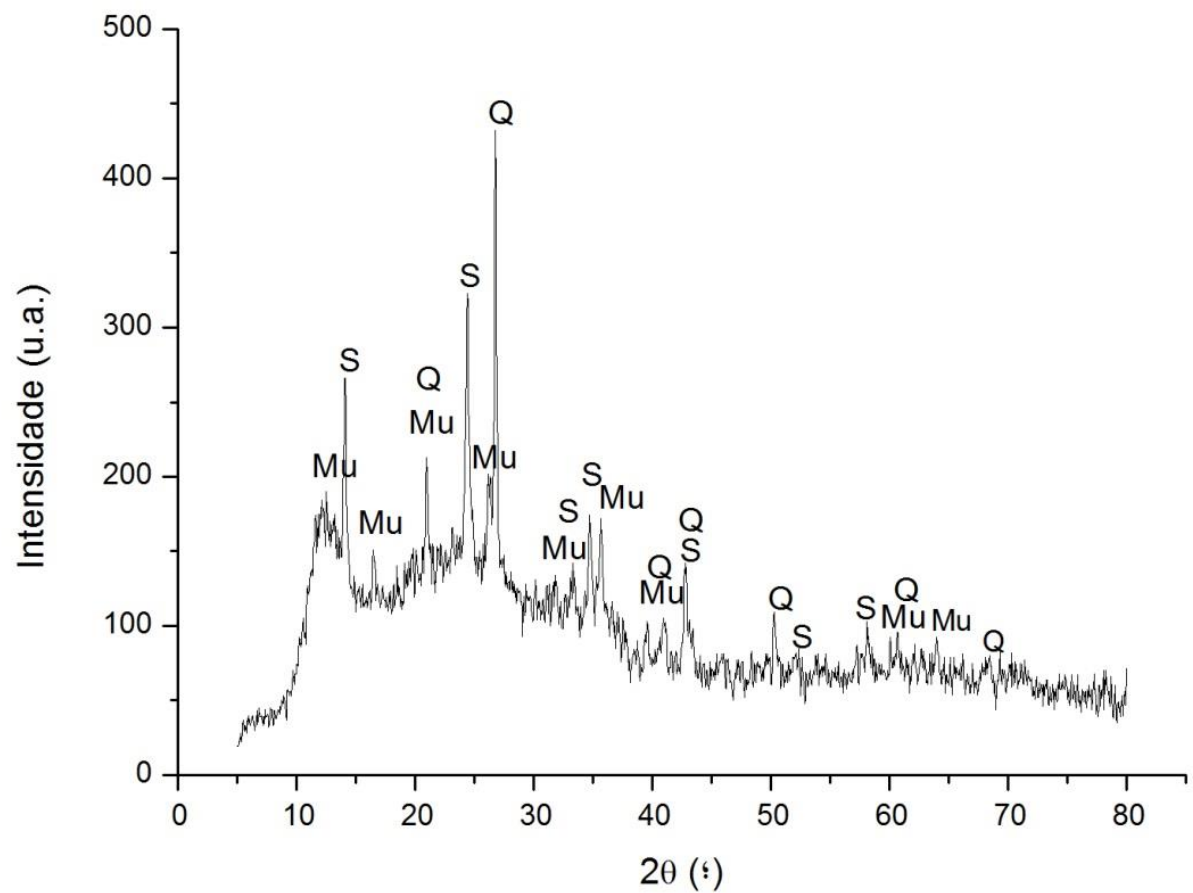

Fonte: autor da dissertação

A fórmula geral da sodalita é $\mathrm{M}_{m}\left[\mathrm{TO}_{2}\right]_{t} \mathrm{X}_{x}$, em que $\mathrm{T}$ é um átomo de $\mathrm{Si}, \mathrm{Al}, \mathrm{Gr}, \mathrm{Ga} e$ $\mathrm{B}$, em que $\mathrm{X}$ pode ser $\mathrm{Cl}, \mathrm{Br}, \mathrm{OH}, \mathrm{H}_{2} \mathrm{O}$, etc. e em que $\mathrm{M}$ é um átomo alcalino ou alcalino terroso, com poros de comunicação formado por anéis de seis membros resultando em uma abertura com tamanho de poro de $2,8 \AA$.

A sodalita cujas cargas da estrutura são balanceadas com ânions hidróxido é chamada de hidroxisodalita. A estruturada é formada por cavidades regulares de octraedro truncado chamadas de cavidades sodalita (ou cavidade- $\beta$ ), conforme está ilustrado nas Figuras 2 e 3c.

\subsubsection{Composição Química}

A composição química e o teor de carbono total das três amostras de materiais zeolíticos (por \% mássica) são apresentados nas Tabelas 2 e 3, respectivamente. De acordo com a Tabela 1, todos os materiais são constituídos principalmente de $\mathrm{SiO}_{2}, \mathrm{Al}_{2} \mathrm{O}_{3}$, $\mathrm{Fe}_{2} \mathrm{O}_{3}$ e $\mathrm{Na}_{2} \mathrm{O}$. Outros componentes como $\mathrm{CaO}, \mathrm{SO}_{3}$ e $\mathrm{TiO}_{2}$ foram encontrados em 
menores quantidades, entre 4,57\%. e 1,08\%. Estudos indicam que a menor razão $\mathrm{SiO}_{2} / \mathrm{Al}_{2} \mathrm{O}_{3}$ resulta em um material com maior capacidade de troca cationica (QUEROL et al., 2002; IZIDORO et al., 2012), isto é confirmado nos resultados de CTC apresentados posteriormente. A razão $\mathrm{SiO}_{2} / \mathrm{Al}_{2} \mathrm{O}_{3}$, similar a CTC, seguiu a ordem crescente: ZCM $(1,46)$ $<$ ZCP $(1,7)<$ ZCC $(1,85)$.

O teor de carbono total (Tabela 3) segue a ordem decrescente: ZCP $>$ ZCC $>$ ZCM. Estes resultados corroboram como parâmetro de perda ao fogo (PF) das mesmas amostras como mostra a Tabela 3.

A amostra ZCP, conforme mencionado anteriormente, foi sintetizada a partir de cinzas de fundo, as quais são expostas em menor tempo aos gases de combustão e, portanto, não foi completamente queimada, assim contendo maior quantidade de carbono não queimado. Por outro lado, as cinzas precursoras da ZCM foram expostas a temperaturas mais elevadas e por um maior tempo, portanto, esta apresentou menor teor de carbono na matéria-prima e no produto. Em geral, a amostra ZCP é um material que é pobre em compostos inorgânicos e rico em carbono não queimado. 
Tabela 2 - Composição química por FRX dos materiais zeolíticos obtidos das diferentes amostras de cinzas (\% mássica).

\begin{tabular}{|c|c|c|c|}
\hline Composição & $\overline{Z C P}$ & $\overline{Z C C}$ & $\overline{Z C M}$ \\
\hline $\mathrm{SiO}_{2}$ & 27,3 & 33,3 & 33,5 \\
\hline $\mathrm{Al}_{2} \mathrm{O}_{3}$ & 16,1 & 18,0 & 23,0 \\
\hline $\mathrm{Fe}_{2} \mathrm{O}_{3}$ & 13,1 & 15,2 & 11,9 \\
\hline $\mathrm{Na}_{2} \mathrm{O}$ & 6,71 & 5,78 & 10,7 \\
\hline $\mathrm{CaO}$ & 3,33 & 4,57 & 2,12 \\
\hline $\mathrm{SO}_{3}$ & 3,19 & 1,08 & 1,74 \\
\hline $\mathrm{TiO}_{2}$ & 1,25 & 1,09 & 1,43 \\
\hline $\mathrm{K}_{2} \mathrm{O}$ & 0,443 & 0,399 & 0,383 \\
\hline $\mathrm{MgO}$ & 0,747 & 0,909 & 1,06 \\
\hline $\mathrm{ZnO}$ & 0,185 & 0,22 & 0,65 \\
\hline $\mathrm{MnO}$ & 0,106 & 0,124 & 0,067 \\
\hline $\mathrm{Cr}_{2} \mathrm{O}_{3}$ & $<0,001$ & 0,018 & 0,024 \\
\hline $\mathrm{PbO}$ & 0,015 & 0,023 & 0,07 \\
\hline $\mathrm{ZrO}_{2}$ & 0,103 & 0,085 & 0,123 \\
\hline SrO & 0,036 & 0,03 & 0,034 \\
\hline $\mathrm{NiO}$ & 0,033 & 0,015 & $<0,001$ \\
\hline $\mathrm{CuO}$ & $<0,001$ & 0,015 & 0,018 \\
\hline $\mathrm{Y}_{2} \mathrm{O}_{3}$ & 0,026 & 0,019 & 0,037 \\
\hline $\mathrm{Cl}$ & 0,03 & $<0,001$ & $<0,001$ \\
\hline $\mathrm{BaO}$ & 0,039 & 0,035 & 0,018 \\
\hline $\mathrm{Nb}_{2} \mathrm{O}_{5}$ & $<0,001$ & $<0,001$ & 0,003 \\
\hline $\mathrm{Ce}_{2} \mathrm{O}_{2}$ & $<0,001$ & 0,037 & 0,04 \\
\hline $\mathrm{PF}^{*}$ & 27,3 & 19,0 & 13,1 \\
\hline $\mathrm{SiO}_{2} / \mathrm{Al}_{2} \mathrm{O}_{3}$ & 1,70 & 1,85 & 1,46 \\
\hline
\end{tabular}


Tabela 3 - Análise de carbono total das amostras de material zeolítico

\begin{tabular}{cc}
\hline Amostras & C (\%) \\
\hline ZCP & 15,62 \\
ZCC & 9,74 \\
ZCM & 4,14 \\
\hline
\end{tabular}

Fonte: autor da dissertação

\subsubsection{Características Físico-químicas}

As características físico-químicas das três amostras de material zeolítico são apresentadas na Tabela 4. De acordo com a Tabela 4, os valores de $\mathrm{pH}$ dos materiais zeolíticos são muito próximos e variaram de 9,1 a 9,5. Os valores de pH são superiores a 7, devido a ativação hidrotérmica alcalina com solução de $\mathrm{NaOH}$. Os valores de condutividade variaram de 213,5 a 296,0 $\mu \mathrm{S} \mathrm{cm}^{-1}$ e coincidem com outros estudos de caracterização de amostras de zeólita sintetizadas de cinzas de carvão da mesma usina (IZIDORO et al., 2012).

A amostra de ZCM apresentou altos valores de $\mathrm{pH}$ e condutividade quando comparada com as outras amostras.Este resultado é devido ao seu menor tamanho de partícula (Apêndice D), o que possivelmente contribuiu para uma maior solubilização de espécies químicas elevando os parâmetros de pH e condutividade.

Os valores de densidade aparente seguiram a ordem decrescente: ZCM > ZCC > ZCP. Estes resultados confirmam que as amostras de ZCM possuem menores tamanhos de partículas e, portanto, a massa necessária para ocupar um determinado volume é maior quando comparada às outras amostras. A área superficial específica seguiu a mesma ordem decrescente da densidade aparente sendo 69,5 $\mathrm{m}^{2} \mathrm{~g}^{-1}$ (ZCM), 68,0 $\mathrm{m}^{2} \mathrm{~g}^{-1}$ (ZCC) e $35,2 \mathrm{~m}^{2} \mathrm{~g}^{-1}$ (ZCP). Estes resultados mostram que as amostras com menor tamanho de partícula e maior densidade também apresentam maior área superficial específica (ZCM e ZCC).

Os valores de CTC dos materiais zeolíticos, apresentados na Tabela 4, seguiram a ordem decrescente: ZCM > ZCP> ZCC. Conforme previamente mencionado, a menor 
razão $\mathrm{SiO}_{2} / \mathrm{Al}_{2} \mathrm{O}_{3}$ (apresentada na Tabela 2) é relacionada com a maior capacidade de troca catiônica destes materiais. Outros estudos de caracterização de amostras de zeólita sintetizadas de cinzas de carvão mineral provenientes da mesma origem obtiveram resultados similares de área superficial específica e CTC (IZIDORO et al., 2012).

Tabela 4 - Características físico-químicas das amostras de ZCP, ZCC e ZCM.

\begin{tabular}{cccccc}
\hline Amostras & $\mathbf{p H}$ & $\begin{array}{c}\text { Condutividade } \\
\left(\boldsymbol{\mu S} \mathbf{~ c m}^{-1}\right)\end{array}$ & $\begin{array}{c}\text { Densidade } \\
\text { Aparente } \\
\left(\mathbf{g ~ c m}^{-3}\right)\end{array}$ & $\begin{array}{c}\text { BET } \\
\left(\mathbf{m}^{\mathbf{2}} \mathbf{~ g}^{-1}\right)\end{array}$ & $\begin{array}{c}\text { CTC } \\
\left(\mathbf{m e q ~ g}^{-1}\right)\end{array}$ \\
\hline ZCP & 9,1 & 217,0 & 0,47 & 35,2 & 1,60 \\
ZCC & 9,2 & 213,5 & 0,58 & 68,0 & 1,37 \\
ZCM & 9,5 & 296,0 & 0,63 & 69,5 & 2,36 \\
\hline
\end{tabular}

Fonte: autor da dissertação

5.1.4 Morfologia dos Produtos Sintetizados

As micrografias eletrônicas de varredura dos três tipos de materiais zeolíticos são mostradas nas Figuras 18, 19 e 20. Os materiais cristalinos (partículas com arranjos regulares indicados por setas) estão presentes em todas as amostras (AVERILL, 2012). A mesma morfologia já foi observada em outros estudos, indicando que os cristais de zeólita são depositados na superfície das partículas de cinzas durante a ativação hidrotérmica e, portanto, partículas irregulares são uma caractrerístca do material (OJHA et al., 2004; IZIDORO et al., 2012). 
Figura 18- MEV do material zeolítico (ZCP) sintetizado a partir de cinzas de carvão por ativação hidrotérmica alcalina.

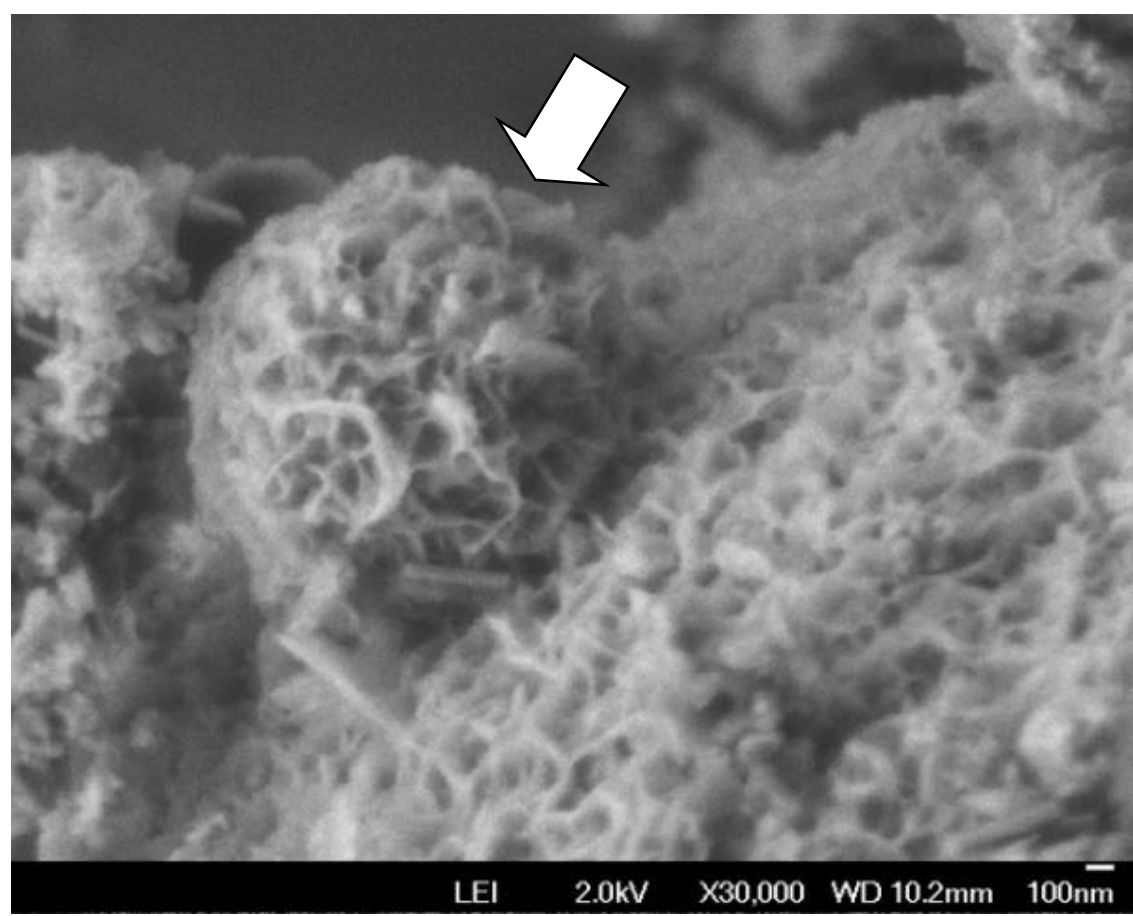

Fonte: autor da dissertação

Figura 19- MEV do material zeolítico (ZCC) sintetizado a partir de cinzas de carvão por ativação hidrotérmica alcalina.

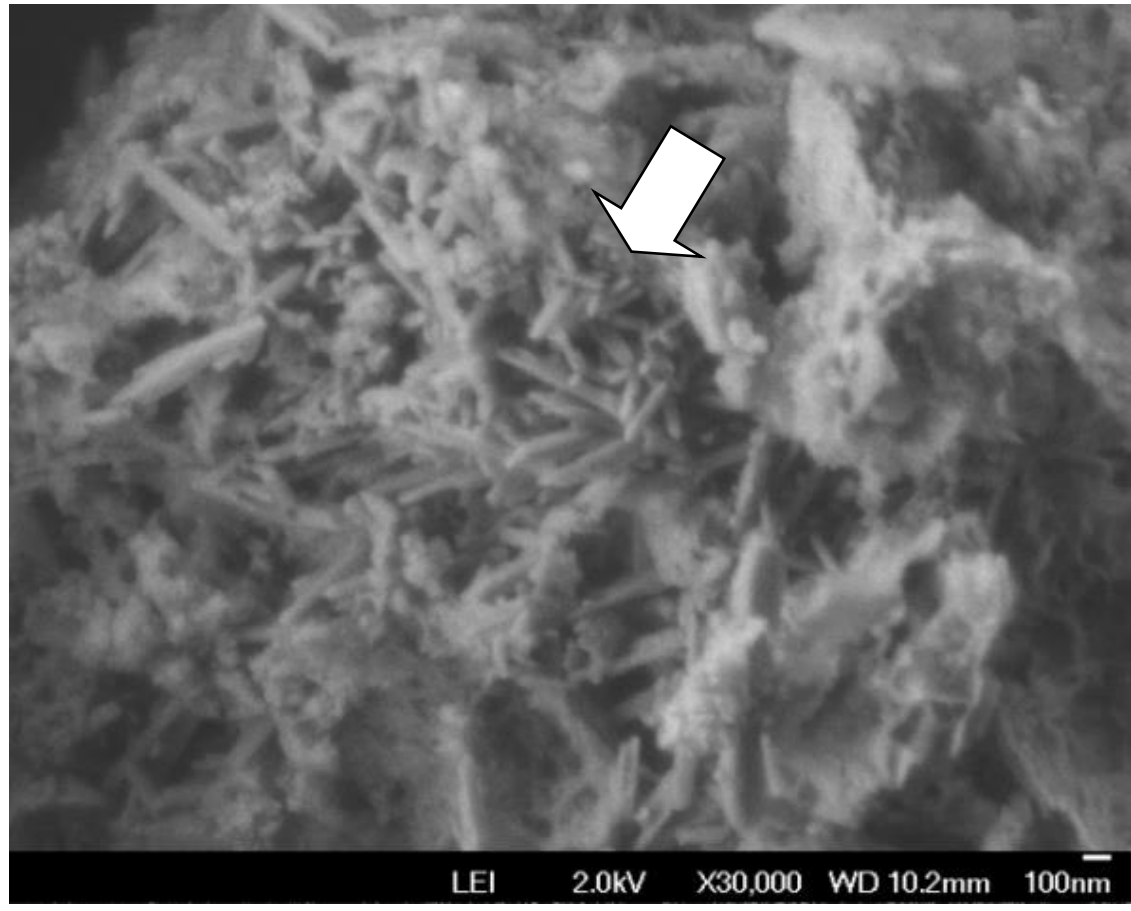

Fonte: autor da dissertação 
Figura 20- MEV do material zeolítico (ZCM) sintetizado a partir de cinzas de carvão por ativação hidrotérmica alcalina.

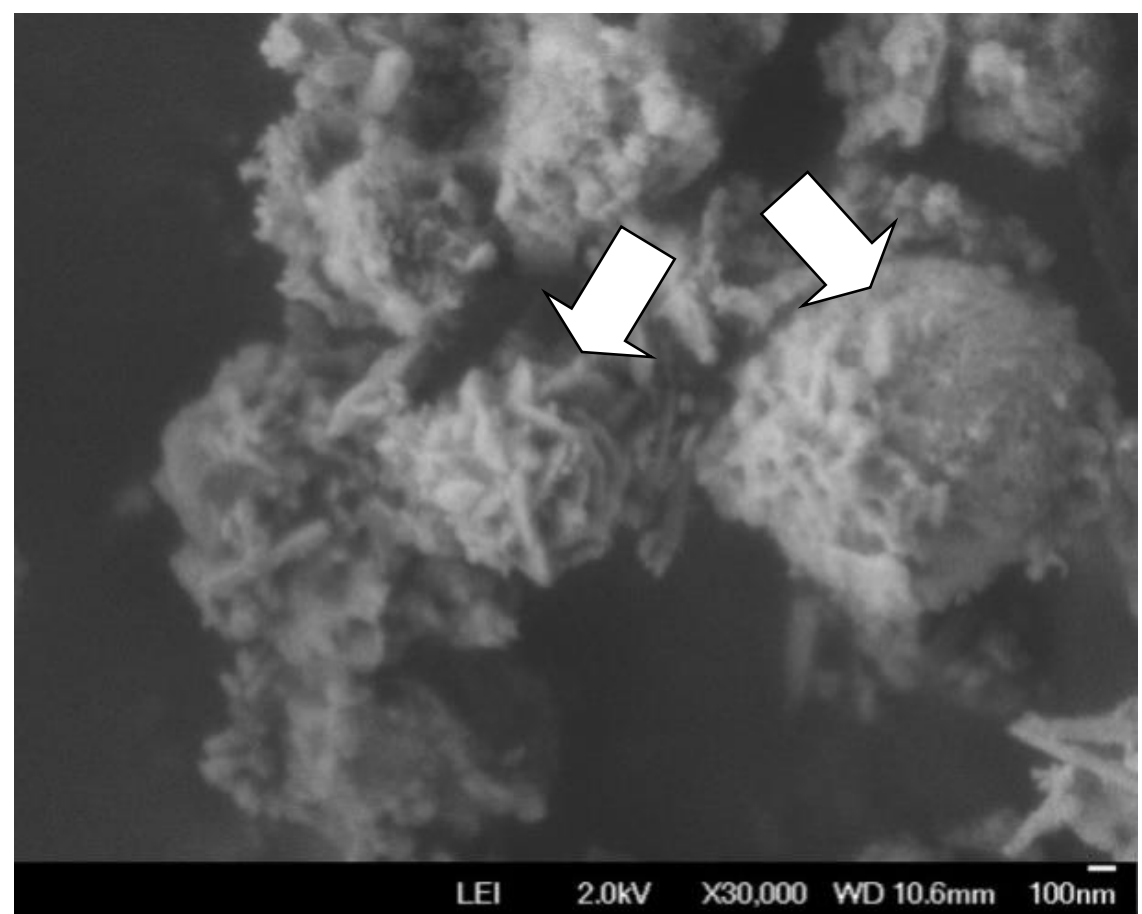

Fonte: autor da dissertação

\subsection{Tratamento de efluente usando materiais zeolíticos}

As concentrações dos íons metálicos presentes na amostra do efluente (DA1) antes e depois do tratamento com os materiais zeolíticos (ZCM, ZCC e ZCP), usando duas doses diferentes de zeólita, assim como os valores de $\mathrm{pH}$ e condutividade de cada solução são apresentados nas Tabelas 5, 6 e 7, respectivamente. Os valores limites das concentrações de metais e de $\mathrm{pH}$ estipulados pela legislação ambiental brasileira (BRASIL, 2011) para o lançamento de efluentes em corpos d'água,também estão apresentados nas tabelas. 
Tabela 5- Resultado da análise do lixiviado de aterro de cinzas (DA1) antes e depois do tratamento com ZCM usando diferentes doses e os parâmetros de lançamento.

\begin{tabular}{|c|c|c|c|c|}
\hline \multirow[b]{2}{*}{ Parâmetros } & \multirow{2}{*}{$\begin{array}{c}\text { DA1 } \\
\left(\mathrm{mg} \mathrm{L}^{-1}\right)\end{array}$} & \multicolumn{2}{|c|}{ ZCM (mg.t-1) } & \multirow{2}{*}{$\begin{array}{l}\mathrm{VMP}^{*} \\
\left(\mathrm{mg} \mathrm{L}^{-1}\right)\end{array}$} \\
\hline & & (Dose $10 \mathrm{gL}^{-1}$ ) & (Dose $20 \mathrm{gL}^{-1}$ ) & \\
\hline $\mathrm{Cr}$ & $0,15 \pm 0,01$ & $0,15 \pm 0,001$ & $0,15 \pm 0,001$ & 0,1 \\
\hline Mn & $0,133 \pm 0,004$ & $<0,1$ & $<0,1$ & 1,0 \\
\hline $\mathrm{Ni}$ & $1,11 \pm 0,02$ & $0,012 \pm 0,002$ & $0,013 \pm 0,002$ & 2,0 \\
\hline Cd & $0,043 \pm 0,0003$ & $<0,01$ & $<0,01$ & 0,2 \\
\hline $\mathrm{Zn}$ & $0,112 \pm 0,002$ & $<0,01$ & $<0,01$ & 5,0 \\
\hline Mg & $5,5 \pm 0,4$ & $0,323 \pm 0,001$ & $0,134 \pm 0,001$ & - \\
\hline $\mathrm{Ca}$ & $1052 \pm 7$ & $93 \pm 3$ & $41,6 \pm 0,3$ & - \\
\hline $\mathrm{Fe}$ & $0,49 \pm 0,01$ & $0,243 \pm 0,001$ & $0,133 \pm 0,001$ & 15,0 \\
\hline Co & $2,0 \pm 0,4$ & $<0,01$ & $<0,01$ & - \\
\hline As & $1,09 \pm 0,04$ & $0,275 \pm 0,03$ & $<0,01$ & 0,5 \\
\hline pH & 6,43 & 8,19 & 11,08 & 5 a 9 \\
\hline $\begin{array}{l}\text { Condutividade } \\
\text { (mS/cm) }\end{array}$ & 106,2 & 10,85 & 14,3 & - \\
\hline
\end{tabular}

$\left({ }^{*}\right)$ Valor Máximo Permitido estabelecidos pela Resolução № 430 (13 de maio de 2011) do Conselho Nacional do Meio Ambiente- CONAMA

Fonte: autor da dissertação

De acordo com a Tabela 5, a DA1 apresentou concentrações do $\mathrm{Cr}$ e As acima dos limites permitidos de lançamento, portanto, deve ser tratada antes de ser lançada. A elevada concentração do elemento $\mathrm{Ca}$, no efluente, é devido à lixiviação do calcário usado como uma camada de neutralização no local de disposição de cinzas de carvão (como mostrado na Figura 11).

A amostra de ZCM removeu de forma efetiva os elementos $\mathrm{Ni}, \mathrm{Cd}, \mathrm{Zn}$ e Co, independentemente da dose. No entanto, a maior remoção dos elementos $\mathrm{Mg}, \mathrm{Ca}, \mathrm{Fe}$ e As foi na dose $20 \mathrm{~g} \mathrm{~L}^{-1}$, como mostra a Tabela 5 .

Os resultados do tratamento do efluente utilizando a amostra ZCM demonstraram que o material possui elevado potencial na remoção de arsênio, porém não sendo eficiente para remoção do $\mathrm{Cr}$ em nenhuma das doses de zeólita. 
Em relação ao $\mathrm{Mn}$, os valores de concentração do efluente tratado e não tratado foram muito próximos, e acredita-se que o material também não é eficiente para a remoção desse metal, embora este fato não afete o tratamento do efluente, uma vez que todas as concentrações deste elemento estão abaixo dos limites permitidos.

De acordo com a Tabela 5, os valores de $\mathrm{pH}$ dos sobrenadantes após o tratamento foram mais elevados e aumentaram com a dose. Este fato se deve à síntese hidrotérmica do material zeolítico com solução de $\mathrm{NaOH}$. Assim, como relatado por MORENO et al. (2001), a remoção dos elementos pode ser causada pelo próprio processo de troca iônica e/ou pela precipitação dos elementos na solução alcalina.

Tabela 6- Resultado da análise do lixiviado de aterro de cinzas (DA1) antes e depois do tratamento com ZCC usando diferentes doses e os parâmetros de lançamento.

\begin{tabular}{|c|c|c|c|c|}
\hline \multirow[b]{2}{*}{ Parâmetros } & \multirow{2}{*}{$\begin{array}{c}\text { DA1 } \\
\left(\mathrm{mg} \mathrm{L}^{-1}\right)\end{array}$} & \multicolumn{2}{|c|}{$\mathrm{ZCC}\left(\mathrm{mg} \cdot \mathrm{L}^{-1}\right)$} & \multirow{2}{*}{$\begin{array}{c}\text { VMP* }^{*} \\
\left(\mathrm{mg} \mathrm{L}^{-1}\right)\end{array}$} \\
\hline & & (Dose $10 \mathrm{gL}^{-1}$ ) & (Dose $20 \mathrm{gL}^{-1}$ ) & \\
\hline $\mathrm{Cr}$ & $0,15 \pm 0,01$ & $0,15 \pm 0,001$ & $0,15 \pm 0,001$ & 0,1 \\
\hline Mn & $0,133 \pm 0,004$ & $<0,1$ & $<0,1$ & 1,0 \\
\hline $\mathbf{N i}$ & $1,11 \pm 0,02$ & $<0,01$ & $<0,01$ & 2,0 \\
\hline Cd & $0,043 \pm 0,0003$ & $<0,01$ & $<0,01$ & 0,2 \\
\hline $\mathrm{Zn}$ & $0,112 \pm 0,002$ & $<0,01$ & 0,032 & 5,0 \\
\hline Mg & $5,5 \pm 0,4$ & $0,46 \pm 0,02$ & $0,292 \pm 0,001$ & - \\
\hline $\mathrm{Ca}$ & $1052 \pm 7$ & $71 \pm 3$ & $30 \pm 0,2$ & - \\
\hline $\mathrm{Fe}$ & $0,49 \pm 0,01$ & $<0,1$ & $0,268 \pm 0,001$ & 15,0 \\
\hline Co & $2,0 \pm 0,4$ & $<0,01$ & $<0,01$ & - \\
\hline As & $1,09 \pm 0,04$ & $0,128 \pm 0,001$ & $0,446 \pm 0,006$ & 0,5 \\
\hline $\mathrm{pH}$ & 6,43 & 8,09 & 11,34 & 5 a 9 \\
\hline $\begin{array}{l}\text { Condutividade } \\
\text { (mS/cm) }\end{array}$ & 106,2 & 9,9 & 13,05 & - \\
\hline
\end{tabular}

$\left({ }^{\star}\right)$ Estabelecidas pela Resolução № 430 (13 de maio de 2011) do Conselho Nacional do Meio AmbienteCONAMA

Fonte: autor da dissertação

Nos resultados pode-se observar que embora a dose de $20 \mathrm{~g} \mathrm{~L}^{-1}$ seja mais eficaz na remoção de As, o valor de pH para a solução sobrenadante, após o tratamento, teve um valor acima do limite determinado pela legislação ambiental, de modo que a dose de 
$10 \mathrm{~g} \mathrm{~L}^{-1}$ é suficiente para remoção de arsênio desse efluente. O tratamento do efluente resultou em um menor valor de condutividade devido à remoção dos íons presentes na solução. Por outro lado, o valor de condutividade das soluções tratadas aumentou com o aumento da dose devido à maior lixiviação de alguns elementos presentes na fase sólida.

A amostra de ZCC pôde remover com sucesso os elementos de $\mathrm{Ni}, \mathrm{Cd}, \mathrm{Zn}, \mathrm{Mg}$, $\mathrm{Ca}, \mathrm{Fe}$ e Co do lixiviado do aterro de cinzas (Tabela 6). Não foram identificadas diferenças muito significativas entre as concentrações de elementos quando diferentes doses foram utilizadas o que pode ser atribuído à heterogeneidade das amostras. Semelhante à ZCM, a amostra de ZCC não foi eficiente para a remoção de cromo em qualquer dose de zeólita usada, porém foi satisfatória para a remoção de arsênio quando foi utilizada a dose de 10 g.L-1. Ambas as amostras, ZCC e ZCM, apresentaram o mesmo comportamento em relação aos valores de $\mathrm{pH}$ e condutividade.

Tabela 7 - Resultado da análise do lixiviado de Aterro de Cinzas (DA1) antes e depois do tratamento com ZCP usando diferentes doses e os parâmetros de lançamento.

\begin{tabular}{|c|c|c|c|c|}
\hline \multirow[b]{2}{*}{ Parâmetros } & \multirow{2}{*}{$\begin{array}{c}\text { DA1 } \\
\left(\mathrm{mgL}^{-1}\right)\end{array}$} & \multicolumn{2}{|c|}{$\mathrm{ZCP}\left(\mathrm{mg} \cdot \mathrm{L}^{-1}\right)$} & \multirow{2}{*}{$\begin{array}{l}\text { VMP* }^{*} \\
\left(\mathrm{mgL}^{-1}\right)\end{array}$} \\
\hline & & (Dose $10 \mathrm{gL}^{-1}$ ) & (Dose $20 \mathrm{gL}^{-1}$ ) & \\
\hline $\mathrm{Cr}$ & $0,15 \pm 0,01$ & $0,15 \pm 0,001$ & $0,15 \pm 0,001$ & 0,1 \\
\hline Mn & $0,133 \pm 0,004$ & $<0,1$ & $<0,1$ & 1,0 \\
\hline $\mathrm{Ni}$ & $1,11 \pm 0,02$ & $0,035 \pm 0,002$ & $<0,01$ & 2,0 \\
\hline Cd & $0,043 \pm 0,0003$ & $<0,01$ & $<0,01$ & 0,2 \\
\hline $\mathrm{Zn}$ & $0,112 \pm 0,002$ & $<0,01$ & $<0,01$ & 5,0 \\
\hline Mg & $5,5 \pm 0,4$ & $3,46 \pm 0,02$ & $0,464 \pm 0,001$ & - \\
\hline $\mathbf{C a}$ & $1052 \pm 7$ & $186 \pm 2$ & $17 \pm 0,07$ & - \\
\hline $\mathrm{Fe}$ & $0,49 \pm 0,01$ & $0,278 \pm 0,01$ & $0,243 \pm 0,001$ & 15,0 \\
\hline Co & $2,0 \pm 0,4$ & $0,029 \pm 0,002$ & $<0,01$ & - \\
\hline As & $1,09 \pm 0,04$ & $0,63 \pm 0,03$ & $1,043 \pm 0,003$ & 0,5 \\
\hline pH & 6,43 & 7,65 & 11,0 & 5 a 9 \\
\hline $\begin{array}{c}\text { Condutividade } \\
(\mathrm{mS} / \mathrm{cm})\end{array}$ & 106,2 & 8,6 & 5,01 & - \\
\hline
\end{tabular}

( $^{*}$ Estabelecidas pela Resolução № 430 (13 de maio de 2011) do Conselho Nacional do Meio AmbienteCONAMA

Fonte: autor da dissertação 
De acordo com a Tabela 7, a amostra ZCP apresentou o mesmo comportamento de remoção para os elementos $\mathrm{Ni}, \mathrm{Cd}, \mathrm{Zn}, \mathrm{Mg}, \mathrm{Ca}$ e Co, mas não obteve remoção de $\mathrm{Cr}$. Além disso, esta amostra não apresentou um tratamento satisfatório da DA1, considerando a remoção dos principais elementos tóxicos.

Em geral, os resultados mostraram que as amostras de ZCM e ZCC foram efetivas na remoção de As em ambas as doses, no entanto, a ZCM apresentou ser mais eficaz dentre todas as amostras de materiais zeolíticos usando diferentes doses. Este fato pode estar relacionado à sua maior área superficial específica (Tabela 4), o que deve permitir uma difusão favorável de ânions arsenato na estrutura interna da zeólita.

A remoção de $\mathrm{Cr}(\mathrm{VI})$ e As $(\mathrm{V})$ da água por um adsorvente é altamente dependente do $\mathrm{pH}$ da solução, pois este afeta a carga superficial do adsorvente e seu grau de ionização, além disso, a especiação do adsorbato (JACHUŁA e HUBICKI, 2013)

Os grupos funcionais hidroxila de superfície ativa da zeólita são reconhecidos como sítios dos grupos silanol $(\mathrm{Si}-\mathrm{OH})$ e aluminol $(\mathrm{Al}-\mathrm{OH})$, pois os constituintes principais deste material são $\mathrm{SiO}_{2}$ e $\mathrm{Al}_{2} \mathrm{O}_{3}$ (QUIO e ZHENG, 2007). Ainda, segundo os autores, os grupos aluminol terminais da zeólita foram confirmados como os sítios reativos para os ânions de arsenato, uma vez que a capacidade de adsorção de grupos de superfície silanol mostrou-se significativamente menor.

Os valores de $\mathrm{pH}$ obtidos nas amostras de lixiviados após o tratamento com zeólita foram de 8 e 11 para a dosagem de adsorvente de $10 \mathrm{~g} \mathrm{~L}^{-1}$ e $20 \mathrm{~g} \mathrm{~L}^{-1}$, respectivamente.

Considerando $\mathrm{pH}$ das amostras após tratamento com zeólita as formas predominantes do íon arsenato são $\mathrm{HAsO}_{4}{ }^{2-}$ em $\mathrm{pH} 8,0$ e $\mathrm{HAsO}_{4}{ }^{2-}$ e $\mathrm{AsO}_{4}{ }^{3-}$ em $\mathrm{pH} 11,0$, conforme apontado nos estudos de SMEDLEY e KINNIBURGH (2002).

A reação de troca catiônica pode ser representada pela equação 5:

$$
=\mathrm{AlT}-\mathrm{OH}+\mathrm{HAsO}_{4}^{-} \quad \longrightarrow \quad=\mathrm{AlT}_{\mathrm{T}}-\mathrm{HAsO}_{4}{ }^{-}+\mathrm{OH}^{-}
$$

$\mathrm{Na}$ equação 5, o grupo aluminol terminal é representado por $\mathrm{Al}$ T-OH. A estequiometria de reação dependerá do estado predominante de protonação do grupo superficial aluminol e do oxiânion arsenato (SHEVADE e FORD, 2004). Portanto, a capacidade de adsorção do material zeolítico é determinada principalmente pela quantidade de grupos $\mathrm{Al}-\mathrm{OH}$ terminais acessíveis para os ânions arsenato. 
Em geral, há uma diminuição na adsorção de As (V) quando em pH mais elevado, pois a adsorção de ânions de ácido forte por óxidos e hidróxidos metálicos diminui com o aumento do pH (STUMM, 1992). Além disso, a superfície do adsorvente torna-se mais negativa com o aumento do pH, o que não é favorável à adsorção de ânions.

Em relação ao $\mathrm{Cr}(\mathrm{VI})$, não há um ânion monovalente simples em meio aquoso, mas sim uma série de ânions cromato que dependem do $\mathrm{pH}$ e da concentração em solução. Acima do $\mathrm{pH} 6$, a espécie dominante é $\mathrm{CrO}_{4}{ }^{2-}$. Além disso, em valores de $\mathrm{pH}$ superiores a 6 , há a formação de complexos hidroxílicos do cromo devido a presença de $\mathrm{OH}^{-}$(YOSOF e MALEK, 2009).

A complexação superficial tem sido utilizada como modelo para descrever a adsorção de íons $\operatorname{Cr}(\mathrm{VI})$ em algumas superfícies de minerais sólidos (RAl et al., 1989; WENG, et al., 2001).

Os sítios reativos superficiais para um material zeolítico hidratado podem ser representados como grupos funcionais hidroxila protonados, neutros e desprotonados, os quais são $\mathrm{S}-\mathrm{OH}_{2}+\mathrm{S}-\mathrm{OH}$ e S-O-, respectivamente, em que S representa Si e AI (WENG, et al., 2008).

Em pH elevado, o grupo funcional hidroxila neutro, $\mathrm{S}-\mathrm{OH}$, é o único sitio ativo que possibilita a adsorção de $\mathrm{CrO}_{4}{ }^{2-}$ e a remoção de $\mathrm{Cr}(\mathrm{VI})$ é atribuída principalmente à formação do complexo S-CrO4- (equação 6).

$$
\mathrm{S}-\mathrm{OH}+\mathrm{CrO}_{4}^{2-} \rightarrow \mathrm{S}-\mathrm{CrO}^{2-}+\mathrm{OH}^{-}
$$

$\mathrm{Em} \mathrm{pH} \geq 8$, os grupos funcionais $\mathrm{S}-\mathrm{OH}$ estão principalmente na forma desprotonada e, também neste $\mathrm{pH}$, há uma maior quantidade de $\mathrm{OH}^{-}$que compete com os íons $\mathrm{CrO}_{4}{ }^{2-}$ pelos sítios de superfície ativa. Consequentemente, há uma dificuldade na formação de complexos com $\mathrm{Cr}$, sendo este o mecanismo da zeólita para remoção deste ânion em solução aquosa. Além disso, como já foi explicado, nas soluções alcalinas a carga superficial do adsorvente torna-se mais carregada negativamente e não favorece a adsorção de espécies aniônicas de $\mathrm{Cr}(\mathrm{VI})$.

\subsection{Tratamento de efluente usando zeólita modificada com surfactante}

O cromo e o arsênio estão presentes no efluente como espécies aniônicas, conforme foi explicado no texto acima. Sendo assim, foram realizados estudos adicionais visando aumentar a eficiência de remoção dessas espécies pelo material zeolítico. 
Nas Tabelas 8 e 9, são mostradas as concentrações dos elementos metálicos presentes no efluente antes (DA1) e após o tratamento com as zeólitas de cinzas de carvão modificadas por surfactante, bem como os valores de $\mathrm{pH}$ e condutividade permitidos para o lançamento de efluentes em corpos d'água, segundo legislação ambiental vigente (CONAMA, 2011). Os resultados obtidos com a utilização da zeólita comercial A e o ensaio do "branco" também são apresentados na Tabela 9.

Os resultados apresentados na Tabela 8 demonstraram que não houve remoção de arsênio e cromo com nenhuma das zeólitas modificadas com HDTMA-Br 1,8 mmol.L-1 a partir dos três diferentes tipos de cinzas de carvão.

Tabela 8 - Análise de efluente de aterro de cinzas antes e após tratamento com zeólitas modificadas com HDTMA-Br 1,8 $\mathrm{mmol} \mathrm{L}^{-1}$.

\begin{tabular}{|c|c|c|c|c|c|}
\hline Parâmetros & $\begin{array}{c}\text { DA1 } \\
\left(\mathrm{mg} \mathrm{L}^{-1}\right)\end{array}$ & $\begin{array}{c}\text { ZMP } \\
\left(\mathrm{mg} \mathrm{L}^{-1}\right)\end{array}$ & $\begin{array}{c}\text { ZMC } \\
\left(\mathrm{mg} \mathrm{L}^{-1}\right)\end{array}$ & $\begin{array}{c}\text { ZMM } \\
\left(\mathrm{mg} \mathrm{L}^{-1}\right)\end{array}$ & $\begin{array}{c}\text { VMP* }^{*} \\
\left(\mathrm{mg} \mathrm{L}^{-1}\right)\end{array}$ \\
\hline $\mathrm{Cr}$ & $0,142 \pm 0,001$ & $0,149 \pm 0,001$ & $0,147 \pm 0,001$ & $0,148 \pm 0,001$ & 0,1 \\
\hline Mn & $<0,1$ & $<0,1$ & $<0,1$ & $<0,1$ & 1,0 \\
\hline $\mathrm{Ni}$ & $<0,01$ & $<0,01$ & $<0,01$ & $<0,01$ & 2,0 \\
\hline Cd & $<0,01$ & $<0,01$ & $<0,01$ & $<0,01$ & 0,2 \\
\hline $\mathrm{Zn}$ & $<0,01$ & $0,024 \pm 0,001$ & $0,112 \pm 0,001$ & $0,08 \pm 0,001$ & 5,0 \\
\hline Mg & $3,55 \pm 0,03$ & $4,42 \pm 0,02$ & $4,63 \pm 0,04$ & $4,68 \pm 0,05$ & - \\
\hline $\mathrm{Ca}$ & $619 \pm 4$ & $108,99 \pm 0,01$ & $109,00 \pm 0,01$ & $109,2 \pm 0,03$ & - \\
\hline $\mathrm{Fe}$ & $<0,1$ & $<0,1$ & $<0,1$ & $<0,1$ & 15,0 \\
\hline Co & $<0,01$ & $<0,01$ & $<0,01$ & $<0,01$ & - \\
\hline As & $1,7 \pm 0,03$ & $1,73 \pm 0,01$ & $1,73 \pm 0,02$ & $1,81 \pm 0,01$ & 0,5 \\
\hline $\mathrm{pH}$ & 7,33 & 8,9 & 8,51 & 8,45 & 5 a 9 \\
\hline $\begin{array}{l}\text { Condutividade } \\
\text { (mS/cm) }\end{array}$ & 9,19 & 7,07 & 6,79 & 6,85 & - \\
\hline
\end{tabular}

$\left(^{*}\right)$ Estabelecidas pela Resolução № 430 (13 de maio de 2011) do Conselho Nacional do Meio AmbienteCONAMA

Fonte: autor da dissertação 
Observou-se uma remoção de $75 \%$ e $23 \%$ de arsênio no tratamento do efluente com a zeólita modificada com HDTMA-Br $20 \mathrm{mmol}^{-1}$ e a zeólita comercial A, respectivamente (Tabela 9). O enquadramento da legislação ambiental foi alcançado no tratamento com a zeólita modificada em relação ao arsênio. Além disso, os dois materiais zeolíticos não apresentaram uma remoção significativa para o cromo. O resultado do BR indicou que o material zeolítico pode liberar uma pequena fração de As e não foi possível verificar se o mesmo ocorre para o $\mathrm{Cr}$, pois o elemento não foi detectado pelo equipamento.

Tabela 9- Análise de efluente de aterro de cinzas antes e após tratamento com zeólita modificada com HDTMA-Br 20 mmol.L-1 e zeólita comercial A.

\begin{tabular}{|c|c|c|c|c|c|}
\hline Parâmetros & $\begin{array}{c}\text { DA1 } \\
\left(\mathrm{mg} \mathrm{L}^{-1}\right)\end{array}$ & $\begin{array}{l}\text { ZMM-20 } \\
\left(\mathrm{mg} \mathrm{L}^{-1}\right)\end{array}$ & $\begin{array}{c}\mathrm{ZA} \\
\left(\mathrm{mg} \mathrm{L}^{-1}\right)\end{array}$ & $\begin{array}{c}\text { BR } \\
\left(m g L^{-1}\right)\end{array}$ & $\begin{array}{l}\text { VMP* }^{*} \\
\left(\mathrm{mg} \mathrm{L}^{-1}\right)\end{array}$ \\
\hline $\mathrm{Cr}$ & $0,142 \pm 0,001$ & $0,123 \pm 0,001$ & $0,138 \pm 0,001$ & $<0,01$ & 0,1 \\
\hline Mn & $<0,1$ & $<0,1$ & $<0,1$ & $<0,1$ & 1,0 \\
\hline $\mathbf{N i}$ & $<0,01$ & $<0,01$ & $<0,01$ & $<0,01$ & 2,0 \\
\hline Cd & $<0,01$ & $<0,01$ & $<0,01$ & $<0,01$ & 0,2 \\
\hline $\mathrm{Zn}$ & $<0,01$ & $0,07 \pm 0,001$ & $<0,01$ & $<0,01$ & 5,0 \\
\hline Mg & $3,55 \pm 0,03$ & $3,07 \pm 0,05$ & $1,98 \pm 0,01$ & $<0,1$ & - \\
\hline $\mathrm{Ca}$ & $619 \pm 4$ & $544 \pm 2$ & $13,9 \pm 0,01$ & $0,69 \pm 0,01$ & - \\
\hline $\mathrm{Fe}$ & $<0,1$ & 0,403 & $<0,1$ & $<0,1$ & 15,0 \\
\hline Co & $<0,01$ & $<0,01$ & $<0,01$ & $<0,01$ & - \\
\hline As & $1,7 \pm 0,03$ & $0,42 \pm 0,01$ & $1,31 \pm 0,01$ & $0,015 \pm 0,001$ & 0,5 \\
\hline $\mathrm{pH}$ & 7,33 & 8,32 & 9,09 & 10,42 & 5 a 9 \\
\hline $\begin{array}{c}\text { Condutividade } \\
(\mathrm{mS} / \mathrm{cm})\end{array}$ & 9,19 & 9,76 & 23 & 0,203 & \\
\hline
\end{tabular}

$\left(^{*}\right)$ Estabelecidas pela Resolução $N^{\circ} 430$ (13 de maio de 2011) do Conselho Nacional do Meio AmbienteCONAMA

Fonte: autor da dissertação 
O processo de adsorção do surfactante catiônico sobre a superfície da zeólita é governado principalmente por mecanismo de troca catiônica e interações hidrofóbicas (HAGGERLY e BOWMAN, 1994; LI e BOWMAN, 1997; LI, 1998, 1999; BOWMAN, 2003).

Quando uma zeólita é misturada com a solução do surfactante em concentração menor do que a concentração micelar crítica (CMC), as moléculas catiônicas do surfactante formam uma monocamada na superfície externa da zeólita carregada negativamente via troca iônica. O aumento da concentração do surfactante, excedendo a CMC, causa a formação de uma bicamada via interação hidrofóbica entre as caudas do surfactante devido às forças coercivas fracas de Van der Waals. Observa-se primeiramente a formação de monocamadas e/ou bicamadas incompletas. Após, com um novo aumento da concentração, ocorre à formação de bicamada completa, onde a carga superficial da zeólita passa de negativa para positiva. Os grupos positivamente carregados da cabeça do surfactante são balanceados por contra-íons fracamente adsorvidos,como o brometo, no caso do HDTMA-Br.

O valor da CMC do HDTMA-Br de 0,9 mmol $\mathrm{L}^{-1}$ foi determinado por LI e BOWMAN (1997). Portanto, as concentrações de HDTMA-Br 1,8 e 20 mmol L-1 usadas nesse estudo eram 2 e 22 vezes maiores do que a CMC, respectivamente. Estudos anteriores indicaram a formação de bicamada incompleta no processo de adsorção do surfactante na superfície das zeólitas de cinzas de carvão modificadas com essas duas concentrações de HDTMA-Br (FUNGARO e BORRELY, 2012).

O mecanismo de adsorção dos íons cromatos e arsenatos sobre zeólita modificada com surfactante é principalmente atribuído à troca iônica com o ânion de compensação de carga $\left(\mathrm{Br}^{-}\right)$presente na bicamada de surfactante na superfície do material (HAGGERTY e BOWMAN, 1994; LI e BOWMAN, 1998; BOWMAN et al., 2000; LI, 2004). No entanto, esta explicação aplica-se somente aos adsorventes modificados com concentração de surfactante de pelo menos $80 \%$ da sua capacidade de troca iônica externa (CTCE). Outros mecanismos de adsorção potenciais incluem: adsorção física, complexação superficial, precipitação superficial de oxiânions com HDTMA e/ou redução química de ânions em formas menos solúveis (SZALA et al, 2015).

A remoção do íon $\mathrm{HAsO}_{4}$ - foi possível pelo mecanismo de troca iônica apenas com a amostra ZMM-20 (Tabela 9), a qual foi preparada com concentração de HDTMA-Br acima de $80 \%$ da CTCE da zeólita (FUNGARO e MAGDALENA, 2014). O mecanismo 
pode ser conceitualmente representado pela equação 7 (SWARNKAR, AGRAWAL e TOMAR, 2011)

$2 \mathrm{ZMM}-\mathrm{Br}+\mathrm{HAsO}_{4}^{2-} \quad \longrightarrow \quad=\mathrm{ZMM}_{2}-\mathrm{HAsO}_{4}+2 \mathrm{Br}^{-}$

No caso das zeólitas modificadas com HDTMA-Br 1,8 mmol L-1, cuja concentração é < 10\% do CTCE, a adsorção seria somente possível nos grupos Al-OH terminais da superfície da zeólita. No entanto, os sítios estão ocupados pelo surfactante.

A remoção do íon $\mathrm{CrO}_{4}{ }^{2-}$ presente no efluente, foi somente possível pela zeólita modificada com HDTMA-Br $\left(20 \mathrm{mmol} \cdot \mathrm{L}^{-1}\right)$. O mecanismo de adsorção desse ânion foi por troca iônica, porém esta adsorção não foi suficiente para enquadrar o efluente nos limites máximos exigidos pela legislação ambiental. Este fato ocorreu devido há uma forte competição dos íons $\mathrm{HAsO}_{4}^{-}$, bem como do $\mathrm{OH}^{-}$, com o cromato para a troca com o $\mathrm{Br}^{-}$do surfactante. Além disso, essa espécie necessitaria de dois sítios de troca por ser bivalente (YUSOF e MALEK, 2009).

A remoção de As (V) e Cr (VI) do efluente usando zeólita A pura comercial, não foi significativa (Tabela 9). Esse fato demonstra que a zeólita de cinzas de carvão tem mais sítios $\mathrm{Al}-\mathrm{OH}$ acessíveis do que a zeólita $\mathrm{A}$, pois apresentou remoção de $75 \%$ de As. A forte influência do $\mathrm{pH}$, no caso do cromo,foi o fator que mais influenciou para os dois materiais, conforme já foi discutido. Artigos de literatura comprovaram que a remoção de As (V) e $\mathrm{Cr}(\mathrm{VI})$ usando zeólita A é eficiente apenas após a modificação com surfactante e $\mathrm{pH}$ inicial adequado ou a incorporação de íons de ferro ou cobre (TASHAUOEl et al, 2010; PILLEWAN et al., 2014).

Cabe ressaltar que ambos os materiais, zeólita de cinzas de carvão não modificada e zeólita modificada com HDTMA-Br $20 \mathrm{mmol} \mathrm{L}^{-1}$ apresentaram remoção de $75 \%$ do As (V) presente no efluente por mecanismos diferentes. Portanto, a modificação da zeólita com surfactante, nas condições do presente estudo,não aumentou a eficiência de remoção do arsênio da solução aquosa.

Todos os resultados observados no tratamento do efluente com as zeólitas modificadas confirmaram os mecanismos de adsorção dos cromatos e arsenatos sobre as zeólitas não modificadas discutidos no item anterior. 


\subsection{Avaliação da remoção de Cr e As}

Uma avaliação de novos tratamentos focando apenas na remoção de $\mathrm{Cr}$ e As do lixiviado do aterro de cinzas de carvão foi realizada nessa etapa de estudo. Esse procedimento foi conduzido devido às seguintes considerações: (1) são os elementos cujas concentrações estão acima do padrão de lançamento de efluentes segundo a legislação; (2) são elementos que apresentam alta toxicidade; (3) a presença dos dois elementos simultaneamente e o $\mathrm{Cr}$ com concentração muito baixa na amostra dificulta a eficiência do tratamento; (4) como nenhum dos tratamentos anteriores foi possível atingir uma concentração do $\mathrm{Cr}$ abaixo do limite de lançamento de efluentes segundo a legislação.

5.4.1 Tratamento com zeólita e acidificação prévia da solução aquosa

A remoção de $\mathrm{Cr}(\mathrm{VI})$ em água, é altamente dependente do $\mathrm{pH}$ da solução, o que subsequentemente afeta a superfície do adsorvente, o seu grau de ionização e a especiação do adsorbato (SCHUMI, KRIEG e KEIZER, 2001). As espécies de cromo hexavalente são muito solúveis em soluções aquosas e aumentam com o pH.

Em pH baixo, há uma maior concentração de grupos funcionais protonados. Além disso, estão principalmente presentes o $\mathrm{H}_{2} \mathrm{AsO}_{4}^{-}$e $\mathrm{O} \mathrm{HCrO}_{4}^{-}$(Figura 3), sendo estas espécies mais facilmente removidas pelos grupos funcionais presentes na superfície da zeólita. Portanto, para realização deste ensaio foi ajustado a mistura em pH 4, pois neste valor a solução aquosa apresenta a maior concentração das espécies citadas.

Os resultados apresentados na Tabela 10 demonstraram que o material adsorvente em pH 4 apresentou menor eficiência na remoção do As, quando comparado com os resultados em $\mathrm{pH}$ elevado, para ambas as doses. A remoção do As utilizando a amostra ZCM não apresentou resultados significativos, na dose de $10 \mathrm{~g} \mathrm{~L}^{-1}$. Já na dose de $20 \mathrm{~g} \mathrm{~L}^{-1}$, houve uma remoção de aproximadamente $58 \%$ do As, e diferentemente dos resultados obtidos em pH elevado, o material conseguiu adsorver uma pequena fração de $\mathrm{Cr}$. 
Tabela 10- Valores de concentração do As e $\mathrm{Cr}$ e pH final do efluente após tratamento com ZCM em pH 4.

\begin{tabular}{ccccc}
\hline \multirow{2}{*}{ Parâmetros } & DA1 $\left(\mathbf{m g ~ L}^{-1}\right)$ & $\left(\right.$ Dose 10 $\left.\mathbf{g L}^{-1}\right)$ & $\left(\right.$ Dose 20 $\left.\mathbf{g L}^{-1}\right)$ & VMP * \\
$\left(\mathbf{m g ~ L}^{-1}\right)$ \\
\hline Cr & $0,129 \pm 0,001$ & $0,136 \pm 0,0004$ & $0,122 \pm 0,001$ & 0,1 \\
As & $1,57 \pm 0,02$ & $1,30 \pm 0,02$ & $0,66 \pm 0,01$ & 0,5 \\
pH & 7,98 & 3,51 & 3,44 & $5 \mathrm{a} 9$ \\
\hline
\end{tabular}

$\left(^{*}\right)$ Estabelecidas pela Resolução № 430 (13 de maio de 2011) do Conselho Nacional do Meio AmbienteCONAMA

Fonte: autor da dissertação

\subsubsection{Processo de duas etapas}

O experimento foi realizado em duas etapas visando primeiramente a remoção do As, uma vez que este elemento tende a ser preferencialmente removido pela zeólita. A segunda etapa do experimento visava remover o Cr. Como se pode observar nas Tabelas 10 e 11, inicialmente houve uma alta remoção do As, e como previsto pelos resultados anteriores, pode ocorrer a liberação de $\mathrm{Cr}$ no meio. Porém, este aumento não é expressivo para inviabilizar um processo de tratamento.

Os valores da Tabela 11 demonstram que o processo utilizando duas etapas de zeólita com $10 \mathrm{~g} . \mathrm{L}^{-1}$, foi menos eficiente do que quando utilizado diretamente $20 \mathrm{~g} . \mathrm{L}^{-1}$, sendo a remoção do As de $56 \%$ e $75 \%$, respectivamente. A diminuição da eficiência pode ter sido causada pela baixa concentração do elemento, que acaba dificultando sua remoção. 
Tabela 11- Valores de concentraçãodo As e Cr do efluente após tratamento em duas etapas com ZCM.

\begin{tabular}{ccccc}
\hline Parâmetros & $\begin{array}{c}\text { DA1 } \\
\left(\mathbf{m g ~ L}^{-1}\right)\end{array}$ & $\begin{array}{c}\mathbf{Z C M}^{*} \\
\left(\mathbf{m g ~ L}^{-1}\right)\end{array}$ & $\begin{array}{c}\mathbf{Z C M - 2}^{\star *} \\
\left(\mathbf{m g ~ L}^{-1}\right)\end{array}$ & $\begin{array}{c}\text { VMP *** } \\
\left.\mathbf{( m g ~ L}^{-1}\right)\end{array}$ \\
\hline Cr & $0,129 \pm 0,02$ & $0,136 \pm 0,0003$ & $0,150 \pm 0,001$ & 0,1 \\
As & $1,487 \pm 0,01$ & $0,671 \pm 0,002$ & $0,654 \pm 0,006$ & 0,5 \\
pH & 7,77 & 8,10 & 7,8 & 5 a 9
\end{tabular}

$\left.{ }^{*}\right)$ Amostra de material zeolítico do filtro manga

$\left.{ }^{* *}\right)$ Amostra de material zeolítico do filtro manga

${ }^{\star \star * *}$ Estabelecidas pela Resolução № 430 (13 de maio de 2011) do Conselho Nacional do Meio AmbienteCONAMA

Fonte: autor da dissertação

Como evidenciado na Tabela 12, a MZCM, do procedimento de duas etapas, apresentou alta eficiência na remoção de As, enquanto que em relação à concentração de Cr não houve alteração.

Tabela 12- Valores de concentraçãodo As e $\mathrm{Cr}$ do efluente após tratamento em duas etapas com ZCM e zeólita magnética.

\begin{tabular}{ccccc}
\hline Parâmetros & $\begin{array}{c}\text { DA1 } \\
\left(\mathbf{m g} \cdot \mathbf{L}^{-1}\right)\end{array}$ & $\begin{array}{c}\mathbf{Z C M}^{*} \\
\left(\mathbf{m g} \mathbf{L}^{-1}\right)\end{array}$ & $\begin{array}{c}\text { MZCM } \\
\left(\mathbf{m g} \cdot \mathbf{L}^{-1}\right)\end{array}$ & $\begin{array}{c}\mathrm{VMP}^{* *} \\
\left(\mathbf{m g L}^{-1}\right)\end{array}$ \\
\hline Cr & $0,129 \pm 0,02$ & $0,139 \pm 0,003$ & $0,137 \pm 0,005$ & 0,1 \\
As & $1,487 \pm 0,01$ & $0,706 \pm 0,02$ & $0,402 \pm 0,02$ & 0,5 \\
pH & 7,77 & 8,05 & 7,5 & 5 a 9 \\
\hline
\end{tabular}

(*) Amostra de material zeolítico do filtro manga

${ }^{(* *}$ Estabelecidas pela Resolução № 430 (13 de maio de 2011) do Conselho Nacional do Meio AmbienteCONAMA

Fonte: autor da dissertação 


\subsubsection{Zeólitas modificadas por surfactante}

Segundo YOSOF e MALEK (2009) a baixa remoção de cromo usando altas concentrações de HDTMA-Br (>100\% da CTCE da zeólita), pode ocorrer devido a formação em excesso das micelas na solução, que estavam fracamente ligadas ao material. Além disso, as micelas na solução acabam competindo também com os íons cromato. HAGGERTY e BOWMAN (1994) também observaram que zeólitas modificadas com altas concentrações de HDTMA-Br (>100\% da CTCE) apresentam menor efetividade na remoção dos íons cromato. Portanto, para realização deste experimento foi mantida a concentração de HDTMA-Br (20 mmol L-1) mas com uma dose maior de zeólita modificada.

Na Tabela 13 são apresentados os resultados da remoção do Cr e As pela dose de $20 \mathrm{~g} \mathrm{~L}^{-1}$ da ZMM-20, indicando que com o aumento da dose há uma diminuição na efienciecia de remoção dos elementos citados, quando comparados com a dose de $10 \mathrm{~g}$ $\mathrm{L}^{-1}$. Este fato pode ocorrer devido a ligação de bicamadas completas com sítios das zeólitas que estejam com camadas incompletas. Neste experimento o $\mathrm{Cr}$ não é lixiviado pela zeólita porque o surfactante impede este processo.

Tabela 13- Valores de concentraçãodo As e Cr do efluente após tratamento com zeólita modificada com HDTMA-Br 20 mmol. $\mathrm{L}^{-1}$ na dose $20 \mathrm{gL}^{-1}$

\begin{tabular}{cccc}
\hline Parâmetros & $\begin{array}{c}\text { DA1 } \\
\left(\mathbf{m g} \cdot \mathbf{L}^{-1}\right)\end{array}$ & $\begin{array}{c}\text { ZMM-20 }\left(\mathrm{mg}^{-1} \mathbf{L}^{-1}\right) \\
\left(\text { Dose } \mathbf{2 0} \mathbf{g L}^{-1}\right)\end{array}$ & $\begin{array}{c}\text { VMP * } \\
\left(\mathbf{m g L}^{-1}\right)\end{array}$ \\
\hline Cr & $0,129 \pm 0,02$ & $0,118 \pm 0,001$ & 0,1 \\
As & $1,487 \pm 0,01$ & $0,535 \pm 0,003$ & 0,5 \\
pH & 7,77 & 8,8 & 5 a 9
\end{tabular}

$\left(^{*}\right)$ Estabelecidas pela Resolução № 430 (13 de maio de 2011) do Conselho Nacional do Meio AmbienteCONAMA

Fonte: autor da dissertação

$\mathrm{Na}$ Tabela 14, é apresentada a comparação entre os efluentes da primeira e segunda coletas. Como se pode observar o $\mathrm{Cr}$ apresenta baixas concentrações em 
ambos os casos. Porém, a concentração de $\mathrm{Cr}$ na DA1 mesmo não atendendo a legislação ambiental, está próxima ao padrão de lançamento. Na segunda coleta, mesmo após 40 dias sem chuva o que contribuiria para um aumento da concentração dos elementos presentes no efluente, a amostra de efluente DA2 apresentou concentração de Cr muito abaixo do limite máximo permitido pela legislação.

Tabela 14- Resultado da análise do efluente do aterro de cinzas na primeira e na segunda coleta.

\begin{tabular}{|c|c|c|c|}
\hline Parâmetros & $\begin{array}{c}\text { DA1 } \\
\left(\mathrm{mg} \cdot \mathrm{L}^{-1}\right)\end{array}$ & $\begin{array}{c}\text { DA2 } \\
\left(\mathrm{mg} \cdot \mathrm{L}^{-1}\right)\end{array}$ & $\begin{array}{l}\text { VMP * } \\
\left(\mathrm{mgL}^{-1}\right)\end{array}$ \\
\hline $\mathrm{Cr}$ & $0,15 \pm 0,01$ & $0,015 \pm 0,004$ & 0,1 \\
\hline Mn & $0,133 \pm 0,004$ & $<0,1$ & 1,0 \\
\hline $\mathbf{N i}$ & $1,11 \pm 0,02$ & $0,016 \pm 0,005$ & 2,0 \\
\hline Cd & $0,043 \pm 0,0003$ & $<0,01$ & 0,2 \\
\hline $\mathrm{Zn}$ & $0,112 \pm 0,002$ & $<0,01$ & 5,0 \\
\hline $\mathrm{Mg}$ & $5,5 \pm 0,4$ & $4,05 \pm 0,08$ & - \\
\hline $\mathrm{Ca}$ & $1052 \pm 7$ & $109,13 \pm 0,01$ & - \\
\hline $\mathrm{Fe}$ & $0,49 \pm 0,01$ & $<0,1$ & 15,0 \\
\hline Co & $2,0 \pm 0,4$ & $<0,01$ & - \\
\hline As & $1,09 \pm 0,04$ & $1,70 \pm 0,01$ & 0,5 \\
\hline $\mathrm{pH}$ & 6,43 & 6,57 & 5 a 9 \\
\hline
\end{tabular}

${ }^{*}$ ) Estabelecidas pela Resolução № 430 (13 de maio de 2011) do Conselho Nacional do Meio AmbienteCONAMA

Fonte: autor da dissertação

A lixiviação do As é dependente do $\mathrm{pH}$, sendo que as maiores concentrações ocorrem em $\mathrm{pH}$ baixo. As principais formas do arsênio lixiviado no aterro de cinzas são inorgânicas e dependentes das condições redox da água, sendo As pentavalente em 
condições com maior oxigenação e As trivalente em condições com menor oxigenação (KIM et al., 2009).

Segundo SMEDLEY e KINNIBURGH (2002) o arsênio é um dos elementos mais problemáticos ao meio ambiente, uma vez que possui alta mobilidade e toxicidade em diferentes variações de condições redox, diferentemente do Cr que pode apresentar íons com menor mobilidade e não tóxicos dependendo do Eh. Deste modo, evidencia-se a importância da remoção de As, presente em concentrações acima dos padrões de lançamento em ambos os casos deste presente estudo. 


\section{CONCLUSÕES}

Na primeira etapa do trabalho, a sodalita foi obtida como fase zeolítica por meio de síntese hidrotérmica das cinzas manga, cinzas ciclone e cinzas pesadas. Os materiais zeolíticos das cinzas manga, cinzas ciclone e cinzas pesadas apresentaram relação direta entre a razão $\mathrm{SiO}_{2} / \mathrm{Al}_{2} \mathrm{O}_{3}$ e a capacidade de troca catiônica (CTC) para todas as amostras.

O material zeolítico preparado com as cinzas manga apresentou a menor razão $\mathrm{SiO}_{2} / \mathrm{Al}_{2} \mathrm{O}_{3}$, maior CTC, menor teor de carbono e, portanto, o maior potencial na adsorção de íons metátlicos.

Os materiais zeolíticos foram usados na remoção de elementos tóxicos presentes no lixiviado do aterro de cinzas de carvão em ensaios em batelada. Dentre os elementos determinados no lixiviado, as concentrações de As e Cr estavam acima do padrão de lançamento de efluentes.

Os testes de adsorção utilizando os materiais zeolíticos dos três tipos de cinzas apresentaram remoção significativa para $\mathrm{Ni}, \mathrm{Cd}, \mathrm{Zn}$ e Co.

A remoção de As obtendo-se concentração abaixo do valor previsto pela legislação ambiental foi possível utilizando as amostras de material zeolítico de cinzas manga e ciclone, enquanto a remoção do $\mathrm{Cr}$ não foi efetiva com nenhum dos materiais.

A amostra de material zeolítico das cinzas manga apresentou a maior eficiência de remoção dos elementos tóxicos. O processo em batelada com duas etapas não apresentou melhoria nos resultados quando comparado com o processo único utilizando maior dosagem do material zeolítico.

$\mathrm{Na}$ segunda etapa do trabalho, a modificação dos materiais zeolíticos com surfactante não melhorou a eficiência de remoção do As. No entanto, houve certa remoção do $\mathrm{Cr}$ no tratamento com material zeolítico das cinzas manga modificado com surfactante na concentração de $20 \mathrm{mmol} \mathrm{L}^{-1}$, de tal forma que a concentração ficou em um valor muito próximo ao limite permitido pela legislação.

Concluiu-se, portanto, que as zeólitas preparadas a partir da síntese hidrotérmica alcalina de cinzas leves de carvão do filtro manga e do filtro ciclone, podem ser utilizadas no tratamento de efluentes contendo As e íons metálicos. 


\section{PROPOSTA DE TRABALHOS FUTUROS}

A síntese de cinzas de carvão para formação de zeólitas e suas aplicações para tratar diversos tipos de efluentes não se limita apenas a este estudo. Alguns tópicos iniciais do trabalho não puderam ser desenvolvidos a tempo de serem incluídos na presente dissertação. Sendo assim, algumas sugestões para trabalhos futuros, seriam:

1. Sintetizar material zeolítico na forma granular e realizar o estudo da remoção de As e Cr em efluente simulado por processo de adsorção utilizando coluna de leito fixo;

2. Aplicar o processo de adsorção em coluna de leito fixo no tratamento de efluente real;

3. Avaliar o tratamento do efluente em duas etapas: A primeira etapa será realizada para a adsorção do arsênio e outros íons catiônicos sobre zeólita por coluna de leito fixo. $\mathrm{Na}$ segunda etapa, o efluente será tratado por fitorremediação para retirada do cromo visando potencial aplicação em wetland;

4. Realizar ensaios do tratamento do efluente gerado no aterro das cinzas de carvão em escala piloto e in situ. 


\section{REFERÊNCIAS BIBLIOGRÁFICAS}

AGRAFIOTI, E.; KALDERIS, D.; DIAMADOPOULOS, E. Arsenic and chromium removal from water using biochars derived from rice husk, organic solid wastes and sewage sludge Department of Environmental Engineering, Technical University of Crete, Chania, Greece. 2014

AHMAD, A. L.; OOI, B. S. A study on acid reclamation and copper recovery using low pressure nanofiltration membrane. Chemical Engineering Journal, v. 56, p. 257-263, 2010.

AHMARUZZAMAN, M. A review on the utilization of fly ash. Progress in Energy and Combustion Science, v. 36, p. 327-363, 2010.

ALCÂNTARA, R. R. Síntese, caracterização de nanomaterial zeolítico de cinzas de carvão organomodificado e aplicação como adsorvente na remediação de água contaminada por RODAMINA B e AZUL DIRETO 71. 2016. Dissertação (Mestrado) Instituto de Pesquisas Energéticas e Nucleares, São Paulo. Disponível em: $<$ http://www.teses.usp.br>. Acesso em: 20 out. 2018

ALYÜZ, B.; VELI, S. Kinetics and equilibrium studies for the removal of nickel and zinc from aqueous solutions by ion exchange resins. Journal of Hazardous Materials, v. 167, p. 482-488, 2009.

ARANTES, F. R. Estudo do comportamento magnético de nanopartículas de magnetita de nanofios de níquel em cristais líquidos liotrópicos. 2010. Dissertação (Mestrado) Instituto de Física, São Paulo

ATKINS, P.; PAULA, J. D. Físico-Química. Rio de Janeiro: LTC: v. 3, p. 279, 2004.

AVERILL, B. A. Principles of General Chemistry. Cap.12: Solids p. 1403-1521, 2012.

BALTPURVINS, K. A., BURNS, R.C., LAWRANCE, G. A.; STUART, A. D. Effect of electrolyte composition on zinc hydroxide precipitation by lime. Water Research. v. 31, p. 973-980, 1997.

BARRA, C.; SANTELLI, R. E.; ABRÃO, J. J.; GUARDIA, M. de la. Especiação de arsênio uma revisão. Química Nova, v. 23, p. 58-70, 2000.

BARAKAT, M. A. New trends in removing heavy metals from industrial wastewater. Arabian Journal of Chemistry, v. 4, n. 4, p. 361-377, 2011.

BERTOLINI, T. C. R. Estudo comparativo sobre a adsorção de diferentes classes de corantes em zeólitas de cinzas de carvão: modelagem cinética e de equilíbrio. 2014. Dissertação (Mestrado) Instituto de Pesquisas Energéticas e Nucleares, São Paulo Disponível em: <http://www.teses.usp.br>. Acesso em: 20 out. 2018

BOND, G. C. Heterogeneous Catalysis: Principles and Applications, 2nd ed, Clarendon, Oxford, 1987.

BOWMAN, R.S. Applications of surfactant-modified zeolites to environmental remediation. Microporous and Mesoporous Materials, v. 61, p. 43-56, 2003. 
BRASIL. Lei Federal n० 12.305, de 2 de agosto de 2010. Institui a Política Nacional de Resíduos Sólidos; altera a Lei no 9. 605, de 12 de fevereiro de 1998; e dá outras providências. Diário Oficial da União, Brasília, DF, 3 ago. 2010

BRASIL. MINISTÉRIO DO MEIO AMBIENTE, CONSELHO NACIONAL DO MEIO AMBIENTE - CONAMA. Resolução no. 430, de 13 de Maio de 2011. Brasília DF, n. 92, 16 de Maio de $2011 . \quad$ Disponível em: <http://www.mma.gov.br/port/conama/legiabre.cfm?codlegi=646> Acesso em 20 de Outubro de 2018.

BRECK, D.W. Zeolite molecular sieves: structure, chemistry, and use. Malabar: New York, Robert E Krieger Publishing Company, 1984.

BROOKINS, D. G. Eh-pH Diagrams for Geochemistry. Springer-Verlag, Berlin. 1988.

BRUNO, M. Utilização de zeólitas sintetizadas a partir de cinzas de carvão na remoção de corante em água. 2008. Dissertação (Mestrado) Instituto de Pesquisas Energéticas e Nucleares, São Paulo Disponível em: <http://www.teses.usp.br>. Acesso em: 20 out. 2018

CAMPANER, V. P. Dispersão geoquímica de elementos e radionuclídeos na atmosfera e no solo de uma área com atividades de usinas termelétricas de mineração e carvão. 2013. Dissertação (Mestrado) Universidade Estadual de Campinas, São

Paulo.

CORMA, A. From microporous to mesoporous molecular sieve material sand their use in catalysis. Chemical Reviews, v. 97, n. 6, p. 2373-2419, 1997

COOMBS, D.S.; ALBERTI, A.; ARMBRUSTER, T.; ARTIOLI, G.; COLELLA, C.; GALLI, E.; GRICE, J.D.; LIEBAU, F.; MANDARINO, J.A.; MINATO, H.; NICKEL, E.H.; PASSAGLIA, E.; PEACOR, D.R.; QUARTIERI, S.; RINALDI, R.; ROSS, M.I.; SHEPPARD, R.A.; TILLMANNS, E.; VEZZALINI, G. Recommended nomenclature for zeolite minerals; Report of the Subcommittee on Zeolites of the International Mineralogical Association, Commission on New Minerals and Mineral Names. European Journal of Mineralogy, v. 10, p. 1037-1081, 1998.

CORELLA, C. Ion exchange equilibria in zeolite mineral. Mineralium Deposita, v. 31, p. 554-562, 1996.

CRAESMEYER, G. R. Tratamento de efluente contendo urânio com zeólita magnética. 2013. Dissertação (Mestrado) Instituto de Pesquisas Energéticas e Nucleares, São Paulo

CSÉFALVAY, E.; PAUER, V.; MIZSEY, P. Recovery of copper from process waters by nanofiltration and reverse osmosis. Desalination, v. 240, p. 132-142, 2009.

DEPOI, F. S.; POZEBON, D.; KALKREUTH, W. D. Chemical characterization of feed coals and combustion-by-products from Brazilian power plants. International Journal of Coal Geology v. 76, p. $227-236,2008$.

DRIEHAUS, W.; SEITH, R.; JEKEL, M. Oxidation of arsenate (III) with manganese oxides in water treatment. Water Researchgate, v. 29, n. 1, p. 297-305, 1995. 
DZOMBAK, D. A., MOREL, F. M. M. Surface Complexation Modelling- Hydrous Ferric Oxide. John Wiley, New York. 1990.

ECCLES, H. Treatment of metal-contaminated wastes: why select a biological process? Trends Biotechnology, v. 17, p. 462-465, 1999.

FIGOLI, A.; CASSANO, A.; CRISCUOLI, A.; MOZUMDER, M. S. I.; UDDIN, M. T.; ISLAM, M.A.; DRIOLI, E. Influence of operating parameters on the arsenic removal bynanofiltration. Water Research, v. 44, p. 97-104, 2010.

FLUES, M.; SATO, I. M.; SCAPIN, M. A.; COTRIM, M. E. B.; CAMARGO, I. M. C. Toxic elements mobility in coal and ashes of Figueira coal power plant, Brazil. Fuel, v.103, p. 430-436, 2013.

FLUES, M.; SATO, I. M.; COTRIM, M. B.; FIGUEIREDO FILHO, P. M.; CAMARGO, I. M. C. Avaliação da influência da operação da termoelétrica a carvão na concentração dos metais e As no solo de Figueira, PR-Brasil. Química Nova, v. 31, p. 25-30, 2008.

FOO, K. Y.; HAMEED, B. H. The environmental applications of activated carbon/zeolite composite materials. Advances in Colloid and Interface Science, v. 162, p. 22-28, 2011.

FUNGARO, D. A.; MAGDALENA, C. P. Counterion effects on the adsorption of acid Orange 8 from aqueous solution onto HDTMA-Modified nanozeolite from fly ash. Environmental and Ecology Research., v. 2, p. 97-106, 2014.

FUNGARO, D. A.; MAGDALENA, C. P., Counterion Effectsonthe Adsorption of Acid Orange 8 from Aqueous Solution onto HDTMA-Modified Nanozeolite from Fly Ash. Environmental and Ecology Research, v. 2, p. 97 - 106, 2014.

FUNGARO, D. A.; YAMAURA, M.; CARVALHO, T. E. M. Adsorption of anionic dyes from aqueous solution on zeolite from fly ash-iron oxide magnetic nanocomposite. International Journal of Molecular Sciences, v. 2, p. 305-316, 2011.

FUNGARO, D. A; YAMAURA, M.; CARVALHO, T. E. M.; GRACIANO, J. E. A. Zeolite from Fly Ash-Iron Oxide Magnetic Nanocomposite: Synthesis and Application as an Adsorbent for Removal of Contaminants from Aqueous Solution. In: ANDREYEV, M. K; ZUBKOV, O. L. (Ed.). Zeolites: Synthesis, Chemistry and Applications. Hauppauge, N.Y.: Nova Science Publishers, 2012

FUNGARO, D. A.; IZIDORO, J. C. Remediação de drenagem ácida de mina usando zeólitas sintetizadas a partir de cinzas leves de carvão. Química Nova, v. 29, p. 735-740, 2006.

FU, F.; WANG, Q. Removal of heavy metal ions from wastewaters: A review. Journal of Environmental Management, v. 92, n. 3, p. 407-418, mar. 2011.

GIANNETTO, G. Zeolitas -caracteristicas, propiedades y aplicacione sindustriales. Caracas: EdIT Editorial Innovación 1990.

GHOBARKAR, H.; SCHAF, O.; GUTH, U. Zeolites-from kitchen to space. Progress in Solid State Chemistry, v. 27, p. 29-73, 1999. 
GISI, S. de; LOFRANO, G.; GRASSI, M.; NOTARNICOLA, M. Characteristics and adsorption capacities of low-cost sorbents for wastewater treatment A review. Sustainable Materials and Technologies. v. 9, p. 10-40, 2016.

GODE, F.; PEHLIVAN, E. Removal of chromium (III) from aqueous solutions using Lewatit $\mathrm{S}$ 100: the effect of $\mathrm{pH}$, time, metal concentration and temperature. Journal of Hazardous Materials, v. 136, p. 330-337, 2006.

GRASSI, M.; KAYKIOGLU, G.; BELGIORNO, V.; LOFRANO, G. Removal of Emerging Contaminants from Water and Wastewater by Adsorption Process. In: LOFRANO, G. Emerging Compounds Removal from Wastewater. Fisciano, University of Salerno, 2012, v.1, p. 15-17.

GUISNET, M.; RIBEIRO, F. R. Zeólitos - um nanomundo ao serviço da catálise. Lisboa: Fundação Calouste Gulbenkian, 2004.

GUPTA, V. K.; CARROTT, P. J. M.; RIBEIRO CARROTT, M. M. L.; SUHAS. Low Cost Adsorbents: Growing Approach to Wastewater Treatment - A Review. Critical Reviews in Environmental Science and Technology, v. 39, p. 783-842, 2009.

GUPTA, V. K.; SUHAS, G. K. V. Application of low-cost adsorbents for dye removal - A review. Journal of Environment Management, v. 90, p. 2313-2342, 2009.

HAGGERLY, G.M.; BOWMAN, R. S. Sorption of chromate and other inorganic anions by organo-zeolite. Environmental Science \& Technology, v. 28, p. 452-458, 1994.

HUISMAN, J. L.; SCHOUTEN, G.; SCHULTZ, C. Biologically produced sulphide for purification of process streams, effluent treatment and recovery of metals in the metal and mining industry. Hydrometallurgy, v. 83, p.106-113, 2006.

IZIDORO, J. C. Estudos sobre a remoção de íons metálicos em água usando zeólitas sintetizadas a partir de cinzas de carvão. 2008. Dissertação (Mestrado) Instituto de Pesquisas Energéticas e Nucleares, São Paulo.

IZIDORO, J. C.; FUNGARO, D. A.; SANTOS, F. S.; WANG, S. Characteristics of Brazilian coal fly ashes and their synthesized zeolites. Fuel Processing Technology, v. 97, p. 3844, 2012.

IZIDORO, J. C.; MIRANDA, C. da S.; GUILHEN, S. N.; FUNGARO, D. A., WANG, S. Treatment of coal ash landfill leachate using zeolitic materials from coal combustion byproducts. Advanced Materials and Technologies for Environmental Sciences, v. 2, p.177-186, 2018

JHA, B.; SINGH, D. N. A review on synthesis, characterization and industrial applications of fly ash zeolites. Journal of Materials Education, v. 33, p. 65-132, 2011.

JACHUŁA, J.; HUBICKI, Z. Removal of $\mathrm{Cr}(\mathrm{VI})$ and $\mathrm{As}(\mathrm{V})$ ions from aqueous solutions by polyacrylate and polystyrene anion exchange resins. Applied Water Science, v. 3, p. 653-664, 2013.

KANG, S.Y.; LEE, J.U.; MOON, S.H.; KIM, K.W. Competitive adsorption characteristics of $\mathrm{Co}^{2+}, \mathrm{Ni}^{2+}$, and $\mathrm{Cr}^{3+}$ by IRN-77 cation exchange resin in synthesized wastewater. Chemosphere. v. 56, p. 141-147, 2004. 
KIM, S. A.; KAMALA-KANNAN, S.; OH, S.; CHO, M.; BAE, S. Simultaneous removal of chromium (VI) and Reactive Black 5 using zeolite supported nano-scale zero-valent iron composite. Environment Earth Science, v. 75, p. 447, 2016.

KIM, K.; PARK, S. M.; KIM, J.; KIM, S. H.; MOON, J. H. G. C. W. Arsenic concentration in porewater of an alkaline coal ash disposal site: roles of siderite precipitation/dissolution and soil cover. Chemosphere, v. 77, p. 222-227, 2009.

KIMBROUGH, D. U., COHEN, Y., WINER, A. M., CREELMAN, L., MABUNI, C. A Critical Assessment of Chromium in the Environment Critical Reviews in Environmental Science and Technolog. Environmental Science and Technology, v. 29, p.1-46, 1999.

KOSHY, N.; SINGH, D. N. Fly ash zeolites for water treatment applications. Journal of Environmental Chemical Engineering, v. 4, p. 1460-1472, 2016

KURNIAWAN, T.A.; CHAN, G. Y. S.; LO, W. H.; BABEL, S. Physico-chemical treatment techniques for wastewater laden with heavy metals. Chemical Engineering Journal, $v$. 118, p. 83-98. 2006.

LACERDA, L. V. Síntese e caracterização de zeólita tipo sodalita obtida a partir de cinzas volantes de carvão mineral utilizando na usina termoelétrica de Candiota-RS. 2015. Dissertação (Mestrado) - Universidade Federal do Rio Grande do Sul, Porto Alegre.

LANGE, C. N. Contaminação do solo e mobilidade de As, $\mathrm{Cd}, \mathrm{Mo}, \mathrm{Pb}$ e $\mathrm{Zn}$ em colunas de solo franco arenoso com cinza de carvão. 2012. Dissertação (Mestrado) Instituto de Pesquisas Energéticas e Nucleares, São Paulo. Disponível em: <http://www.teses.usp.br>. Acesso em: 20 out. 2018

LEUNG, W.C.; WONG, M. F.; CHUA, H.; LO, W.; LEUNG, C.K. Removal and recovery of heavy metals by bacteria isolated from activated sludge treating industrial effluents and municipal wastewater. Water Science Technology, v. 41, p. 233-240. 2000.

LIMA, A. J. C. de. Desativação e regeneração de catalisadores zeolíticos (HY e HZSM-5) utilizados em craqueamento catalítico fuidizado -FCC 2015. Dissertação (Mestrado) Universidade Federal do Rio Grande do Norte, Natal.

LI, Z.; BOWMAN, R. Counterion effects on the sorption of cationic surfactant and chromate on natural clinoptilolite. Environment. Science Technology, p. 31, p. 2407-2412, 1997.

$\mathrm{LI}$, Z. Influence of solution $\mathrm{pH}$ and ionic strength on chromate uptake by surfactantmodified zeolite. Journal Environment Engineering, v. 130, p. 205-208, 2004.

LIU, F. N.; ZHANG, G. L.; MENG, Q.; ZHANG, H.Z. Performance of nanofiltrationand reverse osmosis membranes in metal effluent treatment. Chinese Journal of Chemical Engineering, v. 16, p. 441-445, 2008.

OJHA, K.; PRADHAN, N. C.; SAMANTA, A. M. Zeolite from fly ash: synthesis and characterization. Bulletin of Materials Science, v. 27, p. 555-564, 2004. 
MAGDALENA, C. P. Síntese de zeólitas de cinzas de carvão modificada por surfactante e aplicação na remoção de ácido laranja 8 de solução aquosa: estudo em leito móvel, coluna de leito fixo e avaliação ecotoxicológica. 2015. Tese (Doutorado) Instituto de Pesquisas Energéticas e Nucleares, São Paulo. Disponível em: <http://www.teses.usp.br>. Acesso em: 20 out. 2018

MANISSAO, N. Ambientes micelares em química analítica. Química Nova, v. 24, p. 87-93 2001

MASCARENHAS, A. J. S.; OLIVEIRA, E. C.; PASTORE, H. O. Peneiras Moleculares: Selecionando as Moléculas por seu Tamanho. Química Nova, v. 2, p. 25-34, 2001. Disponível em: < http://qnesc.sbq.org.br/online/cadernos/02/peneiras.pdf> Acesso em: 07 de Agosto de 2018.

MAINGANYE, D.; OJUMU, T. V.; PETRIK, L. Synthesis of Zeolites Na-P1 from South African Coal Fly Ash: Effect of Impeller Design and Agitation. Materials, v. 6, p. 20742089, 2013.

MARTINEZ-BRAVO, Y. M.; ROIG-NAVARRO, A. F.; LOPEZ, F. J.; HERNANDEZ, F. Multielemental determination of arsenic, selenium and chromium( $(\mathrm{VI})$ species in water by high-performance liquid chromatography-inductively coupled plasma mass spectrometry. Journal of Chromatography A, v. 926, p. 265-274, 2001.

MARUI, Y.; RYOUSUKE, I.; HIROSHI, T.; HIROHISA, U. Analysis of nucleation of zeolite A from clear solutions. Journal of Crystal Growth, v. 237-239, p. 2148-2152, abr. 2002.

MARCHUCK, G.I. MATHEMATICALS Models in Environmental Problems, Studies in Mathematics and its Applications, North Holland, Elsevier Science Publishers, v. 16, p. 217, 1986.

MASTERS, A. F; MASCHMEYER, T. Zeolites - From curiosity to cornerstone. Microporous Mesoporous Materials, v. 142, p. 423-438, 2011.

MEYBECK, M. HELMER, R. An introduction to water quality. in: CHAPMAN, D. Water quality assessment. Cambridge University Press. p. 585. 1992.

MIRETZKY, P.; CIRELLI, A. F. $\mathrm{Cr}(\mathrm{VI})$ and $\mathrm{Cr}(\mathrm{III})$ removal from aqueous solution by raw and modified lignocellulosic materials: A review. Journal of Hazardous Materials, v. 180, p. 1-19, 2010.

MORENO, N.; QUEROL, X.; CARLES, A. Utilization of zeolites synthesized from coal fly ash for the purification of AMDs. Environmental Science \& Technology, v. 35, p. 35263534, 2001.

MORIYAMA, R.; TAKEDA, S.; ONOZAKI, M.; KATAYAMA, Y.; SHIOTA, K.; FUKUDA, T.; SUGIHARA, H.; TANI, Y. Large-scale synthesis of artificial zeolite from coal fly ash with a small charge of alkaline solution. Fuel, v. 84, p. 1455-1461, 2005.

MOHAMMADI, T.; RAZMI, A.; SADRZADEH, M. Effect of operating parameters on $\mathrm{Pb}$ separation from wastewater using electrodialysis. Desalination, v. 167, p. 379-385, 2004.

MURTHY, Z. V. P.; CHAUDHARI, L. B.; Application of nanofiltration for the rejection of nickel ions from aqueous solutions and estimation of membrane transport parameters. Journal of Hazardous Materials, v.160, p. 70-77, 2008. 
MUTHUKRISHNAN, M.; GUHA, B. K. Effect of $\mathrm{pH}$ on rejection of hexavalentchromium by nanofiltration. Desalination, v. 219, p. 171-178, 2008.

NATARAJ, S. K.; HOSAMANI, K.M.; AMINABHAVI, T. M. Potential application of an electrodialysis pilot plant containing ion-exchange membranes in chromium removal. Desalination, v. 217, p. 181-190, 2007.

NGUYEN, C. M.; BANG, S.; CHO, J.; KIM, K.W. Performance and mechanism of arsenic removal from water by a nanofiltration membrane. Desalination, v. 245, p. 82-94, 2009.

OLIVEIRA, E. A. de. Estudo do potencial de utilização da biomassa de Luffa cylindrica na descontaminação de efluentes contendo íons metálicos e corantes têxteis. 2007. Tese (Doutorado) Universidade Estadual de Maringá, Maringá.

OLIVEIRA, T. F. de. Tratamento de água para abastecimento público por sistema de separação por membrana de ultrafiltração: estudo de caso na ETA alto da Boa Vista (São Paulo, SP). 2010. Dissertação (Mestrado) Escola Politecnica da Universidade de São Paulo, São Paulo.

POOLE, C.; PRIJATAMA, H.; RICE, N. M. Synthesis of zeolite adsorbents by hydrothermal treatment of PFA wastes: a comparative study. Minerals Engineering. $v$. 13, p. 831-842, 2000.

PAGANA, A. E.; SKLARI, S. D.; KIKKINIDES, E. S.; ZASPALIS, V. T. Microporous ceramic membrane technology for the removal of arsenic and chromium ions from contaminated water. Microporous and Mesoporous Materials, v. 110, p. 150-156. 2008.

PANDEY, V. C.; SINGH, J. S.; SINGH, R. P.; SINGH, N. S.; YUNUS, M. Arsenic hazards in coal fly ash and its fate in Indian scenario. Resources, Conservation and Recycling v. 55, p. 819-835, 2011.

PANTSAR-KALLIO, M.; MANNINEN, P. K. G. Simultaneous determination of toxic arsenic and chromium species in water samples by ion chromatography-inductively coupled plasma mass spectrometry. Journal of Chromatography, v. 779, p. 139-146, 1997.

PILLEWAN, P.; MUKHERJEE, S.; MEHER, A. K.; RAYALU, S., BANSIWAL, A. Removal of arsenic (III) and arsenic (V) using copper exchange zeolite-a. Environmental Progress \& Sustainable Energy, v. 33, p. 1274-1282. 2004.

PINO, G. A. H. Biossorção de Metais Pesados Utilizando Pó da Casca de Coco Verde (Cocos nucifera) 2005. Dissertação (Mestrado) Pontifícia Universidade Católica do Rio de Janeiro, Rio de Janeiro.

POOLE, C.; PRIJATAMA, H.; RICE, N. M. Synthesis of zeolite adsorbents by hydrothermal treatment of PFA wastes: a comparative study. Minerals Engineering. $v$. 13, p. 831-842, 2000.

PRASAD, B.; MORTIMER, R. J. "Treatment of acid mine drainage using fly ash zeolite." Water Air and Soil Pollution, v. 218, p. 667-679,2011.

QIU, W.; ZHENG, Y. Arsenate removal from water by an alumina-modified zeolite recovered from fly ash. Journal of Hazardous Materials, v.148, p.721-726, 2007. 
QUEROL, X.; PLANA, F.; ALASTUEY, A.; LÓPEZ-SOLER, A. Synthesis of Na-zeolites from fly ash. Fuel, v.76, p. $793-799,1997$.

QUEROL, X.; MORENO, N.; UMANÃ, J. C.; ALASTUEY, A.; HERNANDÉZ, E.; LÓPEZSOLER, A.; PLANA, F. Synthesis of zeolites from coal fly ash: an overview. International Journal Coal Geology, v.50, p. 413-423, 2002.

QUISPE, D.; PEREZ-LOPEZ, R.; SILVA, L. F.; NIETO, J. M. Changes in mobility of hazardous elements during coal combustion in Santa Catarina power plant (Brazil). Fuel, v. 94, p. 495-503, 2012.

RAI, D.; EARY, L. E.; ZACHARA, J. M. Environmental chemistry of chromium. Science of the Total Environment, v. 86, p. 15-23, 1989.

ROVANI, S. Preparo e caracterização de carvão e carvão ativado a partir de resíduos agroindustriais e aplicação na remoção de estrogênios. 2015. Tese (Doutorado) Universidade Federal do Rio Grande do Sul, Porto Alegre.

ROZIC, M.; SIPUSIC, D. I.; SEKOVANIC, L.; MILJANIC, S.; CURKOVIC, L.; HRENOVIC, J. Sorption phenomena of modification of clinoptilolite tuffs by surfactant cations. Colloid Interface Science, v. 331, p. 295-301, 2009.

SCHUMI, R.; KRIEG, H. M.; KEIZER, K. Adsorption of $\mathrm{Cu}(\mathrm{II})$ and $\mathrm{Cr}(\mathrm{VI})$ ions by chitosan: kinetics and equilibrium, Water SA v. 27, p. 1-7, 2001.

SEMERJIAN, L.; AYOUB, G. M. High-pH-magnesium coagulation-flocculation in wastewater treatment, Advances in Environmental Research, v. 7, p. 389- 403, 2003.

SILVA, C. J. Mobilidade de As, Cd, Mo, $\mathrm{Pb}$ e $\mathrm{Zn}$ em colunas de latossolo argiloso com cinza de carvão e Contaminação do solo. 2013. Dissertação (Mestrado) Instituto de Pesquisas Energéticas e Nucleares, São Paulo.

SMART, L.; MOORE, E. Solid State Chemistry: An introduction. Chapman \& Hall: London, 1992.

SMEDLEY, P. L; KINNIBURGH, D. G. A review of the source, behaviour and distribution of arsenic in natural waters. Applied Geochemistry, v. 17, p. 517-568, 2002.

SMITH, A. H.; STEINMAUS, C. M. Health Effects of Arsenic and Chromium in Drinking Water: Recent Human Findings. Public Health, v. 30, p. 107- 122, 2009.

SHAHALAM, A. M.; AL-HARTHY, A.; AL-ZAWHRY, A. Feed water pretreatment in RO systems in the Middle East. Desalination, v. 150, p. 235-245, 2002.

SHAMMAS, N. K. Coagulation and flocculation, in: Wang, L. K.; Hung, Y. T.; Shammas, N. K. (Eds.), Physicochemical Treatment Processes, Humana Press, New Jersey, vol. 3, p. $103-140,2004$

SHEVADE, S; FORD, R. G. Use of synthetic zeolites for arsenate removal from pollutant water. Water Research, v. 38, p. 3197-3204, 2004.

SHUPACK, S. I. The chemistry of chromium and some resulting analytical problems. Environmental Health Perspectives, v. 92, p. 7-11, 1991. 
STUMM, W. Chemistry of the Solid-Water Interface, John Wiley \& Sons, New York, 1992.

SULLIVAN, E. J.; HUNTER,D. B.; BOWMAN, R. S. Topological and thermal properties of surfactant-modified clinoptilolite studied by tapping-mode atomic force microscopy and high-resolution thermogravimetric analysis. Clays and Clay Mines, v. 45, p. 42-53, 1997.

SWARNKAR, V.; AGRAWAL, N.; TOMAR, R. "Sorption of $\operatorname{Cr}(V I) \& A s(V)$ on HDTMAModified Zeolite," International Journal of Scientific \& Engineering Research, v. 2, p. 1. 2011. Disponivel em: <https://www.ijser.org/paper/Sorption_of_Cr_HDTMAModified_Zeolites.html> Acessado em: 18 de Agosto de 2018

TRIVUNAC, K.; STEVANOVIC, S. Removal of heavy metal ions from water by complexation-assisted ultrafiltration. Chemosphere, v. 64, p. 486-491, 2006.

USPHS- United States Public Health Service. Toxicological profile. Agency for Toxic Substances and Disease Registry; EUA, 2000.

USPHS- United States Public Health Service. 9th Report on Carcinogens, National Toxicology Program, EUA, 2001.

WENG, C. H.; HUANG, C. P.; ALLEN, H. E.; SANDERS, P. F. Cr(VI) Adsorption onto hydrous concrete particles from groundwater, Journal Environment Engineering, v. 127, p. 1124-1131, 2001.

WENG, C. H.; SHARMA, Y.C.; CHU, S. H. Adsorption of $\mathrm{Cr}(\mathrm{VI})$ from aqueous solutions by spent activated clay. Journal of Hazardous Materials, v. 155, p. 65-75, 2008.

WESTHOLM, L. J.; REPO, E.; SILLANPÄÄ, M. Filter materials for metal removal from minedrainage-a review. Environmental Science and Pollution Research, v. 21, p.9109-9128, 2014.

YAN, X. P.; KERRICH, R.; HENDRY, M. J. Distribution of arsenic(III), arsenic(V) and total inorganic arsenic in porewaters from a thick till and clay-rich aquitard sequence, Saskatchewan, Canada. Geochimica et Cosmochimica Acta, v. 64, p. 2637-2648, 2000.

YUSOF, A. M.; MALEK, N. A. Removal of $\mathrm{Cr}(\mathrm{VI})$ and $\mathrm{As}(\mathrm{V})$ from aqueous solutions by HDTMA-modified zeolite Y. Journal Hazard Mater.15: v.162, p. 1019-1024, 2009.

YUAN, P.; FAN, M. D.; YANG, D.; HE, H.P.; LIU, D.; YUAN, A.H.; ZHUA, J.X.; CHEN, T.H. Montmorillonite-supported magnetite nanoparticles for the removal of hexavalent chromium $[\mathrm{Cr}(\mathrm{VI})]$ from aqueous solutions. Journal of Hazardous Materials, v.166, $p$. 821-829, 2009.

YUAN, P.; LIU, D.; FAN, M. D.; YANG, D.; ZHU, R. L.; GE, F.; ZHU, J.X.; HE, H. P. Removal of hexavalent chromium $[\mathrm{Cr}(\mathrm{VI})]$ from aqueous solutions by the diatomite supported/unsupported magnetite nanoparticles. Journal of Hazardous Materials, v. 173, p. 614-621, 2010.

ZAMZOW, M. J.; EICHBAUM, B. R.; SANDGREN, K. R.; SHANKS, D. E. Removal of heavy metals and other cations from wastewater using zeolites, Separation Science and Technology , v. 25, p. 1555-1569, 1990. 
ZUIM, D. R. Estudo da adsorção de componentes do aroma de café (benzaldeído e ácido acético) perdidos durante o processo de produção do café solúvel. 2010. Dissertação (Mestrado) Universidade Federal do Paraná, Curitiba. 


\section{APÊNDICES}

APÊNDICE A- Características físico-químicas das cinzas manga, ciclone e pesada.

Tabela 1 - Composição química das amostras de cinzas de carvão (\% em massa)

\begin{tabular}{|c|c|c|c|}
\hline Componentes & $\overline{C P}$ & $\overline{C C}$ & CM \\
\hline $\mathrm{SiO}_{2}$ & 45,4 & 46,0 & 49,2 \\
\hline $\mathrm{Al}_{2} \mathrm{O}_{3}$ & 17,0 & 16,2 & 21,6 \\
\hline $\mathrm{Fe}_{2} \mathrm{O}_{3}$ & 10,2 & 13,2 & 9,86 \\
\hline $\mathrm{CaO}$ & 2,76 & 3,57 & 2,06 \\
\hline $\mathrm{K}_{2} \mathrm{O}$ & 2,46 & 2,20 & 2,74 \\
\hline $\mathrm{SO}_{3}$ & 1,46 & 1,54 & 1,65 \\
\hline $\mathrm{TiO}_{2}$ & 0,863 & 0,86 & 1,20 \\
\hline $\mathrm{MgO}$ & 0,936 & 0,848 & 1,02 \\
\hline $\mathrm{Na}_{2} \mathrm{O}$ & 0,942 & 1,01 & 1,23 \\
\hline $\mathrm{ZnO}$ & 0,136 & 0,222 & 0,682 \\
\hline $\mathrm{MnO}$ & 0,084 & 0,099 & 0,061 \\
\hline $\mathrm{P}_{2} \mathrm{O}_{5}$ & 0,039 & $<0,001$ & 0,097 \\
\hline $\mathrm{Cr}_{2} \mathrm{O}_{3}$ & 0,055 & 0,062 & 0,048 \\
\hline $\mathrm{PbO}$ & $<0,001$ & 0,02 & 0,049 \\
\hline $\mathrm{As}_{2} \mathrm{O}_{3}$ & 0,026 & 0,034 & 0,16 \\
\hline $\mathrm{ZrO}_{2}$ & 0,063 & 0,067 & 0,099 \\
\hline $\mathrm{Rb}_{2} \mathrm{O}$ & 0,012 & 0,011 & 0,014 \\
\hline $\mathrm{SrO}$ & 0,02 & 0,022 & 0,029 \\
\hline $\mathrm{NiO}$ & $<0,001$ & 0,009 & 0,011 \\
\hline $\mathrm{CuO}$ & 0,012 & 0,015 & 0,022 \\
\hline $\mathrm{Y}_{2} \mathrm{O}_{3}$ & 0,016 & $<0,001$ & 0,028 \\
\hline $\mathrm{V}_{2} \mathrm{O}_{5}$ & 0,06 & 0,053 & 0,082 \\
\hline $\mathrm{MoO}_{3}$ & 0,014 & 0,016 & 0,03 \\
\hline $\mathrm{BaO}$ & 0,038 & $<0,001$ & $<0,001$ \\
\hline $\mathrm{SiO}_{2} / \mathrm{Al}_{2} \mathrm{O}_{3}$ & 2,47 & 2,57 & 2,19 \\
\hline
\end{tabular}

Fonte: autor da dissertação 
Tabela 2 - Carbono total presente nas amostras de cinzas de carvão (\% em massa)

\begin{tabular}{cc}
\hline Amostras & $\mathbf{C}(\%)$ \\
\hline CP & 26,83 \\
CC & 15,72 \\
CM & 3,05 \\
\hline
\end{tabular}

Fonte: autor da dissertação

Tabela 3 - Características físicas e químicas das cinzas de carvão gerados na UTFG

\begin{tabular}{cccccccc}
\hline Amostra & pH & $\mathbf{C}(\boldsymbol{\mu S})$ & $\begin{array}{c}\text { P. por } \\
\text { Calcinação } \\
(\%)\end{array}$ & $\begin{array}{c}\text { D. } \\
\text { Aparente } \\
\left(\mathbf{g ~ c m}^{-3}\right)\end{array}$ & $\begin{array}{c}\text { BET } \\
\left(\mathbf{m}^{2} \mathbf{~}^{-1}\right)\end{array}$ & $\begin{array}{c}\text { Área S. } \\
\text { Externa } \\
\left(\mathbf{m}^{2} \mathbf{g}^{-1}\right)\end{array}$ & $\begin{array}{c}\text { CTC } \\
\left(\mathbf{m e q} \mathbf{~}^{-1}\right)\end{array}$ \\
\hline $\mathbf{C P}$ & 7,56 & 121,0 & 17,4 & 0,6 & 13,5 & 0,188 & 0,05 \\
$\mathbf{C C}$ & 7,58 & 138,0 & 13,9 & 0,8 & 11,5 & 0,234 & 0,07 \\
$\mathbf{C M}$ & 7,56 & 183,0 & 8,00 & 0,8 & 8,4 & 1,35 & 0,16 \\
\hline
\end{tabular}

Fonte: autor da dissertação

Tabela 4 - Concentração dos elementos lixiviados a partir das cinzas e os valores máximos permitidos

\begin{tabular}{ccccc}
\hline $\begin{array}{c}\text { Espécie } \\
\text { Química }\end{array}$ & $\mathbf{C P}$ & $\mathbf{C C}$ & $\mathbf{C M}$ & LMP $^{*}\left(\mathbf{m g ~ L}^{-1}\right)$ \\
& $<0,010$ & $<0,010$ & $<0,010$ & 5,0 \\
$\mathrm{Ag}$ & $0,086 \pm 0,001$ & $0,111 \pm 0,002$ & $1,27 \pm 0,2$ & 1,0 \\
$\mathrm{As}$ & $0,236 \pm 0,001$ & $0,161 \pm 0,001$ & $0,0269 \pm$ & 70 \\
$\mathrm{Ba}$ & $0,0266 \pm 0,0002$ & $0,031 \pm 0,001$ & $0,2731 \pm$ & 0,5 \\
$\mathrm{Cd}$ & $<0,01$ & $0,014 \pm 0,001$ & $0,039 \pm 0,0004$ & 5,0 \\
$\mathrm{Cr}$ & $<0,001$ & $<0,001$ & $<0,001$ & 0,1 \\
$\mathrm{Hg}$ & $0,0527 \pm 0,0003$ & $0,0527 \pm 0,0003$ & $0,047 \pm 0,002$ & 1,0 \\
$\mathrm{~Pb}$ & $0,107 \pm 0,01$ & $0,13 \pm 0,2$ & $0,138 \pm 0,002$ & 1,0 \\
$\mathrm{Se}$ & & & 0,0001 & \\
\hline
\end{tabular}

(*) LML= Limite máximo no lixiviado segundo - NBR 10004 (ABNT, 2004a).

Fonte: autor da dissertação 
Tabela 5 - Concentração dos elementos solubilizados a partir das cinzas e os valores máximos permitidos

\begin{tabular}{|c|c|c|c|c|}
\hline \multirow{2}{*}{$\begin{array}{l}\text { Espécie } \\
\text { Química }\end{array}$} & \multicolumn{3}{|c|}{ Concentração (mg L-1) } & \multirow{2}{*}{$\operatorname{LMP}^{\star}\left(\mathrm{mg} \mathrm{L}^{-1}\right)$} \\
\hline & $\mathrm{CP}$ & CC & CM & \\
\hline $\mathrm{Ag}$ & $<0,010$ & $<0,010$ & $<0,010$ & 0,05 \\
\hline Al & $3,4 \pm 0,04$ & $0,79 \pm 0,05$ & $0,27 \pm 0,01$ & 0,2 \\
\hline As & $9,95 \pm 0,2$ & $0,17 \pm 0,01$ & $0,7 \pm 0,03$ & 0,01 \\
\hline $\mathrm{Ba}$ & $0,038 \pm 0,001$ & $0,15 \pm 0,01$ & $0,022 \pm 0,001$ & 0,7 \\
\hline $\mathrm{Cd}$ & $<0,01$ & $<0,01$ & $<0,01$ & 0,005 \\
\hline $\mathrm{Cr}$ & $0,36 \pm 0,01$ & $<0,01$ & $0,042 \pm 0,003$ & 0,05 \\
\hline $\mathrm{Cu}$ & $<0,05$ & $0,074 \pm 0,005$ & $<0,05$ & 2 \\
\hline $\mathrm{Fe}$ & $0,376 \pm 0,005$ & $0,31 \pm 0,06$ & $<0,1$ & 0,3 \\
\hline $\mathrm{Hg}$ & $<0,001$ & $<0,001$ & $<0,001$ & 0,001 \\
\hline $\mathrm{Mn}$ & $0,013 \pm 0,001$ & $0,027 \pm 0,008$ & $<0,01$ & 0,1 \\
\hline $\mathrm{Na}$ & $190,5 \pm 0,2$ & $92 \pm 2$ & $77 \pm 3$ & 200 \\
\hline $\mathrm{Pb}$ & $<0,1$ & $<0,1$ & $<0,1$ & 0,01 \\
\hline $\mathrm{Se}$ & $0,43 \pm 0,03$ & $0,045 \pm 0,001$ & $0,039 \pm 0,001$ & 0,01 \\
\hline $\mathrm{Zn}$ & $0,093 \pm 0,003$ & $0,21 \pm 0,001$ & $<0,01$ & 5 \\
\hline
\end{tabular}

$\left(^{\star}\right)$ LML= Limite máximo no solubilizado segundo - NBR 10004 (ABNT, 2004b). Fonte: autor da dissertação 
Tabela 6 - Resumo da classificação dos resíduos da combustão do carvão segundo a NBR 10005 e 10006 (ABNT, 2004a;ABNT, 2004b).

\begin{tabular}{ccc}
\hline Amostra & Estudo de Lixiviação & Estudo de Solubilização \\
\hline $\mathrm{CP}$ & Classe II - Não Perigosa & Não Inerte - Classe II A \\
$\mathrm{CC}$ & Classe II - Não Perigosa & Não Inerte - Classe II A \\
CM & Classe I - Perigosa & - \\
\hline
\end{tabular}

Fonte: autor da dissertação

Figura 1 - Espectros de infravermelho das amostras de cinzas de carvão

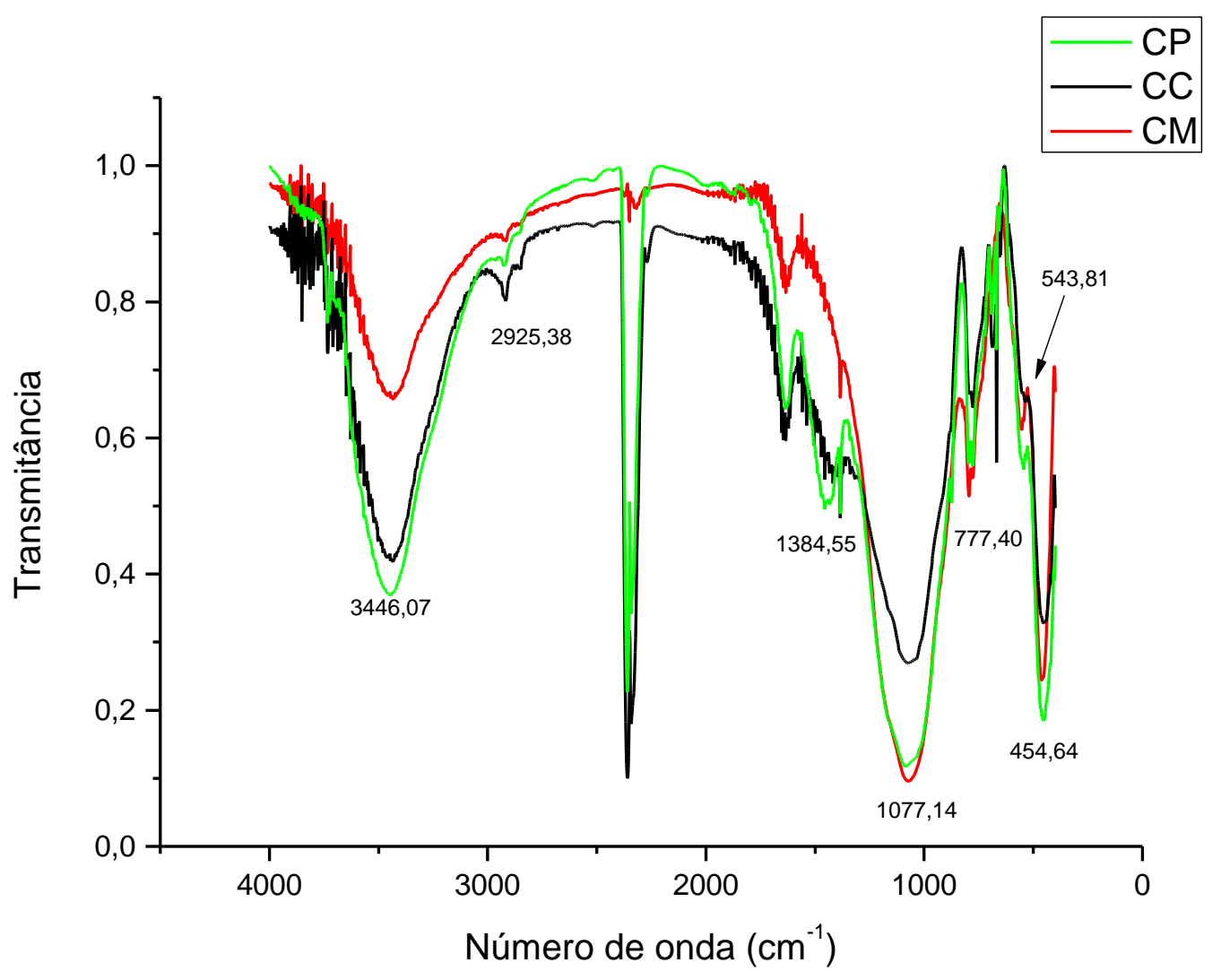

Fonte: autor da dissertação 
FIGURA 2 - Curva TGA-DTG para a amostra de cinza pesada (CP)

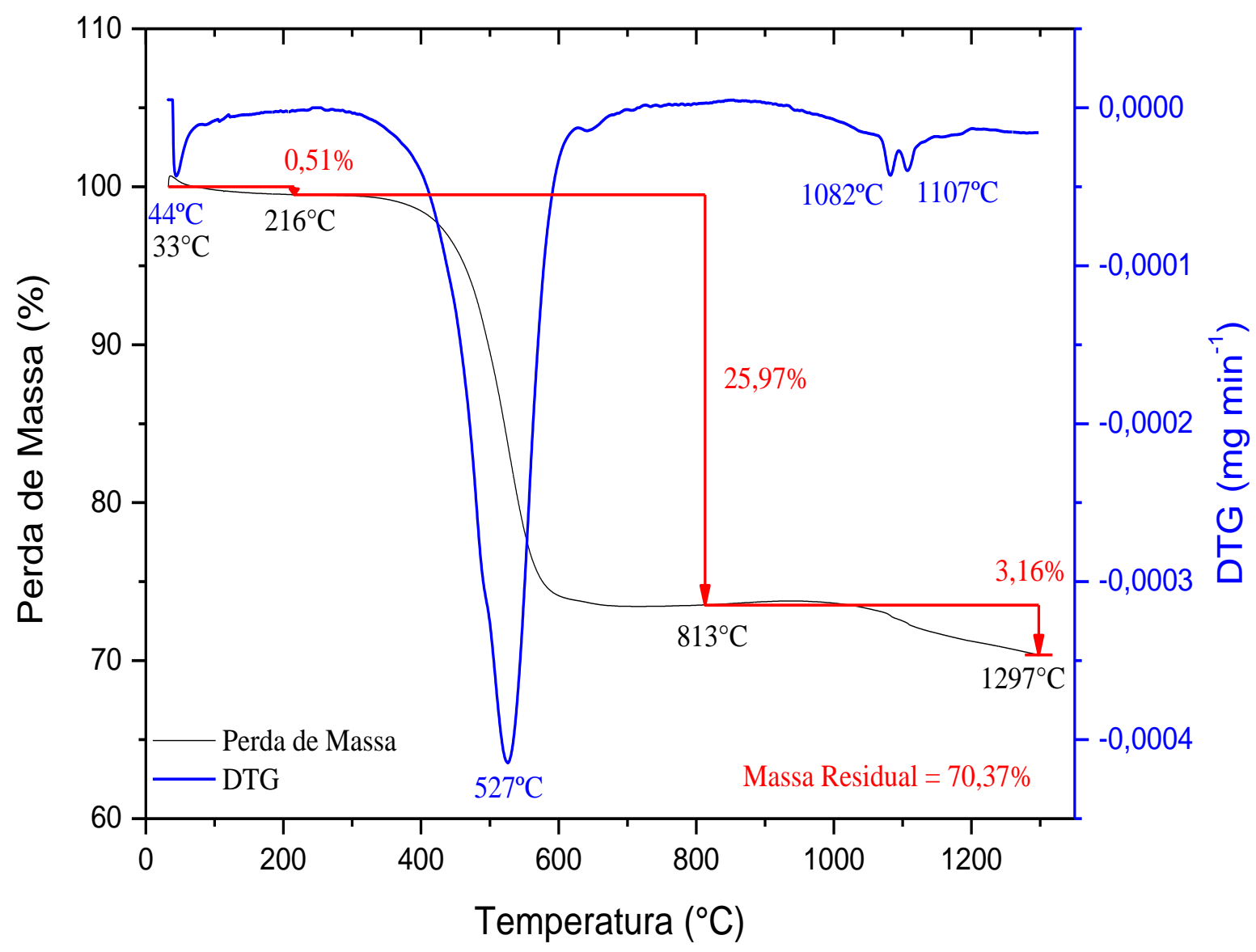

Fonte: autor da dissertação 
Figura 3 - Curva TGA-DTG para a amostra de cinza ciclone (CC)

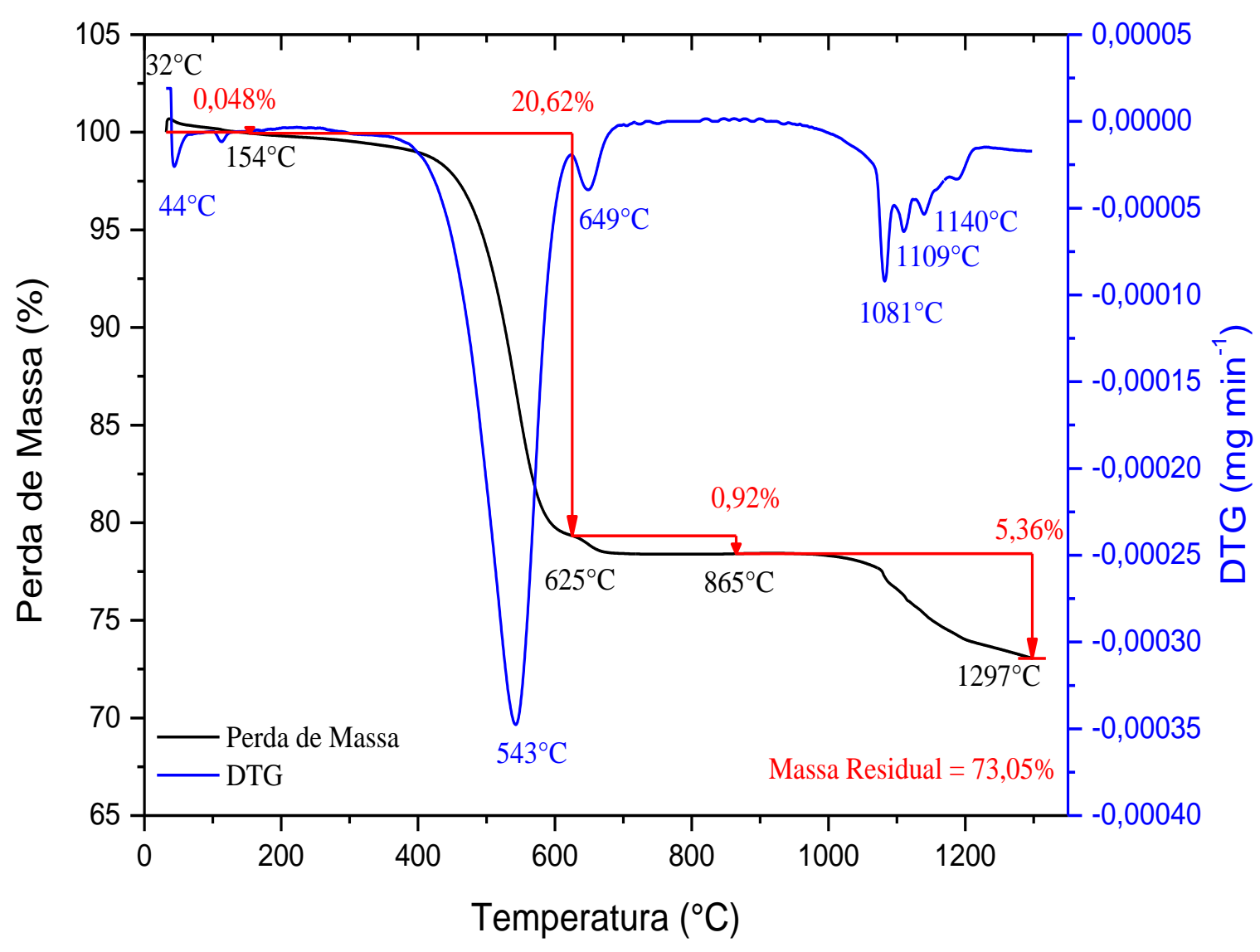

Fonte: autor da dissertação 
Figura 4 - Curva TGA-DTG para a amostra de cinza manga (CM)

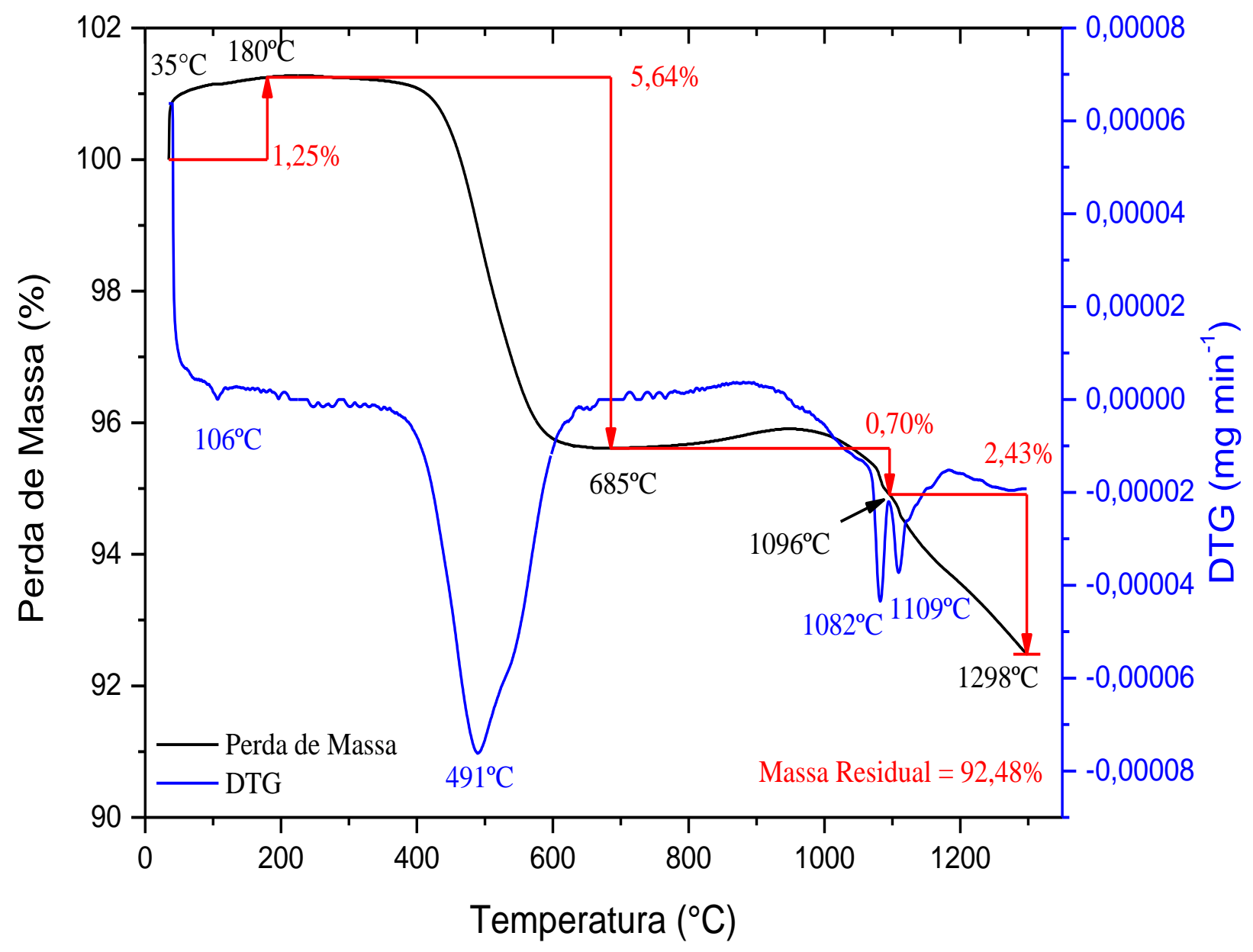

Fonte: autor da dissertação 
APÊNDICE B- Morfologia das cinzas manga, ciclone e pesada.

Figura 1 - Micrografia das amostras de cinzas de carvão obtidas por microscopia eletrônica de varredura (MEV). a) CP; b) CC; c) CM

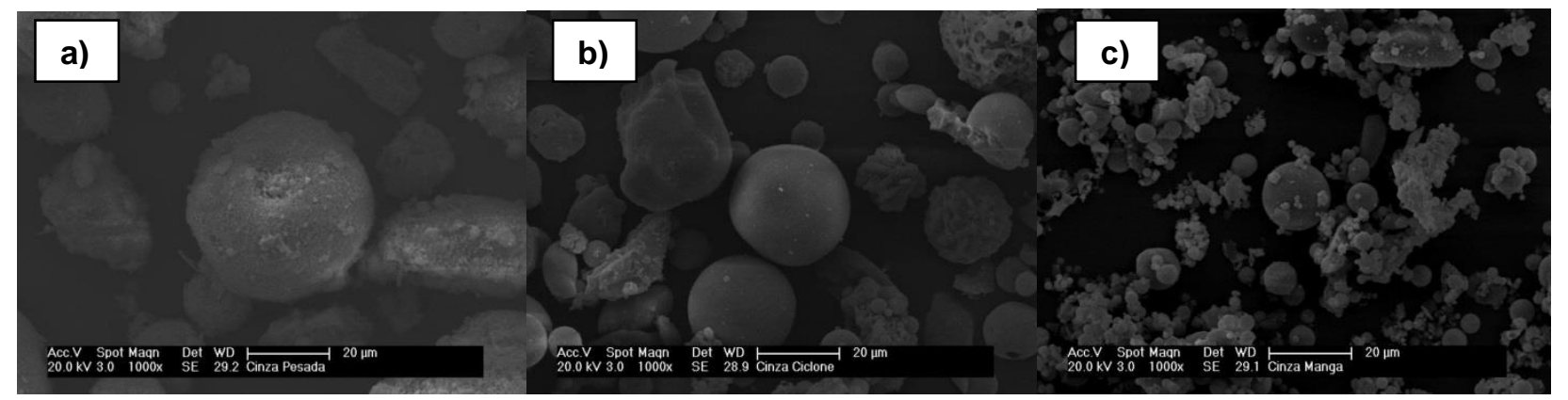

Fonte: autor da dissertação

APÊNDICE C- Composição mineralógica das cinzas manga, ciclone e pesada.

Figura 1- Difratogramas das amostras de cinzas de carvão ( $Q$ = Quartzo, $M u=$ Mulita e $\mathrm{Ma}=$ Magnetita)

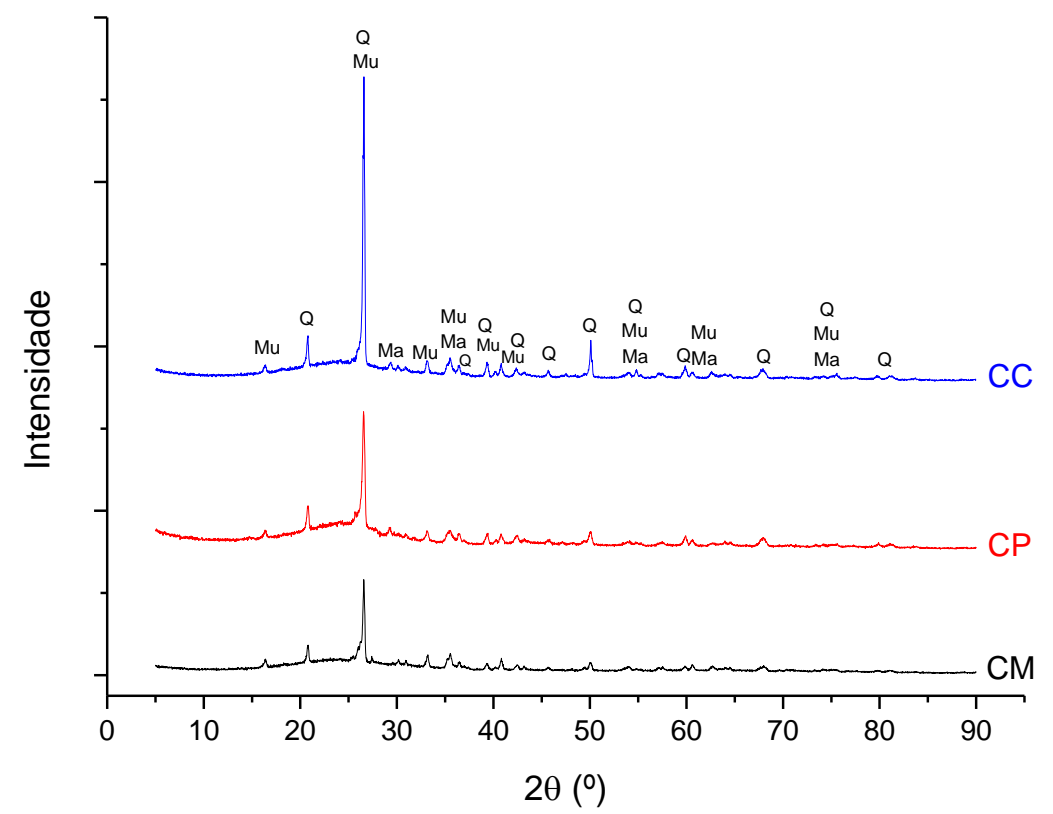

Fonte: autor da dissertação 
APÊNDICE D- Distribuição granulométrica das cinzas manga, ciclone e pesada.

Figura 1 - Curva de distribuição granulométrica da amostra de cinza pesada (CP)

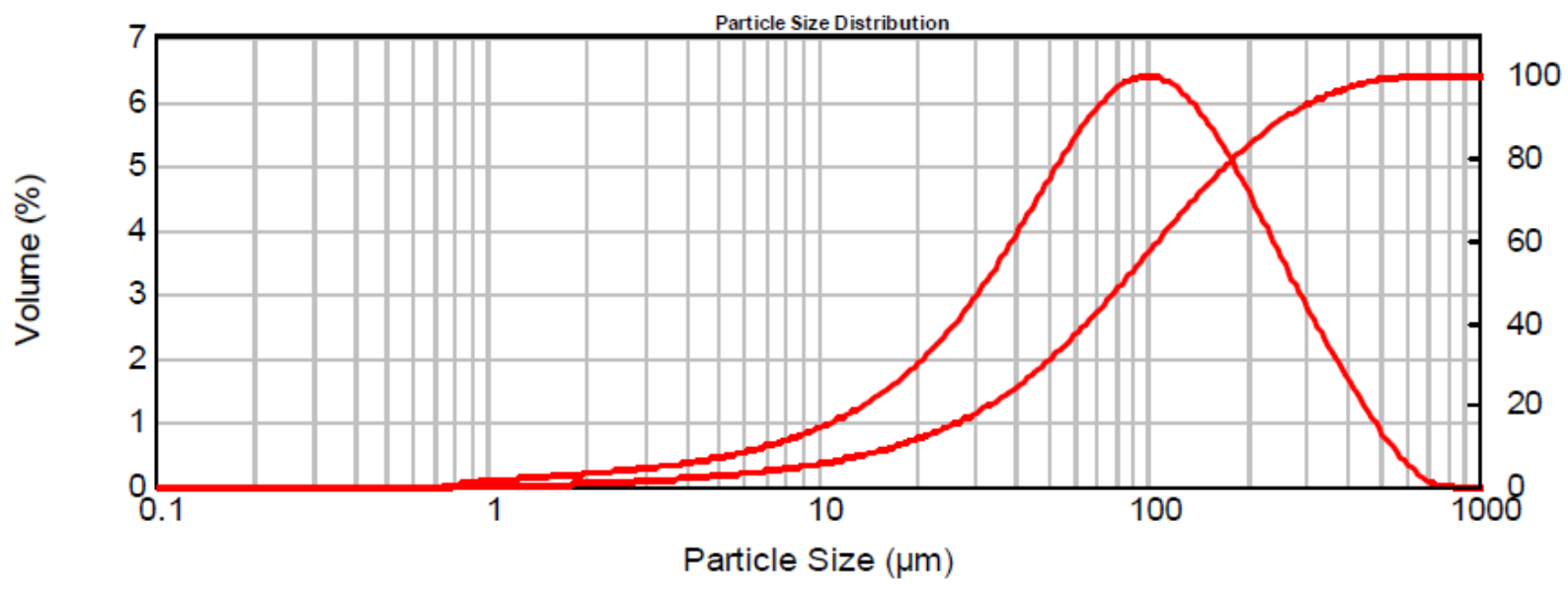

Fonte: autor da dissertação

Figura 2 - Curva de distribuição granulométrica da amostra de cinza ciclone (CC)

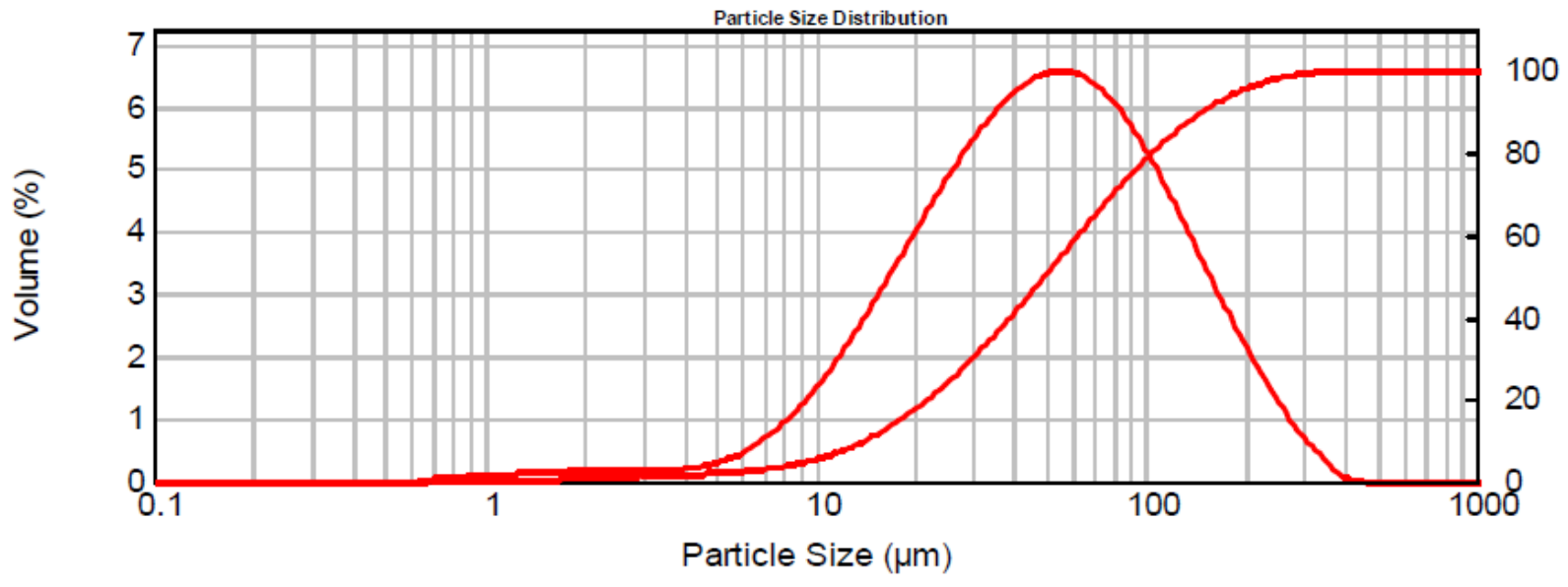

Fonte: autor da dissertação 
Figura 3 - Curva de distribuição granulométrica da amostra de cinza manga (CM)

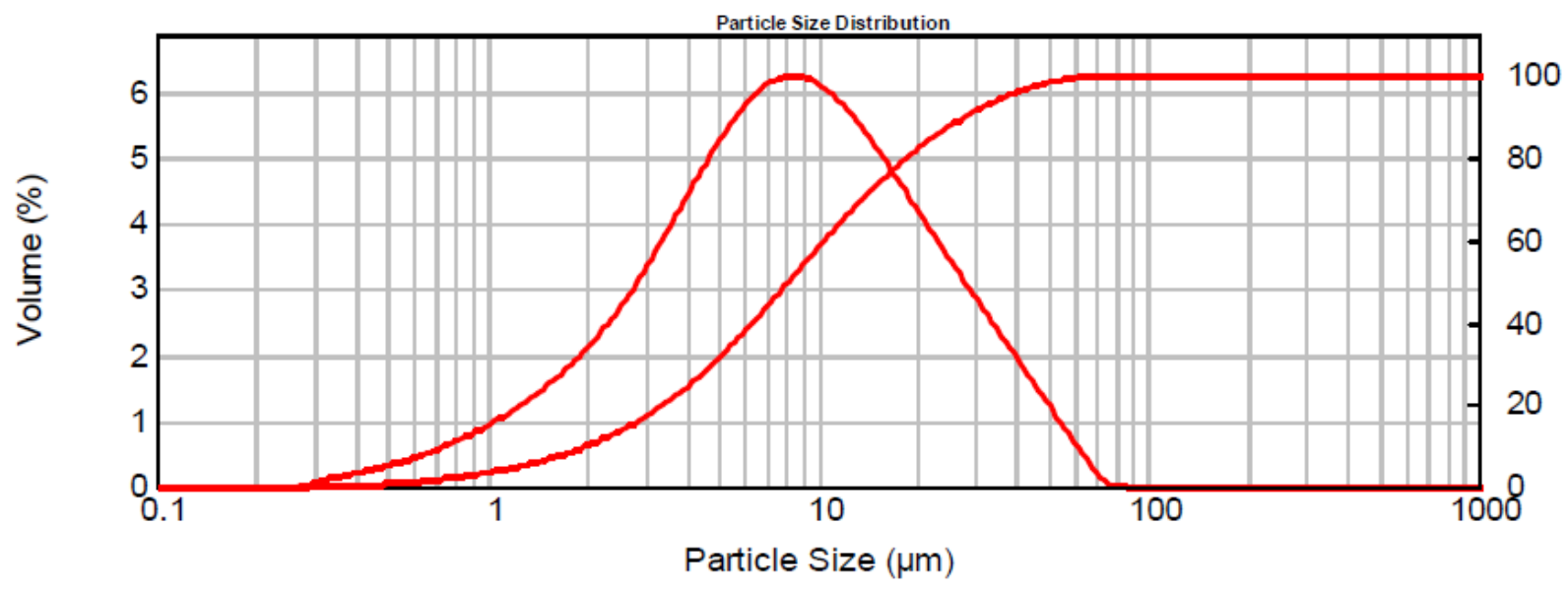

Fonte: autor da dissertação 
INSTITUTO DE PESQUISAS ENERGÉTICAS E NUCLEARES

Diretoria de Pesquisa, Desenvolvimento e Ensino

Av. Prof. Lineu Prestes, 2242 - Cidade Universitária CEP: 05508-000

Fone/Fax(0XX11) 3133-8908

SÃO PAULO - São Paulo - Brasil

http://www.ipen.br

O IPEN é uma Autaquia vinculada à Secretaria de Desenvolvimento, associada à Universiade de São Paulo e gerida técnica e administrativamente pela Comissão Nacional de Energia Nuclear, órgão do Ministério da Ciência, Tecnologia e Inovação. 